\title{
Manual Wheelchair Skill Performance of Persons with Spinal Cord Injuries
}

Citation for published version (APA):

Kilkens, O. J. E. (2005). Manual Wheelchair Skill Performance of Persons with Spinal Cord Injuries.

[Doctoral Thesis, Maastricht University]. https://doi.org/10.26481/dis.20050401ok

Document status and date:

Published: 01/01/2005

DOI:

10.26481/dis.20050401ok

Document Version:

Publisher's PDF, also known as Version of record

\section{Please check the document version of this publication:}

- A submitted manuscript is the version of the article upon submission and before peer-review. There can be important differences between the submitted version and the official published version of record.

People interested in the research are advised to contact the author for the final version of the publication, or visit the DOI to the publisher's website.

- The final author version and the galley proof are versions of the publication after peer review.

- The final published version features the final layout of the paper including the volume, issue and page numbers.

Link to publication

\footnotetext{
General rights rights.

- You may freely distribute the URL identifying the publication in the public portal. please follow below link for the End User Agreement:

www.umlib.nl/taverne-license

Take down policy

If you believe that this document breaches copyright please contact us at:

repository@maastrichtuniversity.nl

providing details and we will investigate your claim.
}

Copyright and moral rights for the publications made accessible in the public portal are retained by the authors and/or other copyright owners and it is a condition of accessing publications that users recognise and abide by the legal requirements associated with these

- Users may download and print one copy of any publication from the public portal for the purpose of private study or research.

- You may not further distribute the material or use it for any profit-making activity or commercial gain

If the publication is distributed under the terms of Article $25 \mathrm{fa}$ of the Dutch Copyright Act, indicated by the "Taverne" license above, 


\section{Manual wheelchair skill performance of persons with spinal cord injuries}

Olga Kilkens 
The study was part of the national research program 'Physical Strain, Work Capacity, and Mechanisms of Restoration of Mobility in the Rehabilitation of Persons with Spinal Cord Injuries', which is one of the research clusters of the ZonMw Rehabilitation program. This multi-center \& multidisciplinary research project is a collaboration between iRv, Institute for Rehabilitation Research, Hoensbroek, IFKB, Institute for Fundamental and Clinical Human Movement Sciences, Faculty of Human Movement Sciences, Vrije Universiteit, Amsterdam, and 8 large SCI-specialized rehabilitation centers in the Netherlands: Heliomare, De Hoogstraat, Hoensbroeck, Het Roessingh, Rijndam, Sint Maartenskliniek, Rehabilitation Center Amsterdam, and Groningen University Hospital Center for Rehabilitation location Beatrixoord

The measurements in the centers were performed under supervision of the rehabilitation physicians:

J. Slootman, F. van Asbeck, H. Bongers, C. Pons, A. Nene, G. Snoek, T. Sluis, M. Bergen, D. van Kuppevelt, E.Angenot, and G. Mulder, and conducted by the research assistants: Linda Valent, Sascha van Langeveld, Jos Bloemen, Marijke Schuitemaker, Karin Postma, Hennie Rijken, Peter Luthart, Annelleke Niezen, and Ferry Woldring.

The production of this thesis is financially supported by:

Biometrics, Bonte Zwolle B.V., Coloplast B.V., De Hoogstraat, Heliomare, Het Roessingh, Hoensbroeck Revalidatiecentrum, Hollister B.V., IRv, Institute for Rehabilitation Research, Revab B.V., Rehabilitation Center Amsterdam, Sunrise Medical B.V., ZonMw

Production: BIFab, Bianca Fraats

Cover design: BiFab, Bianca Fraats

Lay-out: BiFab, Bianca Fraats

Manual wheelchair skill performance of persons with spinal cord injuries / Olga J.E. Kilkens Thesis Maastricht University - With References - With Summary in Dutch

ISBN 90-9019190-9

Copyright $\odot$ 2005, Olga Kilkens 


\title{
Manual wheelchair skill performance of persons with spinal cord injuries
}

\author{
Proefschrift
}

Ter verkrijging van de graad van doctor aan de Universiteit Maastricht,

op gezag van de Rector Magnificus, Prof. mr. G.P.M.F. Mols, volgens het besluit van het College van Decanen,

in het openbaar te verdedigen, op vrijdag 1 aprill 2005 om 14.00 uur

door

Olga José Elise Kilkens 
Promotor:

Prof. dr. W.J.A. van den Heuvel

Co-promotores:

Dr. L.H.V. van der Woude (Vrije Universiteit, Amsterdam)

Dr. M.W.M. Post

Dr. A.J. Dallmeijer (Vu Medisch Centrum, Amsterdam)

Beoordelingscommissie:

Prof. dr. H. Kuipers (voorzitter)

Dr. F.W.A. van Asbeck (Revalidatiecentrum De Hoogstraat, Utrecht)

Prof. dr. H.J. Stam (Erasmus Universiteit, Rotterdam)

Prof. dr. D. Wade (Rivermead Rehabilitation Centre, Oxford, United Kingdom)

Prof. dr. M. IJzerman (Het Roessingh centrum voor revalidatie, Enschede)

The study presented in this thesis was supported by a grant from The Dutch Organization for Health Research and Development (ZonMw, nr. 1453.0003). 
Ik wil graag ledereen bedanken

die heeft bijgedragen aan de totstandkoming van dit proefschrift. 


\section{Contents}

Chapter 1 General introduction 7

$\begin{array}{lll}\text { Chapter } 2 & \text { Wheelchair skills tests, a systematic review } & 17\end{array}$

Chapter 3 The Wheelchair Circuit:

Reliability of a test to assess mobility in persons

with spinal cord injuries

Chapter 4 The Wheelchair Circuit:

Construct validity and responsiveness of a test to assess

manual wheelchair mobility in persons with a spinal cord injury

Chapter 5 Personal characteristics and injury related factors influencing the course of manual wheelchair skill performance during initial inpatient rehabilitation of persons with a spinal cord injury

Chapter 6 The longitudinal relationship between physical capacity and wheelchair skill performance during inpatient rehabilitation of persons with spinal cord injuries

Chapter 7 The relation between manual wheelchair skill performance and participation of persons with spinal cord injuries one year after dlscharge from inpatient rehabilitation.

Chapter 8 Discussion

English summary 
1

General introduction 


\section{Spinal cord injury}

As part of the central nervous system, the spinal cord transmits nerve impulses from the brain to the body and vice versa. The spinal cord is surrounded by vertebrae, which are named according to their location. The cervical vertebrae are situated in the neck, the thoracic vertebrae in the chest, the lumbar vertebrae in the lower back, and the sacral vertebrae run from the pelvis to the end of the spinal column.

A traumatic injury to the spinal cord most frequently occurs when the vertebrae are fractured, dislocated or moved excessively due to trauma (e.g. traffic accidents, falls, sports accidents, etc.) (1, 2). A spinal cord injury (SCI) can also result from non-traumatic causes, such as in spina bifida, or due to tumors, and infections $(1,2)$.

When the spinal cord becomes damaged, the transmission of nerve impulses throughout the body is disrupted, and nerve impulses to and from the area below the spinal cord lesion are affected. The location of the lesion determines how much function has been lost. In general it can be stated that the higher the level of the lesion, the greater the loss of function $(1,2)$. When the lesion is located at the thoracic, lumbar or sacral region, the injury will result in paraplegia, indicating that the sensation, motor- and autonomic function in the lower part of the body and the legs are affected. Cervical lesions usually result in tetraplegia: all four extremities and the trunk are affected to some extend.

Next to the level of the lesion the completeness of the lesion determines the functional outcome after SCI. Completeness is classified using the American Spinal Injury Association Impairment Scale (3). Grades A and B indicate that the lesion is motor-complete, meaning that there is no motor function preserved below the lesion level. Grades $C$ and $D$ indicate that the lesion is incomplete and that there is some motor function preserved below the lesion level. Grade $\mathrm{E}$ indicates that the motor function is normal. The completeness of the lesion may have a prognostic value: in complete SCI neurological recovery rarely occurs while incomplete injuries are expected to show some neurological recovery (4). Besides a loss of sensation and motor functioning, there are several secondary impairments that frequently complicate an SCI (5-7). In most persons with SCI, urinary -, bowel -, and sexual function will be impaired because these functions are controlled at the lower levels of the spinal cord. Other typical secondary impairments are breathing problems, pressure sores, pain, autonomic deregulation, and spasms.

The incidence of SCI has been examined in different studies. In the international literature the Incidence data vary from 9 to 53 new injuries per million persons per year $(7,8)$. Schönherr et al. (9) studied the incidence of SCI in the Netherlands (both traumatic and non-traumatic), and estimated it to be 16 per million persons per year. Van Asbeck et al. (10) estimated the incidence of traumatic SCI to be 10 per million persons per year.

\section{Rehabilitation of persons with spinal cord injury}

Because of a strong progress in medical treatment since World War II, the life expectancy of persons with $\mathrm{SCI}$ is comparable to that of persons without $\mathrm{SCI}(1,11,12)$. As a result, the focus during the rehabilitation of persons with $\mathrm{SCI}$ has moved from medical treatment to the optimization of the independence in daily life and quality of life of persons with an $\mathrm{SCI}(1,11)$. During the rehabilitation 
process a multidisciplinary rehabilitation team and the patient cooperate intensively to reach this goal $(1,2)$.

To help persons with SCI to become as independent as possible, the optimization of their physical capacity, which is reduced due to a loss of active muscle mass and inactivity, and the learning of new skills are essential elements during inpatient rehabilitation $(11,13)$. During the rehabilitation period patients will also receive psychological support to help them to deal and cope with the psychosocial problems they encounter after having sustained an SCI (1).

\section{Wheelchair skill performance}

The majority of persons with SCI will be dependent on a wheelchair for their mobility for the rest of their lives. Post et al. (14) found that in the Netherlands, approximately $82 \%$ of persons with SCI who are admitted for inpatient rehabilitation are wheelchair users, and $60 \%$ are completely wheelchair dependent. In the Netherlands, the majority of persons with SCI use a manual wheelchair (14), which implies the use of the upper body for everyday mobility. To function independently manual wheelchair users need good upper body function, and must possess a variety of wheelchair skills, to be able to deal with the physical barriers they will encounter in various environments in daily life (15). The mastering of wheelchair skills can make the difference between dependence and independence in daily life $(16,17)$, and the actual training of these skills therefore is a vital part of the rehabilitation process.

Although wheelchair skill performance is seen as an important aspect for independent mobility and daily functioning, up till now only little research has been done to examine the development of wheelchair skill performance over time (16, 18-21). MacPhee et al. (16) performed a study on wheelchair skills training in a rehabilitation center in Canada. They found that over the course of an inpatient rehabilitation stay, participants with neurologic- and musculoskeletal disorders who used a wheelchair received on average $\mathbf{1 5 . 4}$ hours of wheelchair skills training. They also found that wheelchair skill performance improved significantly during inpatient rehabilitation.

From the literature it can also be derived that wheelchair skill performance is related to personal- and lesion characteristics, the prevalence of secondary complications, and physical capacity $(6,20-37)$. Up till now however no research has been done to study the longitudinal relationship between manual wheelchair skill performance and personal- and lesion characteristics, secondary complications, and physical capacity during inpatient rehabilitation.

As stated earlier, wheelchair skill performance plays an important role in the independent performance of activities of daily life. It can be expected that there is a positive relationship between manual wheelchair skill performance and participation in persons with $\mathrm{SCl}$. The association between manual wheelchair skill performance and participation in persons with SCI has however never been studied.

Currently, the Functional Independence Measure (FIM) is the most widely accepted and most commonly used measure to evaluate the wheelchair mability of persons with $\mathrm{SCI}(38)$, although it does have some disadvantages. First, it is not sensitive enough to detect small changes in wheelchair mobility $(18,39-42)$, and second, it does not provide information about the physical strain involved in performing a particular task. Because of these disadvantages, several studies used functional tests 
that include the actual performance of wheelchair skills to assess wheelchair functionality in persons with SCI $(16,18-22,32-34,39,40,43-56)$.

Of these tests, only five were presented as measurement instruments $(18,21,40,49,53)$, and only one was specifically designed to assess wheelchair skill performance in persons with $\mathrm{SCI}$ (18).

Thereby, the tests differed greatly with respect to the number of wheelchair skills included and the content of these skills. Skills that were frequently used (i.e. wheelchair propulsion, transfer, curb, and slope) showed a large variation in, for instance, driving distance, objects to transfer to, height of the

curbs, and angle of inclination of slopes. The clinimetric properties of the tests were hardly described. Only two tests had been validated $(18,21)$, and only one test had been adequately tested on both validity and rellability (21).

From this it can be stated that, at the start of our study in 1999, there was no standard test available to measure wheelchair skill performance in persons with SCI.

Within the scope of the present study, a functional test was developed to assess wheelchair skill performance during and after clinical rehabilitation in persons with SCI: the Wheelchair Circuit. The Wheelchair Circuit consists of 8 standardized tasks that are conditional to wheelchair mobility in persons with an SCI, and represent different aspects of wheelchair mobility (i.e. technique, tempo and physical strain).

\section{Restoration of mobility in the rehabilitation of persons with spinal cord injury: a multicenter prospective cohort study}

Restoration of mobility during the rehablitation of persons with $\mathrm{SCI}$ is often directed to a generally wheelchair-bound dally life. However, little is known of the process of mobility restoration in SCI rehabilitation, and the outcome at the level of activities and participation. In 1999, a national research program 'Physical Strain, Work Capacity and Mechanisms of Restoration of Mobility in the Rehabilitation of Persons with Spinal Cord Injurles' was initiated. This program consists of eleven research projects, which are conducted in a network of eight rehabilitation centers specialized in the rehabilitation of persons with SCI (i.e. De Hoogstraat, Hoensbroeck, Heliomare, Groningen University Hospital Center for Rehabilitation location Beatrixoord, RCA, St.Maartenskliniek, Het Roessingh, and Rijndam), four research groups (i.e. Institute for Rehabilitation Research, Institute for Fundamental and Clinical Human Movement Sciences Vrije Universiteit Amsterdam, Roessingh Research \& Development, Department of Physiology Radboud University Nijmegen), and the Dutch - Flemish Society of Paraplegla (for more information about the research program see:

www.fbw.vu.nl/onderzoek/a4zon/ZONenglish/index.html) (57). This thesis concerns one of the eleven research projects: 'Restoration of mobility in the rehabilitation of persons with spinal cord injury", a multidisciplinary prospective cohort study on restoration of mobility in the rehabilitation of persons with SCI, and focuses on manual wheelchair skill performance.

During a period of three years (July 2000 - July 2003), persons who were admitted to one of the participating rehablitation centers with an acute SCI were invited to participate in this study. Persons were eligible to enter the project if they were between 18 and 65 years of age, were classified as $A, B$, C or D on the American Spinal Injury Association impairment scale, were wheelchair users, did not have a progressive disease or psychiatric problem, and had enough knowledge of the Dutch language to understand the purpose of the study and the testing methods. Participants were not allowed to 
perform physically strenuous tests (i.e. the Wheelchair Circuit and the maximum wheelchair exercise test) if they had 1) cardiovascular disorders (the absolute contra-indications as they are stated by the ACSM 2000 guidelines (58), or a resting diastolic blood pressure $>90 \mathrm{~mm} \mathrm{Hg}$ or a resting systolic blood pressure $>180 \mathrm{~mm} \mathrm{Hg}$ ), and/or 2) severe musculoskeletal complaints of the upper extremities, neck or back. After inclusion in the cohort, participants were examined by their rehabilitation physician to check for any of these contraindications.

In this cohort study, physical capacity, basic skills (including wheelchair skills), participation, quality of life, personal- and lesion characteristics, and the prevalence of secondary impairments and comorbidity were systematically measured and monitored at four subsequent occasions: at the start of functional rehabilitation, three months later, at the time of discharge from inpatient rehabilitation, and one year after discharge (Figure 1.1).

The main research questions of the prospective cohort study are:

1. What are the changes in mobility outcome measures at the level of physical capacity and basic skills during and after rehabilitation?

2. What are the most important determinants of the process of restoration of mobility?

3. To what extent is mobility of influence on participation and quality of life?

Figure 1.1 Conceptual framework of the prospective cohort study

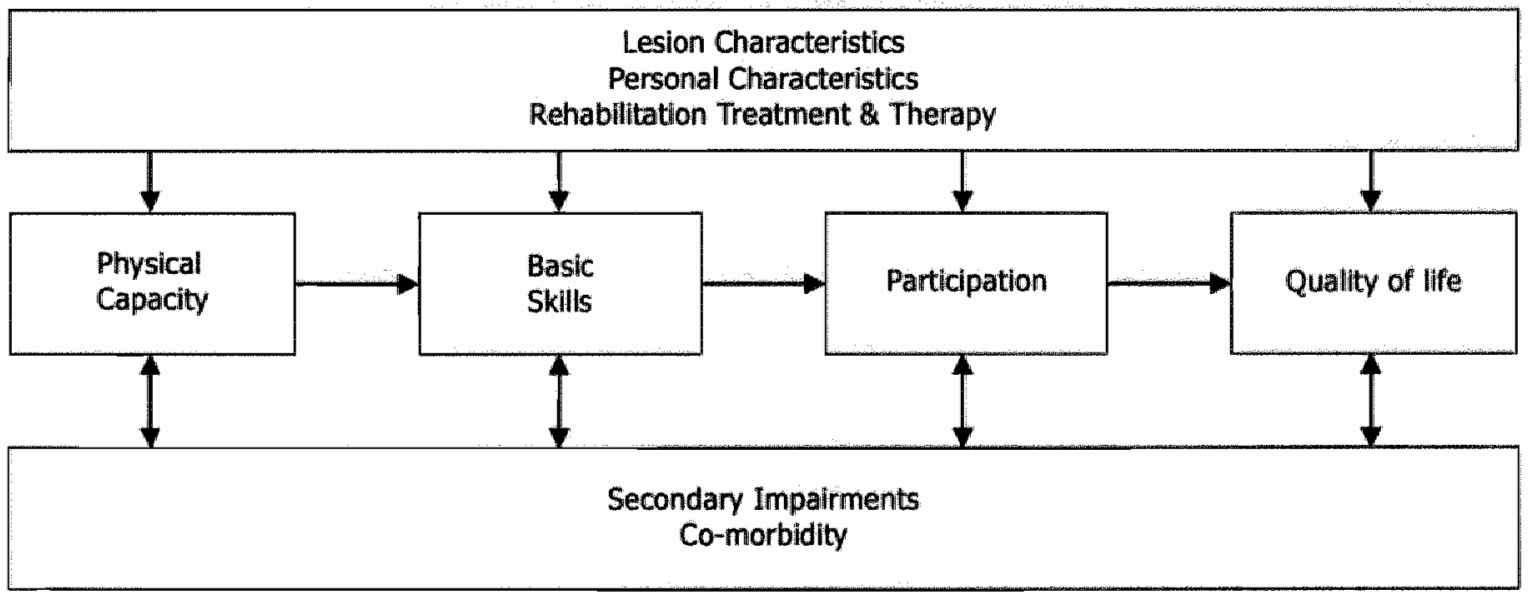

\section{Aims of the study and research questions}

The primary aims of the present study are 1) to assess the clinimetric qualities of the Wheelchair Circuit, 2) to evaluate the development of manual wheelchair skill performance during the inpatient rehabilitation of persons with $\mathrm{SCI}$, and to identify factors that affect this process, and 3) to study the relationship between manual wheelchair skill performance and participation in persons with $\mathrm{SCI}$ after discharge from inpatient rehabilitation. 
The main research questions of this thesis are:

1. Is the Wheelchair Circuit a reliable, valid and responsive test to assess wheelchair skill performance?

2. How does manual wheelchair skill performance develop during inpatient rehabilitation of persons with acute SCI?

3. Is the development of manual wheelchair skill performance related to personal- and lesion characteristics, secondary complications, and physical capacity?

4. Is there a relationship between manual wheelchair skill performance and participation in persons with $\mathrm{SCI}$, one year after discharge from inpatient rehabilitation?

\section{Outline of the thesis}

Chapter 2 describes a systematic review of wheelchair skills tests reported in the literature in the period 1966 - 2001. In chapter 3, the content of the Wheelchair Circuit is described, and the reliability of this test is examined. Chapter 4 reports on the construct validity and the responsiveness of the Wheelchair Circuit. In chapter 5 ; the results of a longitudinal study are described. Subject of the study is the development of wheelchalr skill performance during inpatient rehabilitation, and to determine whether the development of wheelchair skill performance is related to personal characteristics, lesion characteristics, secondary complications and upper extremity pain. Chapter 6 presents the results of a longitudinal study on the relationship between the development of wheelchair skill performance and physical capacity during rehabilitation. Chapter 7 reports on the results of a cross-sectional study. Subject of the study is the relationship between manual wheelchair skill performance and participation one year after discharge from inpatient rehabilitation. In chapter 8 , the thesis is ended with a general discussion of the main findings, the methodology of the study, the practical implications of the findings, and recommendations for future study. 


\section{References}

1. Asbeck van FWA. Handboek dwarslaesie revalidatie. Houten/Diegem: Bohn Stafleu Van Loghum, 1998.

2. Karp G. Life on wheels. Sebastopol: O'Reilly \& Associates, Inc., 1999.

3. American Spinal Injury Association (ASIA): Reference manual for the international standards for neurological classification of spinal cord injury. Marino RJ, Ed. Chicago: American Spinal Injury Association, 2000.

4. Marino RJ, Ditunno JF, Jr., Donovan WH, Maynard F, Jr. Neurologic recovery after traumatic spinal cord injury: data from the Model Spinal Cord Injury Systems. Arch Phys Med Rehabil 1999;80(11):1391-6.

5. Johnson RL. Secondary conditions following spinal cord injury in a population-based sample. Spinal Cord 1998;36(1):45-50.

6. McKinley WO, Jackson AB, Cardenas DD, DeVivo MJ. Long-term medical complications after traumatic spinal cord injury: a regional model systems analysis. Arch Phys Med Rehabil 1999;80(11):1402-10.

7. Shingu $H$, Ikata $T$, Katoh S, Akatsu T. Spinal cord injuries in Japan: a nationwide epidemlological survey in 1990. Paraplegia 1994;32(1):3-8.

8. Shingu $H$, Ohama M, Ikata T, Katoh S, Akatsu T. A nationwide epidemiological survey of spinal cord injuries in Japan from January 1990 to December 1992. Paraplegia 1995;33(4):183-8.

9. Schönherr M, Groothoff J, Mulder D, Eisma W. Rehabilitation of patients with spinal cord lesions in the Netherlands: An epidemiological study. spinal cord 1996;34:679-83.

10. Asbeck van FWA, Post MWM, Pangalila RF. An epidemiological description of spinal cord injuries in the Netherlands in 1994. Spinal Cord 2000;38(7):420-4.

11. Noreau L, Shephard RJ. Spinal cord injury, exercise and quality of life. Sports Med 1995;20(4):226-50.

12. DeVivo MJ, Richards JS, Stover SL, Go BK. Spinal cord Injury. Rehabilitation adds life to years. West J Med 1991;154(5):602-6.

13. Yarkony GM, Roth EJ, Heinemann AW, Wu Y, Katz RT, Lovell L. Benefits of rehabilitation for traumatic spinal cord injury: Multivariate analysis in 711 patients. Arch Neurol 1987;44:93-6.

14. Post MWM, Asbeck van FWA, Dijk van AJ, Schrijvers AJ. Services for spinal cord injured: availability and satisfaction. Spinal Cord 1997;35(2):109-15.

15. Pierce $\mathrm{LL}$. Barriers to access: frustrations of people who use a wheelchair for full-time mobility. Rehabil Nurs 1998;23(3):120-5.

16. MacPhee AH, Kirby RL, Coolen AL, Smith C, MacLeod DA, Dupuis DJ. Wheelchair skills training program: A randomized clinical trial of wheelchair users undergoing initial rehabilitation. Arch Phys Med Rehabil 2004;85(1):41-50.

17. Somers M. Spinall cord injury, functional rehabilitation. Connecticut: Appleton \& Lange; 1992.

18. Taricco M, Apolone G, Colombo C, Filardo G, Telaro E, Liberati A. Functional status ín patients with spinal cord injury: A new standardized measurement scale. Gruppo Interdisciplinare Valutazione Interventi Riabilitativi. Arch Phys Med Rehabil 2000;81(9):1173-80.

19. Capodaglio $P$, Grilli $C$, Bazzini $G$. Tolerable exercise intensity in the early rehabilitation of paraplegic patients. A preliminary study. Spinal Cord 1996;34(11):684-90. 
20. Dallmeijer AJ, Woude van der LHV, Hollander AP, As van HH. Physical performance during rehabilitation in persons with spinal cord injuries. Med Sci Sports Exerc 1999;31(9):1330-5.

21. Kirby RL, Swuste J, Dupuis DJ, MacLeod DA, Monroe R. The Wheelchair Skills Test: A pilot study of a new outcome measure. Arch Phys Med Rehabill 2002;83(1):10-8.

22. Dallmeijer AJ, Woude van der LHV, Hollander AP, Angenot EL. Physical performance in persons with spinal cord injuries after discharge from rehabilitation. Med Sci Sports Exerc 1999;31(8):1111-7.

23. Ballinger DA, Rintala DH, Hart KA. The relation of shoulder pain and range-of-motion problems to functional limitations, disability, and perceived health of men with spinal cord injury: A multifaceted longitudinal study. Arch Phys Med Rehabil 2000;81(12):1575-81.

24. Beekman CE, Miller-Porter L, Schoneberger M. Energy cost of propulsion in standard and ultralight wheelchairs in people with spinal cord injuries. Phys Ther 1999;79(2):146-58.

25. Dahlberg $A$, Kotila $M$, Kautiainen $H$, Alaranta $H$. Functional independence in persons with spinal cord injury in Helsinki. J Rehabil Med 2003;35(5):217-20.

26. Dalyan M, Cardenas DD, Gerard B. Upper extremity pain after spinal cord injury. Spinal Cord 1999;37(3):191-5.

27. Gerhart KA, Bergstrom E, Charlifue SW, Menter RR, Whiteneck GG. Long-term spinal cord injury: functional changes over time. Arch Phys Med Rehabil 1993;74(10):1030-4.

28. Schönherr MC, Groothoff JW, Mulder GA, Eisma WH. Functional outcome of patients with spinal cord injury: rehabilitation outcome study. Clin Rehabil 1999;13(6):457-63.

29. Greenwald BD, Seel RT, Cifu DX, Shah AN. Gender-related differences in acute rehabilitation lengths of stay, charges, and functional outcomes for a matched sample with spinal cord injury: a multicenter investigation. Arch Phys Med Rehabil 2001;82(9):1181-7.

30. Warschausky S, Kay JB, Kewman DG. Hlerarchical linear modeling of FIM instrument growth curve characteristics after spinal cord injury. Arch Phys Med Rehabil 2001;82(3):329-34.

31. Yarkony GM, Roth E], Heinemann AW, Lovell LL. Spinal cord injury rehabilitation outcome: The Impact of age. J Clin Epidemiol 1988;41(2):173-7.

32. Kirby RL, Dupuis DJ, MacPhee AH, Coolen AL, Smith C, Best KL, et al. The Wheelchair Skills Test (version 2.4): Measurement properties. Arch Phys Med Rehabil 2004;85(5):794-804.

33. Duran FS, Lugo L, Ramirez L, Lic EE. Effects of an exercise program on the rehabilitation of patients with spinal cord injury. Arch Phys Med Rehabil 2001;82(10):1349-54.

34. Janssen TWJ, Oers van CAIM, Veeger HE, Hollander AP, Woude van der LHV, Rozendal RH. Relationship between physical strain during standardised ADL tasks and physical capacity in men with spinal cord injuries. Paraplegia 1994;32(12):844-59.

35. Sawka MN, Glaser RM, Laubach LL, Al-Samkari O, Suryaprasad AG. Wheelchair exercise performance of the young, middle-aged, and elderly. J Appl Physiol 1981;50(4):824-8.

36. Morrison SA, Melton-Rogers SL, Hooker SP. Changes in physical capacity and physical strain in persons with acute spinal cord injury. Topics Spinal Cord Inj Rehabil 1997;3(1):1-15.

37. Noreau $L_{r}$ Shephard RJ, Simard $C$, Pare $G_{r}$ Pomerleau P. Relationship of impairment and functional ability to habitual activity and fitness following spinal cord injury. Int J Rehabil Res 1993;16(4):265-75

38. Hall KM, Cohen ME, Wright J, Call M, Werner P. Characteristics of the Functional Independence Measure in traumatic spinal cord injury. Arch Phys Med Rehabill 1999;80:14716. 
39. Bolin I, Bodin Pr Kreuter M. Sitting position - posture and performance in C5 - C6 tetraplegia. Spinal Cord 2000;38(7):425-34.

40. Harvey LA, Batty J, Fahey A. Reliability of a tool for assessing mobility in wheelchairdependent paraplegics. Spinal Cord 1998;36(6):427-31.

41. Ota $T$, Akaboshi $K$, Nagata $M$, Sonoda S, Domen $K_{\text {, Seki }} \mathrm{M}_{\mathrm{r}}$ et al. Functional assessment of patients with spinal cord injury: Measured by the motor score and the Functional Independence Measure. Spinal Cord 1996;34(9):531-5.

42. Catz A, Itzkovich M, Agranov E, Ring H, Tamir A. SCIM - spinal cord independence measure: A new disability scale for patients with spinal cord lesions. Spinal Cord 1997;35:850-6.

43. Taricco M, Colombo C, Adone R, Chiesa G, Di Carlo S, Borsani M, et al. The social and vocational outcome of spinal cord injury patients. Paraplegia 1992;30(3):214-9.

44. Duffill J, Buckley J, Lang D, Neil-Dwyer G, McGinn F, Wade D. Prospective study of omental transposition in patients with chronic spinal injury. $J$ Neurol Neurosurg Psychiatry 2001;71(1):73-80.

45. Dunkeriey AL, Ashburn A, Stack EL. Deltoid triceps transfer and functional independence of people with tetraplegia. Spinal Cord 2000;38(7):435-41.

46. Hutzler Y. Physical performance of elite wheelchair basketball players in armcranking ergometry and in selected wheeling tasks. Paraplegia 1993;31(4):255-61.

47. Janssen TWJ, Oers van CAJM, Woude van der LHV, Hollander AP. Rellability of heart rate responses to non-steady-state activities of daily living in men with spinal cord injuries. Scand J Rehabil Med 1994;26(2):71-8.

48. Janssen TWJ, Oers van CAJM, Rozendaal EP, Willemsen EM, Hollander AP, Woude van der LHV. Changes in physical strain and physical capacity in men with spinal cord injuries. Med Sci Sports Exerc 1996;28(5):551-9.

49. Jebsen RH, Trieschmann RB, Mikulic MA, Hartley RB, McMillan JA, Snook ME. Measurement of time in a standardized test of patient mobility. Arch Phys Med Rehabil 1970;51(3):170-5.

50. Kirby RL, Lugar JA, Breckenridge $C$. New wheelle aid for wheelchairs: controlled trial of safety and efficacy. Arch Phys Med Rehabil 2001;82(3):380-90.

51. Lehmann JF, Warren CG, Halar E, Stonebridge JB, DeLateur BJ. Wheelchair propulsion in the quadriplegic patient. Arch Phys Med Rehabil 1974;55(4):183-6.

52. Mizukami M, Kawai N, Iwasaki Y, Yamamoto Y, Yoshida Y, Koyama N, et al. Relationship between functional levels and movement in tetraplegic patients. A retrospective study. Paraplegila 1995;33(4):189-94.

53. Vanlandewijck YC, Daly DJ, Theisen DM. Field test evaluation of aerobic, anaerobic, and wheelchair basketball skill performances. Int I Sports Med 1999;20(8):548-54.

54. Bonaparte JP, Kirby RL, MacLeod DA. Learning to perform wheelchair wheelles: Comparison of 2 training strategies. Arch Phys Med Rehabil 2004;85(5):785-93.

55. Kirby RL, Ethans KD, Duggan RE, Saunders-Green LA, Lugar JA, Harrison ER. Wheelchair propulsion: Descriptive comparison of hemiplegic and two- hand patterns during selected activities. Am II Phys Med Rehabil 1999;78(2):131-5.

56. Newton AM, Kirby RL, Macphee AH, Dupuis DJ, Macleod DA. Evaluation of manual wheelchair skills: Is objective testing necessary or would subjective estimates suffice? Arch Phys Med Rehabill 2002;83(9):1295-9. 
57. Woude van der LHV, Dallmeijer AJ, Veeger DJ, Drongelen van S, Kilkens OJE, Post MWM, et al. Physical strain, work capacity and restoration of mobility of individuals with a spinal cord injury: A multicenter study. In: Woude van der LHV, editor. 3rd International Congress on Restoration of (Wheeled) Mobility in SCI Rehabilitation: State of the Art; 2004; Amsterdam: Rehabilitation Research and Development Service; 2004. p. 62-3.

58. American College of Sports Medicine. ACSM's guidelines for exercise testing and prescription. 6th ed. Philadelphia: Lippincott Williams \& Wilkins; 2000. 


\section{Wheelchair skills tests, a systematic review}

Olga Kilkens, Marcel Post, Annet Dallmeijer, Henk Seelen, and Luc van der Woude Clinical Rehabilitation 2003; 17: 418-30 


\section{Summary}

Objective: To describe and compare the content, feasibility, outcome parameters, and clinimetric properties of the manual wheelchair skills tests reported in the literature.

Design: A systematic literature search was conducted in MEDLINE, EMBASE, PsychINFO, and Current Contents. Tests were selected if they were observational tests, designed for persons using hand-rim wheelchairs and were intended to assess wheelchair skill performance at the activity level.

Results: The search resulted in 34 papers, in which 24 different wheelchair skills tests were described. The skill most frequently included was wheelchair propulsion, consecutively followed by transferring, negotiating curbs, ascending slopes, traversing tracks, sprinting and performing a wheelie. The three most frequently used outcome parameters were task performance time, independency of task performance, and physical strain during skill performance. Sensitivity to change was evaluated in three tests, validity in 10 tests, and reliability in nine tests.

Conclusions: Many tests are applied to measure wheelchair skill performance using different tasks and outcome measures. This makes it difficult to compare study results. Consensus among researchers as to which skills must be included as well as to standardization of the use of measurement instruments will reduce this problem and will additionally lead to a better insight in the quality of tests. 


\section{Introduction}

The achievement of independent mobility is vital in the rehabilitation of physically disabled individuals. When ambulation is impaired, a hand-rim wheelchair provides a relatively fast and effective means of mobility for people with lower limb disabilities. A hand-rim wheelchair can provide the necessary access to social, vocational, and recreational activities that are conditional to a productive and rewarding life. To function independently, people who use manual wheelchairs for mobility must possess a variety of skills. The ability to propel their wheelchairs over even surfaces brings the freedom to move about within a wheelchair-accessible environment. Independent mobility within a greater variety of environments requires obstacle negotiation skills. These skills can make the difference between dependence and independence in daily life $(1,2)$.

Assessment of wheelchair skills can provide useful information concerning a person's current wheelchair skill performance. In clinical situations, wheelchair skills tests can help to define rehabilitation goals concerning mobility, and can also be used to evaluate the progression made regarding wheelchair mobility during rehabilitation. In research settings, measurement of wheelchair skills can be used to study the effect of an intervention aimed at wheelchair mobility or to study the relation between wheelchair skills and, for example, level of activity and/or participation.

At present there is no systematic overview of wheelchair skills tests available in the literature. It is therefore difficult to decide which test is most suitable in research or in clinical practice.

The objective of this review is to systematically document and describe the content, the target population, the study group, the test feasibility, the outcome parameters, and the clinimetric properties of those hand-rim wheelchair skills tests that are currently reported in the literature. Such an overview may make it easier to choose the most suitable test to assess wheelchair skills in both clinical and research settings.

\section{Methods}

\section{Search strategy}

To locate wheelchair skills tests, a computerized literature search of MEDLINE (1966 - 2001), EMBASE (1989 - 2001), PsycINFO (1967 - 2001) and Current Contents (1998 - 2001) was conducted. The keywords used were: mobility and wheelchair combined with skill, task, measurement, test, ADL, functional, instrument, performance, clinimetrics, psychometrics, pathology, behavior, activity, disability, and assessment. The search strategy is described in the appendix. In addition, the references given in relevant publications were further examined. Only studies written in English that were published in scientific journals were taken into consideration.

\section{Selection criteria}

A test was selected if it was an observational test (3), if it was constructed for persons using hand-rim wheelchairs and when it intended to assess wheelchair-assisted mobility skills at the activity level as described in terms of the International Classification of Functioning, Disability and Health (ICF) (4). In 
the ICF, mobility is defined as: 'moving by changing body position or location or by transferring from one place to another'. Consequently, this review focuses on tests that aim to assess the ability to propel and maneuver a wheelchair under standardized and/or simulated conditions of daily living. Tests aimed at measuring physical capacity were not selected.

The first author performed the selection of the tests, by reading the abstracts of all the initially identified articles. When necessary the full article was obtained and studied. In case of doubt on selection of a test, the other authors were consulted.

\section{Assessment of selected tests}

The wheelchair skills tests were systematically described and compared with respect to the following aspects:

- Content: the skills included in the test.

- Target population: the diagnostic groups for which the test was developed.

- Population at study: the diagnostic groups in which the test was used or studied.

- Feasibility: the amount of time and equipment needed to perform the test.

- Test outcomes: the outcome parameters used to reflect wheelchair skill performance and the complexity and interpretation of the scoring method.

- Clinimetric properties: sensitivity to change, validity and reliability of the test.

\section{Results}

\section{Selection of tests}

The selection process produced 34 papers in which 24 different wheelchair skills tests were described (5-38). Table 2.1 provides an overview of the selected tests, arranged alphabetically, according to the name of the first author of the paper in which the test was mentioned. Of the 24 tests found, seven were presented as measurement instruments and were extensively described in terms of development, content and use $(7,14,18,23,25,35,36)$. In all other papers the aim was to evaluate an intervention or to detect differences between groups. These tests were only briefly described in the Methods section of the article. Only four tests had been given a name: the Valutazione Funzionale Mielolesie (VFM) (7), Tufts Assessment of Motor Performance (TAMP) (14), the Wheelchair Skills Test (WST) (25) and the Wheelchair Obstacle Course (WOC) (36). 
Table 2.1 General overview of the selected wheelchair skills tests

\begin{tabular}{|c|c|c|c|c|}
\hline $\begin{array}{l}\text { Author } \\
\text { Name of test }\end{array}$ & $\mathbf{N}$ & $\begin{array}{l}\text { Target } \\
\text { population }\end{array}$ & Study population & Outcomes \\
\hline Agre (5) & 33 & No information & Persons with splna bifida & Wheelchail propulsion velocity \\
\hline Bolin (6) & 4 & No Information & Persons with SCI & $\begin{array}{l}\text { Task performance times } \\
\text { Physical strain (HRpeak) } \\
\text { Subjective rating of } \\
\text { performance }\end{array}$ \\
\hline $\begin{array}{l}\text { Capodaglio }(7) \\
\text { Taricco }(33,34) \\
\text { VFM }\end{array}$ & $\begin{array}{l}8 \\
47,94\end{array}$ & Persons with SCI & Persons with SCI & $\begin{array}{l}\text { Independency of task } \\
\text { performance }\end{array}$ \\
\hline Dallmeijer $(8,9)$ & 20,19 & No information & Persons with SCI & $\begin{array}{l}\text { Task performance times } \\
\text { Physical strain (\%HRR) }\end{array}$ \\
\hline Duffill (10) & 17 & No information & Persons with SCI & Abillity to perform tasks \\
\hline Dunkerley (11) & 11 & No information & Persons with SCI & Task performance times \\
\hline Durán (12) & 13 & No information & Persons with SCI & $\begin{array}{l}\text { Task performance times } \\
\text { Ability to perform tasks }\end{array}$ \\
\hline Findley (13) & 40 & No information & $\begin{array}{l}\text { Persons with spina bifida, } \\
\text { healthy individuals }\end{array}$ & Wheelchair propulsion velocity \\
\hline $\begin{array}{l}\text { Gans }(14) \\
\text { Haley }(16,17) \\
\text { TAMP }\end{array}$ & $\begin{array}{l}40 \\
206,206\end{array}$ & No information & $\begin{array}{l}\text { Persons with } \\
\text { muscoloskeletal and } \\
\text { neuromuscular disorders }\end{array}$ & $\begin{array}{l}\text { Task performance times } \\
\text { Independency of task } \\
\text { performance } \\
\text { Technique } \\
\text { Movement pattern } \\
\text { Movement control and } \\
\text { coordination }\end{array}$ \\
\hline $\begin{array}{l}\text { Gouvier }(15) \\
\text { Webster }(36,37,38) \\
\text { woC }\end{array}$ & $\begin{array}{l}2 \\
72,87,55\end{array}$ & $\begin{array}{l}\text { Persons with } \\
\text { stroke }\end{array}$ & $\begin{array}{l}\text { Persons with stroke, } \\
\text { healthy individuals }\end{array}$ & Number of collision errors \\
\hline Harvey (18) & 20 & No Information & Persons with SCI & $\begin{array}{l}\text { Independency of task } \\
\text { performance }\end{array}$ \\
\hline Hutzler (19) & 9 & $\begin{array}{l}\text { Wheelchair } \\
\text { athletes }\end{array}$ & $\begin{array}{l}\text { Wheelchair basketball } \\
\text { players with poliomyelitis, } \\
\text { SCI, and amputation }\end{array}$ & $\begin{array}{l}\text { Task performance times } \\
\text { Distance covered }\end{array}$ \\
\hline Janssen (20) & 37 & No information & Persons with SCI & $\begin{array}{l}\text { Task performance times } \\
\text { Physical strain (HRpeak, } \\
\text { HRmean) }\end{array}$ \\
\hline Janssen (21) & 44 & No information & Persons with SCI & Physical strain (\%HRR) \\
\hline Janssen (22) & 37 & No Information & Persons with SCI & Physical strain (\%HRR) \\
\hline Jebsen (23) & 118 & No Information & $\begin{array}{l}\text { Persons with stroke, } \\
\text { amputations, } \mathrm{SCI} \text {, } \\
\text { neuropathy, hip fractures, } \\
\text { and healthy individuals }\end{array}$ & Task performance times \\
\hline
\end{tabular}




\begin{tabular}{|c|c|c|c|c|}
\hline $\begin{array}{l}\text { Author } \\
\text { Name of test }\end{array}$ & $\mathbf{N}$ & $\begin{array}{l}\text { Target } \\
\text { population }\end{array}$ & Study population & Outcomes \\
\hline Kirby (24) & 42 & No information & $\begin{array}{l}\text { Persons with SCI, } \\
\text { amputations, and healthy } \\
\text { indlviduals }\end{array}$ & $\begin{array}{l}\text { Task performance times } \\
\text { Perceived task difficulty } \\
\text { Safety of skill performance } \\
\% \text { subjects able to learn skill }\end{array}$ \\
\hline $\begin{array}{l}\text { Kirby (25) } \\
\text { WST }\end{array}$ & 24 & No information & $\begin{array}{l}\text { Persons with stroke, } \\
\text { amputations, } \mathrm{SCI}, \\
\text { musculoskeletal and } \\
\text { neuromuscular disorders }\end{array}$ & Ability to perform tasks \\
\hline Lehmann (26) & 12 & No information & \begin{tabular}{|l|} 
Persons with SCI \\
\end{tabular} & $\begin{array}{l}\text { Distance covered } \\
\text { Maximum angle of inclination } \\
\text { of slopes }\end{array}$ \\
\hline Mattison (27) & 26 & No Information & $\begin{array}{l}\text { Persons with stroke, } \\
\text { vascullar diseases, } \\
\text { and healthy individuals }\end{array}$ & $\begin{array}{l}\text { Task performance time } \\
\text { Distance covered } \\
\text { Physical strain (HRpeak, } \\
\text { physiological cost) } \\
\text { Perceived exertion during test } \\
\text { performance }\end{array}$ \\
\hline Mizukami (28) & 109 & No information & Persons with SCI & $\begin{array}{l}\text { Independency of task } \\
\text { performance }\end{array}$ \\
\hline Panikoff (29) & 80 & No information & Persons with head injury & $\begin{array}{l}\text { Independency of task } \\
\text { performance }\end{array}$ \\
\hline $\begin{array}{l}\text { Schnelle }(30,31) \\
\text { Simmons }(32)\end{array}$ & $\begin{array}{l}97,76 \\
65\end{array}$ & No information & Nursing home residents & $\begin{array}{l}\text { Maximum propulsion } \\
\text { endurance time } \\
\text { Independency of task } \\
\text { performance } \\
\text { Maximal wheeling distance } \\
\text { Wheelchair propulsion velocity }\end{array}$ \\
\hline Vanlandewijck (35) & 46 & $\begin{array}{l}\text { Wheelchair } \\
\text { athletes }\end{array}$ & $\begin{array}{l}\text { Wheelchair basketball } \\
\text { players with spina bifida, } \\
\mathrm{SCI} \text {, spastic diplegla, polio, } \\
\text { amputations, and healthy } \\
\text { individuals }\end{array}$ & $\begin{array}{l}\text { Task performance time } \\
\text { Distance covered } \\
\text { Wheelchair propulsion velocity }\end{array}$ \\
\hline
\end{tabular}

SCI $=$ Spinal Cord Injury; VFM = Valutazione Funzionale Mielolesie; TAMP = Tufts Assessment of Motor

Performance; WOC $=$ Wheelchair Obstacle Course; WST $=$ Wheelchair Skills Test; HRpeak $=$ peak heart rate reached during task performance; $\% H R R=$ percentage heart rate reserve; $H R$ mean $=$ mean heart rate reached during task performance.

\section{Assessment of selected tests}

\section{Content of tests}

Table 2.2 displays the types of wheelchair skills included in the different tests. Wheelchair propulsion is the most frequently included skill (in 14 tests). It is assessed in different ways: a set period of time $(6,19)$, a fixed distance $(5,6,14,18,25,36)$, or the longest distance possible $(31,35)$. Following wheelchair propulsion, transfer from and to the wheelchair is the most commonly included skill (in 11 
tests). Most tests require the performance of several different transfers $(7,14,18,20-23,28,29)$. The negotiating of curbs, ascending slopes and traversing tracks are third in line of most frequently used skills (each in 10 tests). The height of the curbs used ranged from 0.025 to $0.15 \mathrm{~m}$.

Table 2.2 Content of wheelchair skills tests

\begin{tabular}{|c|c|c|c|c|c|c|c|c|}
\hline Author & Propulsion & Sprint & Curb & Slope & Wheelle & Transfer & Track & $\begin{array}{l}\text { Other wheel- } \\
\text { chair skills }\end{array}$ \\
\hline Agre (5) & 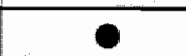 & 0 & & & & & & \\
\hline Bolin (6) & 0 & & 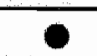 & 0 & & & 9 & \\
\hline $\begin{array}{l}\text { Capodaglio }(7) ; \\
\text { Taricco }(32,33)\end{array}$ & 9 & & 0 & 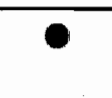 & e & 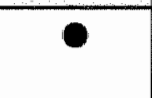 & 9 & 0 \\
\hline Dallmeijer $(8,9)$ & & & . & $\overline{0}$ & & 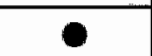 & & 9 \\
\hline Duffill (10) & 0 & & 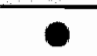 & 0 & & & 0 & 0 \\
\hline Dunkerley (11) & & 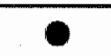 & & & & & 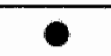 & \\
\hline Durán (12) & & & 9 & 0 & 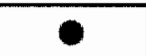 & & - & 0 \\
\hline Findley (13) & 0 & - & & & & & & \\
\hline $\begin{array}{l}\text { Gans }(14) ; \\
\text { Haley }(16,17)\end{array}$ & 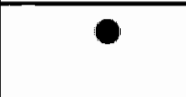 & & & $\overline{0}$ & & 9 & & 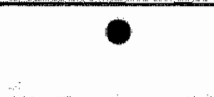 \\
\hline $\begin{array}{l}\text { Gouvier (15); } \\
\text { Webster (36-38) }\end{array}$ & & & & & & & 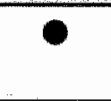 & \\
\hline Harvey (18) & - & & 9 & 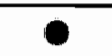 & & - & & \\
\hline Hutzler (19) & 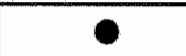 & - & & & & & 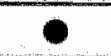 & \\
\hline Janssen (20) & & & 0 & & & $\overline{-1}$ & & \\
\hline Janssen (21) & & & 0 & 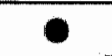 & & 0 & & 0 \\
\hline Janssen (22) & & & 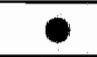 & & & - & & \\
\hline Jebsen (23) & & 9 & & & & 9 & & 9 \\
\hline Kirby (24) & & & & & 0 & & & \\
\hline Kirby (25) & 9 & & - & 0 & 0 & 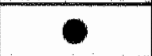 & 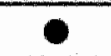 & 0 \\
\hline Lehmann (26) & 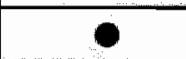 & & & 0 & & & & \\
\hline Mattison (27) & & & & & & & 0 & \\
\hline Mizukami (28) & 0 & & & & & - & & 0 \\
\hline Panikoff (29) & 9 & & 9 & & & 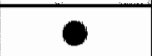 & 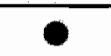 & $\overline{0}$ \\
\hline $\begin{array}{l}\text { Schnelle }(30,31) ; \\
\text { Simmons }(32)\end{array}$ & 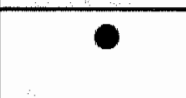 & & & & & & & \\
\hline Vanlandewijck (35) & 0 & $\overline{0}$ & & & & & & 0 \\
\hline
\end{tabular}

Less common wheelchair skills are noted in the column 'other wheelchair skills'.

Two tests $(7,12)$ require both ascending and descending of the curb. All other tests only assess the ascending of the curb. In all but three tests $(7,10,14)$, the slopes used are defined in terms of inclination and length, inclinations ranging from 1 to 11 degrees, length ranging from 3.05 to $21 \mathrm{~m}$. Some examples of tracks used are: slalom $(6,19,25)$, figure of eight (11) and obstacle course (12, 
36). In six tests a sprint is included. Nearly all tests use a sprint over a fixed distance (length ranging from 6.5 to $30 \mathrm{~m}$ ). Although performing a wheelie is an important skill in achieving wheelchair mobility, this skill is only included in four tests.

Eleven tests include, in addition to the skills already mentioned, other specific wheelchair skills, e.g., managing brakes, negotiating doors and loading the wheelchair into a car. Fifteen tests consist entirely of the performance of wheelchair skillis. In eight tests wheelchair skills are a part of a broader measure of ADL skills; these tests encompass other ADL tasks such as eating, bed mobility skills, and washing hands $(7,9,14,18,21,23,28,29)$.

\section{Target population and population at study}

Although only four tests were designed for a specific target population, 16 tests have only been used in study groups with one specific diagnosis, most often spinal cord injury. Four tests were used for persons with varying medical conditions (Table 2.1).

\section{Feasibility}

On the one hand, tests should include enough elements to obtain an in-depth insight into wheelchair skill performance; on the other hand, tests have to be efficient and as short as possible. The completion time was mentioned for only six tests. The VFM (7), the TAMP (14) and the test of Jebsen et al. (23) take up to 1 hour to complete. However, these tests contain other ADL tasks as well as specific wheelchair skills. The performance of Harvey's test (18) requires approximately 15 minutes, the time needed to complete the WST (25) is 30 minutes, and the mean test duration of the wheelchair basketball field test of Vanlandewijck et al. (35) is 1 hour and 22 minutes.

Ideally, tests should not require much space or speciall equipment. In most studies, the materials needed for test performance are not addressed. In their paper, Jebsen et al. (23) dedicated a section to test equipment (a hospital bed, standardized wheelchair and straight chair). Harvey et al. (18) stated that no special equipment is required to perform their test. To assess physical strain during wheelchair skill performance a heart rate monitor is required. Twelve studies provide information on the wheelchairs used during test performance $(6,9,11-13,20-26)$. Three studies used standardized wheelchairs (23-25). In eight studies, participants used their daily use wheelchairs (9, 11-13, 20-22, 25). Bolin et al. (6) aimed to improve the individual fit of the wheelchair in their participants. The participants performed a wheelchair skills test twice: first in their daily use wheelchair and later in an adapted or new wheelchair.

The outcome measures of the different tests are displayed in table 2.1. The most common outcome measure is task performance time. Independence in wheelchair skill performance is assessed by taking into account the use of assistive devices or the amount of help needed from another person. Six tests measure physical strain during skill performance, four tests evaluate distance covered during wheelchair propulsion, four tests rate the velocity of wheelchair propulsion, and three tests assess subjective ratings regarding skill performance.

A test should preferably have an uncomplicated scoring system that is convenient to use and that can be analyzed easily. The scoring of the TAMP (14) is extremely complex: one hundred and thirteen 
skills have to be rated on six measurement dimensions, and rating this test requires extensive training.

\section{Clinimetric properties}

Nine tests $(6,10,11,13,22,24,26,28,31)$ were not evaluated on any of the clinimetric properties. Three tests provide information on sensitivity to change $(7,9,12)$. Only two tests, the VFM (7) and the WST (25), were explicitly subjected to a validation study. For eight other tests $(5,12,19,21,24$, $26,28,31,36)$ information on validity could be retrieved from the articles. The validity of these tests, however, was not explicitly evaluated. Information concerning reliability was given for 10 tests $(7,14$, $15,18-20,23,25,27,35)$. Only five tests $(19,23,25,27,36)$ provided data on both reliability and validity. Table 2.3 displays the 11 tests from which the sensitivity to change and/or the validity have been evaluated. In table 2.4 , the 10 tests that have been assessed on the topic of reliability are shown.

From table 2.4 it can be seen that all available test-retest and inter-rater reliability figures are satisfying up to excellent; the data on validity are less unequivocal (Table 2.3).

Table 2.3 Sensitivity and validity of the selected wheelchair skills tests

\begin{tabular}{|c|c|c|c|}
\hline Author & Sensitivity to change & Content validity & Construct validity \\
\hline Agre (5) & No information & No infoirmation & $\begin{array}{l}\text { Falled to find a relationship } \\
\text { between motor function and } \\
\text { propulsion speed. }\end{array}$ \\
\hline $\begin{array}{l}\text { Capodaglio }(7) \\
\text { Taricco }(33,34)\end{array}$ & $\begin{array}{l}\text { Two groups were tested } \\
\text { before and after a 6-week } \\
\text { rehabilitation program: } \\
\text { conventional or enhanced. No } \\
\text { significant differences } \\
\text { between the groups (7). } \\
\text { Participants were tested at the } \\
\text { start and the end of their } \\
\text { rehabilitation period. Scores } \\
\text { had significantly improvement } \\
\text { for persons with quadriplegia } \\
\text { and high-level paraplegia. } \\
\text { There were no changes in the } \\
\text { scores of persons with low- } \\
\text { level paraplegia (33). }\end{array}$ & $\begin{array}{l}\text { The content of the VFM was } \\
\text { compared to the content of } \\
\text { the FIM, Barthel index, and } \\
\text { QIF. The VFM includes all } \\
\text { basic ADL domains and has } \\
\text { the largest number of tasks in } \\
\text { the domains transfers and } \\
\text { wheelchair use, which are } \\
\text { particularly relevant for } \\
\text { wheelchair dependent people } \\
\text { (33). }\end{array}$ & No Information \\
\hline Dallmeijer $(8,9)$ & $\begin{array}{l}\text { Participants were tested at the } \\
\text { start and at the end of their } \\
\text { rehabilitation period. There } \\
\text { were no changes in physical } \\
\text { strain during the slope ascend } \\
\text { and the transfers. The } \\
\text { performance time of the slope }\end{array}$ & No information & No information \\
\hline
\end{tabular}




\begin{tabular}{|c|c|c|c|}
\hline Author & Sensitivity to change & Content validity & Construct validity \\
\hline a & $\begin{array}{l}\text { ascend significantly } \\
\text { decreased. The performance } \\
\text { time of the transfer did not } \\
\text { change (9). }\end{array}$ & & \\
\hline Durán (12) & $\begin{array}{l}\text { Participants were tested } \\
\text { before and after a 16-week } \\
\text { exercise program. Task } \\
\text { performance times } \\
\text { significantly decreased. The } \\
\text { ability to negotiate curbs } \\
\text { improved. }\end{array}$ & No information & $\begin{array}{l}\text { Mean FIM scores were } \\
\text { associated with an improved } \\
\text { ability to negotiate curbs and } \\
\text { inversely associated with task } \\
\text { performance times. }\end{array}$ \\
\hline $\begin{array}{l}\text { Gouvier (15) } \\
\text { Webster (36-38) }\end{array}$ & No information & No information & $\begin{array}{l}\text { Persons with right-sided } \\
\text { stroke with neglect hit } \\
\text { significantly more objects in } \\
\text { left- than in right-space, and } \\
\text { made significantly more errors } \\
\text { than stroke patients without } \\
\text { neglect and healthy control } \\
\text { subjects }(36,37) \text {. }\end{array}$ \\
\hline Hutzler (19) & No information & No information & $\begin{array}{l}\text { Inverse correlation between } \\
\text { sprint performance time and } \\
\text { the participants' wheelchair } \\
\text { basketball classification } \\
\left(r_{\text {spearman }}=-0.64\right) \text {. No relation } \\
\text { between bodywelght and task } \\
\text { performance times. }\end{array}$ \\
\hline Janssen (21) & No Information & No information & $\begin{array}{l}\text { A lower lesion level was } \\
\text { associated with a lower level } \\
\text { of physical strain during } \\
\text { wheelchair skill performance. } \\
\text { No relation between lesion- } \\
\text { completeness and physical } \\
\text { strain during skill } \\
\text { performance. } \\
\text { Physical strain during skill } \\
\text { performance was inversely } \\
\text { related to strength, sprint } \\
\text { power, peak oxygen uptake, } \\
\text { and maximum power output } \\
\left(r_{\text {pearson }}=-0.41--0.73\right) \text {. } \\
\end{array}$ \\
\hline Jebsen (23) & No information & No information & $\begin{array}{l}\text { Healthy people performed the } \\
\text { tasks concerning wheelchair } \\
\text { mobility faster than persons } \\
\text { with mobility problems. }\end{array}$ \\
\hline
\end{tabular}




\begin{tabular}{|c|c|c|c|}
\hline Author & Sensitivity to change & Content validity & Construct validity \\
\hline Kirby (25) & No information & $\begin{array}{l}\text { Occupational therapists } \\
\text { evaluated the content of the } \\
\text { WST, and unanimously } \\
\text { approved with } 30 \text { of the } 33 \\
\text { skills. }\end{array}$ & $\begin{array}{l}\text { Occupational therapists (OT) } \\
\text { rated whether partlcipants' } \\
\text { wheelchair skills had } \\
\text { improved, not changed or } \\
\text { worsened between two test } \\
\text { trials. They rated that } 13 \\
\text { persons had improved, } 8 \text { had } \\
\text { not changed, and none had } \\
\text { worsened. Accordingly, the } \\
\text { mean improvement in the } \\
\text { total score was larger for the } \\
\text { 'improved persons' than for } \\
\text { the 'unchanged persons'. OT's } \\
\text { also completed a VAS } \\
\text { reflecting the persons' } \\
\text { wheelchair skill performance. } \\
\text { Mean improvement for the } \\
\text { 'improved persons' was } \\
\text { significantly higher than for } \\
\text { the 'unchanged persons'. } \\
\text { Test scores significantly } \\
\text { related to age, and wheelchair } \\
\text { experience. No relation was } \\
\text { found between test scores and } \\
\text { diagnosis. }\end{array}$ \\
\hline Mattison (27) & No information & No information & $\begin{array}{l}\text { There was no relation } \\
\text { between physical strain during } \\
\text { sklll performance and age or } \\
\text { diagnosis. Physical strain was } \\
\text { significantly related to the } \\
\text { percelved exertion during test } \\
\text { performance }\left(r_{\text {pearson }}=0.84\right) \text {. }\end{array}$ \\
\hline Panikoff (29) & No information & No information & $\begin{array}{l}\text { A significant relation between } \\
\text { the ability to perform transfers } \\
\text { and length of coma. }\end{array}$ \\
\hline
\end{tabular}

VFM = Valutazione Funzionale Mielolesie; FIM = Functional Independence Measure; QIF = Quadriplegia Index of Function; WST $=$ Wheelchair Skills Test; VAS = Visual Analogue 5 cale. 
Table 2.4 Reliability of the selected wheelchair skills tests

\begin{tabular}{|c|c|c|c|}
\hline Author & Test-retest reliability & Inter-rater reliability & Intra-rater reliability \\
\hline $\begin{array}{l}\text { Capodaglio }(7) \\
\text { Taricco }(33,34)\end{array}$ & No information & $\begin{array}{l}\text { The inter-rater rellability of the } \\
\text { VFM was demonstrated in } \\
\text { previous studies. These } \\
\text { stiudles were only published in } \\
\text { Italian and were therefore not } \\
\text { retrieved. }\end{array}$ & No information \\
\hline $\begin{array}{l}\text { Gans }(14) \\
\text { Haley }(16,17)\end{array}$ & No Information & $\begin{array}{l}\text { Participants' test performances } \\
\text { were videotaped, and } \\
\text { independently evaluated by } \\
\text { three raters. Regarding } \\
\text { wheelchair skills, inter-rater } \\
\text { reliability was excellent (kappa } \\
=0.65-0.83)(14) \text {. }\end{array}$ & No information \\
\hline $\begin{array}{l}\text { Gouvier (15) } \\
\text { Webster (36-38) }\end{array}$ & No Information & $\begin{array}{l}\text { Two raters scored the number } \\
\text { and type of errors two } \\
\text { participants made during test } \\
\text { performance. Their agreement } \\
\text { on the occurrence of errors } \\
\text { and the type of error made } \\
\text { was successively } 95 \% \text { and } \\
83 \% \text { (15). } \\
\text { Two raters scored the tests. } \\
\text { They agreed } 100 \% \text { on the } \\
\text { occurrence of errors, 80-90\% } \\
\text { on the occurrence of direct } \\
\text { hilts }\left(r_{\text {pearson }}=0.90-0.97\right), \text { and } \\
85-90 \% \text { on the occurrence of } \\
\text { sideswipes errors } \\
\left(r_{\text {pearson }}=0.92-0.95\right)(36) \text {. }\end{array}$ & No information \\
\hline Harvey (18) & No Information & $\begin{array}{l}\text { Two raters scored the test } \\
\text { performances resulting in high } \\
\text { inter-rater reliability } \\
\text { (kappa }=0.82-0.98 \text { ). }\end{array}$ & No information \\
\hline Hutzler (19) & $\begin{array}{l}\text { Excellent test-retest reliability } \\
\text { for task performance time and } \\
\text { propelled distance } \\
\left(r_{\text {spearman }}=0.87-0.99\right) \text { on two } \\
\text { test performances. }\end{array}$ & No information & No information \\
\hline Janssen (20) & $\begin{array}{l}\text { Participants performed three } \\
\text { test trials: two on the same } \\
\text { day (trial } 1 \text { and } 2 \text { ) and one a } \\
\text { week later (trial } 3 \text { ). } \\
\text { Correlations for heart rate } \\
\text { were good for trial } 1 \text { versus } 2 \text {, } \\
\text { and trial } 1 \text { versus } 3 \\
\end{array}$ & No information & No information \\
\hline
\end{tabular}




\begin{tabular}{|c|c|c|c|}
\hline Author & Test-retest rellability & Inter-rater rellability & Intra-rater reliability \\
\hline & $\begin{array}{l}\text { (1 ws 2: } r_{\text {pearson }}=0.79-0.97, \\
\text { ICC }=0.73-0.97,1 \text { vs } 3: \\
r_{\text {pearson }}=0.69-0.95, I C C=0.52- \\
0.92) \text {. } \\
\text { Good correlations for the } \\
\text { performance time of the curb } \\
\text { ascend for trial } 1 \text { versus } 2 \\
\left(r_{\text {pearson }}=0.88, I C C=0.82\right) . \text { Low } \\
\text { correlations for trial } 1 \text { versus } 3 \\
\left(r_{\text {pearson }}=0.31, I C C=0.20\right) \text {. }\end{array}$ & & \\
\hline Jebsen (23) & $\begin{array}{l}\text { Performance times } \\
\text { correlations were excellent } \\
\left(r_{\text {pearson }}=0.85-0.99\right) .\end{array}$ & No Information & No Information \\
\hline Kirby (25) & $\begin{array}{l}\text { Good correlation between the } \\
\text { scores on two different test } \\
\text { occasions ( } r_{\text {spearman }}=0.65 \text { ). }\end{array}$ & $\begin{array}{l}\text { Two raters independently } \\
\text { scored the same videotapes of } \\
\text { test performances, resulting in } \\
\text { an excellent correlation } \\
\text { coefficient ( } r_{\text {spearmam }}=0.95 \text { ). }\end{array}$ & $\begin{array}{l}\text { One rater scored the same } \\
\text { videotapes of persons test } \\
\text { performances twice, resulting } \\
\text { in an excellent correlation } \\
\text { coefficient }\left(r_{\text {spearman }}=0.96\right) \text {. }\end{array}$ \\
\hline Mattison (27) & $\begin{array}{l}\text { Participants performed two } \\
\text { test trials. Good correlations } \\
\text { for distance traveled, physical } \\
\text { strain during wheelchair } \\
\text { propulsion, and propulsion } \\
\text { velocity }\left(r_{\text {pearson }}=0.96,0.84 \text {, }\right. \\
\text { and } 0.70) \text {. }\end{array}$ & No Information & No information \\
\hline $\begin{array}{l}\text { Vanlandewijck } \\
\text { (35) }\end{array}$ & $\begin{array}{l}\text { Excellent correlations for all } \\
\text { tasks }\left(r_{\text {spearman }}=0.80-0.97\right) \text {, } \\
\text { onlly one being good } \\
\left(r_{\text {spearman }}=0.65\right)\end{array}$ & No information & No Information \\
\hline
\end{tabular}

VFM = Valutazione Funzionale Mielolesle; $I C C=$ Intraclass Correlation Coefficient.

\section{Discussion}

A literature search resulted in the selection of 24 different wheelchair skills tests. This collection may be incomplete, since only English-written studies, published in scientific journals were taken into account. However, we feel that we have provided a critical and useful overview of tests in which wheelchair skills are assessed.

\section{Content of tests}

There is limited consensus as to the content of wheelchair skills tests (Table 2.2). Even skills frequently used in tests (wheelchair propulsion, transfer, curb, slope), show a large variation in, for instance, driving distance, objects to transfer to, height of the curbs, and angle of inclination of slopes. The number of skills included in wheelchair skills tests also shows a large variation, ranging 
from one (36) to 113 (14). More research is needed to identify a limited number of skills that together best reflect wheelchair skill performance in people who depend on a manual wheelchair for their mobility.

\section{Target population and population at study}

Although just four tests were designed for a specific target group, 16 tests were only used in a specific group (Table 2.1). The latter tests might also be capable of assessing wheelchair skills in people with other characteristics, but further research on validation and reliability in other subject groups is necessary to test this expectation.

\section{Test outcomes}

Many different outcome parameters are used in the selected tests (Table 2.1). The choice for a particular outcome measure depends on the objectives of the study. Tests can be used to determine the feasibility of manual wheelchair propulsion, to measure the level of independence in wheelchair $A D L$, or to evaluate the effects of interventions. Outcome measurements in the categories time, distance and physical strain are very useful to provide information on the practicability of manual wheelchair mobility in daily life. When a person needs, for example, five minutes to propel his or her wheelchair over a distance of 50 meters, an electric wheelchair may be a more suitable means of mobility. If the goal of a study is to describe the level of independent mobility, a scale of independence in performing wheelchair tasks is an obvious outcome measure. The level of independence in performing well-chosen wheelchair skills is expected to be directly related to independent mobility in daily life. People who cannot perform wheelchair skills independently will not achieve independent mobility in all environmental circumstances. For the assessment of (changes in) wheelchair skill performance in completely independent individuals, outcome measures such as time, distance, and physical strain should be applied. This is also shown by the results of Taricco et al. (33) who measured wheelchair skill performance using a scale of independence. They showed good sensitivity to change in participants with high-level spinal cord injury, but no sensitivity to change in persons with low-level spinal cord injury.

Other outcome measures are relevant, but not so easy to interpret. The test of Dallmeijer et al. $(8,9)$ evaluates both physical strain during wheelchair skill performance and performance time of each skill. These two parameters are, however, interdependent. A decrease in performance time, reflecting better test performance, may result in a higher level of physical strain, indicating worse test performance. This interdependency may obfuscate the interpretation of test results.

Further, wheelchair skill performance relies on both technique and physical capacity. Repeated measurements can, for instance, show that maximal wheeling endurance time has increased over a certain period, which may be the result of an increase in physical capacity, an improved technique resulting in higher mechanical efficiency of wheelchair propulsion, or a result of both. For a correct interpretation of changed outcomes in longitudinal studies, the performance of a wheelchair skills test is best combined with an exercise test that provides information about physical capacity. 
The WST (25) leads to one overall score of wheelchair skill performance, expressed as the sum of the scores obtained on each skill. Such a total score might be very useful for research purposes, but can only lead to valid information if all test items measure the same phenomenon. The authors did not assess this.

\section{Clinimetric properties}

Clinimetric properties of nine tests were not described at all. Only two tests: the VFM (7) and the WST (25) have been extensively validated. The WST is the only test that has been adequately tested on both validity and reliability. More research is needed to assess the clinimetric qualities of the other tests described in the current review before these tests can be recommended for use.

Performance time and physical strain are outcome measures that can be measured objectively. Ordinal scales of dependence, frequently used in wheelchair skills tests, are subject to interpretation. Raters need to assess the amount of help, often expressed in a few number of categories of assistance needed. Therefore, the raters should receive appropriate training. The good inter-rater reliability figures of tests using ratings of independence are promising, but these figures are, in part, obtained in very small study groups. Although also rarely investigated, test-retest analyses of time, distance, velocity and physical strain revealed satisfying results.

The measurement of wheelchair skills will, at least in part, support validity of the tests due to the close resemblance with daily life activities. However the choice of tested tasks, outcome measures and the applicability in different subject groups may influence validity. One aspect of validity that is often ignored is the influence of wheelchair configuration on wheelchair skill performance outcomes. Persons will perform best in a wheelchair that is optimally adjusted to their personal characteristics. To ensure that variations in wheelchair skill performance were not due to changes in wheelchair configuration, some tests were performed in standardized wheelchairs $(23,24,26)$. However, most tests were executed in daily use wheelchairs $(9,12,20,22,25)$. This may have resulted in participants using different wheelchairs on different test occasions, which may have affected sensitivity to change and test-retest reliability or may bias comparisons between persons having wheelchairs of different quality. Use of the daily use wheelchair may, however, improve the validity of the test. Participants are not troubled by an unfamiliar wheelchair, and their test results will be more representative for their wheelchair skill performance in daily life. Therefore a careful choice for, or against standardization of wheelchair configuration has to be made, dependent on the purpose and the design of the study.

In conclusion, this review shows that there is, as yet, no standard test to measure wheelchair skill performance. Only seven out of the 24 tests found were extensively described in terms of development, content and use $(7,14,18,23,25,35,36)$ and only two test have been extensively validated $(7,25)$. In addition, most tests have only been used in one study. Without further research on validity and reliability, these tests should be used with caution.

The use of many different tests makes it difficult, if not impossible, to compare study results. Standardization of the skills tested and the use of measurement instruments are needed to enable comparisons between studies and to give a better insight in the quality of the tests used. Future research could best concentrate on further validation of existing tests instead of developing even more tests. The selection of the best and most relevant items of these tests and combining 
elements of various tests might eventually lead to a superior test. However, it might not be possible to compose the ideal test for all patient groups and purposes. A distinction between a clinical instrument (containing all relevant items for assessment and evaluation of individual treatment) and a research instrument (containing a selection of items of varying difficulty) might be useful. 


\section{References}

1. Somers M. Spinal cord injury, functional rehabilitation. Connecticut: Appleton \& Lange; 1992.

2. Britell $\mathrm{CW}$. Wheelchair prescription. In: Lehmann JF, Kottke FJ, editors. Krusen's handbook of physical medicine and rehabilitation. 4 ed. Philadelphia: W.B. Company Saunders; 1990. p. 548-63.

3. Bussmann JBJ, Stam HJ. Techniques for measurement and assessment of mobility in rehabilitation: A theoretical approach. clinical rehabilitation $1998 ; 12: 455-64$.

4. WHO, International Classification of Functioning, Disability and Health. ICIDH-2 finall draft. Geneva: WHO, 2001.

5. Agre JC, Findley TW, McNally MC, Habeck R, Leon AS, Stradel L, et al. Physical activity capacity in children with myelomeningocele. Arch Phys Med Rehabil 1987;68(6):372-7.

6. Bolin I, Bodin P, Kreuter M. Sitting position - posture and performance in C5 - C6 tetraplegia. Spinal Cord 2000;38(7):425-34.

7. Capodaglio $P$, Grilli $C$, Bazzini G. Tolerable exercise intensity in the early rehabilitation of paraplegic patients. A preliminary study. Spinal Cord 1996;34(11):684-90.

8. Dallmeijer AJ, Woude van der LHV, Hollander AP, As van HH. Physical performance during rehabilitation in persons with spinal cord injuries. Med Sci Sports Exerc 1999;31(9):1330-5.

9. Dallmeijer AJ, Woude van der LHV, Hollander AP, Angenot EL. Physical performance in persons with spinal cord injuries after discharge from rehabilitation. Med Scl Sports Exerc 1999;31(8):1111-7.

10. Duffill J, Buckley J, Lang D, Neil-Dwyer G, McGinn F, Wade D. Prospective study of omental transposition in patients with chronic spinal injury. J Neurol Neurosurg Psychiatry 2001;71(1):73-80.

11. Dunkerley AL, Ashburn A, Stack EL. Deltoid triceps transfer and functional independence of people with tetraplegia. Spinal Cord 2000;38(7):435-41.

12. Duran FS, Lugo L, Ramirez L, Lic EE. Effects of an exercise program on the rehabilitation of patients with spinal cord injury. Arch Phys Med Rehabil 2001;82(10):1349-54.

13. Findley TW, Agre JC. Ambulation in the adolescent with spina bifida. II. Oxygen cost of mobility. Arch Phys Med Rehabil 1988;69(10):855-61.

14. Gans BM, Haley SM, Hallenborg SC, Mann $\mathbf{N}_{r}$ Inacio CA, Faas RM. Description and interobserver reliability of the Tufts Assessment of Motor Performance. Am J Phys Med Rehabil 1988;67(5):202-10.

15. Gouvier WD, Cottam G, Webster JS, Beissel GF, Wofford JD. Behavioral Interventions with stroke patients for improving wheelchair navigation. the international journal of clinical neuropsychology 1984;6(3):186-90.

16. Haley SM, Ludlow LH. Applicability of the hierarchical scales of the Tufts Assessment of Motor Performance for school-aged children and adults with disabilities. Phys Ther 1992;72(3):191202; discussion 202-6.

17. Haley SM, Ludlow LH, Gans BM, Faas RM, Inacio CA. Tufts assessment of motor performance: An empirical approach to identifying motor performance categories. Arch Phys Med Rehabil 1991;72(6):359-66.

18. Harvey LA, Batty J, Fahey A. Reliability of a tool for assessing mobility in wheelchairdependent paraplegics. Spinal Cord 1998;36(6):427-31. 
19. Hutzler $Y$. Physical performance of elite wheelchair basketball players in armcranking ergometry and in selected wheeling tasks. Paraplegia 1993;31(4):255-61.

20. Janssen TWJ, Ders van CAMM, Woude van der LHV, Hollander AP. Reliability of heart rate responses to non-steady-state activities of daily living in men with spinal cord injuries. Scand J Rehabil Med 1994;26(2):71-8.

21. Janssen TWJ, Oers van CAJM, Veeger HE, Hollander AP, Woude van der LHV, Rozendal RH. Relationship between physical strain during standardised ADL tasks and physical capacity in men with spinal cord injuries. Paraplegia 1994;32(12):844-59.

22. Janssen TWJ, Oers van CAJM, Rozendaal EP, Willemsen EM, Hollander AP, Woude van der LHV. Changes in physical strain and physical capacity in men with spinal cord injuries. Med Sci Sports Exerc 1996;28(5):551-9.

23. Jebsen RH, Trieschmann RB, Mikulic MA, Hartley RB, McMillan JA, Snook ME. Measurement of time in a standardized test of patient mobility. Arch Phys Med Rehabil 1970;51(3):170-5.

24. Kirby RL, Lugar JA, Breckenridge C. New wheelie aid for wheelchairs: Controlled trial of safety and efficacy. Arch Phys Med Rehabil 2001;82(3):380-90.

25. Kirby RL, Swuste J, Dupuis DJ, MacLeod DA, Monroe R. The Wheelchair Skills Test: A pilot study of a new outcome measure. Arch Phys Med Rehabil 2002;83(1):10-8.

26. Lehmann JF, Warren CG, Halar $E$, Stonebridge JB, Delateur $B$ J. Wheelchair propulsion in the quadriplegic patient. Arch Phys Med Rehabil 1974;55(4):183-6.

27. Mattison PG, Hunter 3, Spence S. Development of a realistic method to assess wheelchair propulsion by disabled people. Int ] Rehabil Res 1989;12(2):137-45.

28. Mizukami M, Kawai N, Iwasaki Y, Yamamoto $Y$, Yoshida $Y$, Koyama N, et al. Relationship between functional levels and movement in tetraplegic patients. A retrospective study.

Paraplegla 1995;33(4):189-94.

29. Panikoff LB. Recovery trends of functional skills in the head-injured adult. Am J Occup Ther 1983;37(11):735-43.

30. Schnelle JF, MacRae PG, Giacobassi K, MacRae HS, Simmons SF, Ouslander JG. Exercise with physically restrained nursing home residents: Maximizing benefits of restraint reduction. J Am Geriatr Soc 1996;44(5):507-12.

31. Schnelle JF, MacRae PG, Ouslander JG, Simmons SF, Nitta M. Functional incidental training, mobility performance, and incontinence care with nursing home residents. J Am Geriatr Soc 1995;43(1.2):1356-62.

32. Simmons SF, Schnelle JF, MacRae PG, Ouslander JG. Wheelchairs as mobility restraints: Predictors of wheelchair activity in nonambulatory nursing home residents. J Am Geriatr Soc 1995;43(4):384-8.

33. Taricco M, Apolone $G$, Colombo C, Filardo G, Telaro E, Liberati A. Functional status in patients with spinal cord injury: A new standardized measurement scale. Gruppo Interdisciplinare Valutazione Interventi Riabilitativi. Arch Phys Med Rehabil 2000;81(9):1173-80.

34. Taricco $M_{*}$ Colombo $C_{*}$ Adone $R$, Chiesa G, Di Carlo $S_{f}$ Borsani $M$, et al. The social and vocational outcome of spinal cord injury patients. Paraplegia 1992;30(3):214-9.

35. Vanlandewijck YC, Daly DJ, Theisen DM. Field test evaluation of aerobic, anaerobic, and wheelchair basketball skill performances. Int J Sports Med 1999;20(8):548-54. 
36. Webster JS, Cottam G, Gouvier WD, Blanton P, Beissel GF, Wofford J. Wheelchair obstacle course performance in right cerebral vascular accident victims. I Clin Exp Neuropsychol 1989;11(2):295-310.

37. Webster JS, Rapport $\amalg$, Godlewski MC, Abadee PS. Effect of attentional bias to right space on wheelchair mobility. J Clin Exp Neuropsychol 1994;16(1):129-37.

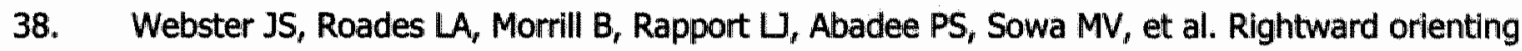
bias, wheelchair maneuvering, and fall risk. Arch Phys Med Rehabil 1995;76(10):924-8. 


\section{Appendix Chapter 2}

\section{Search Strategy}

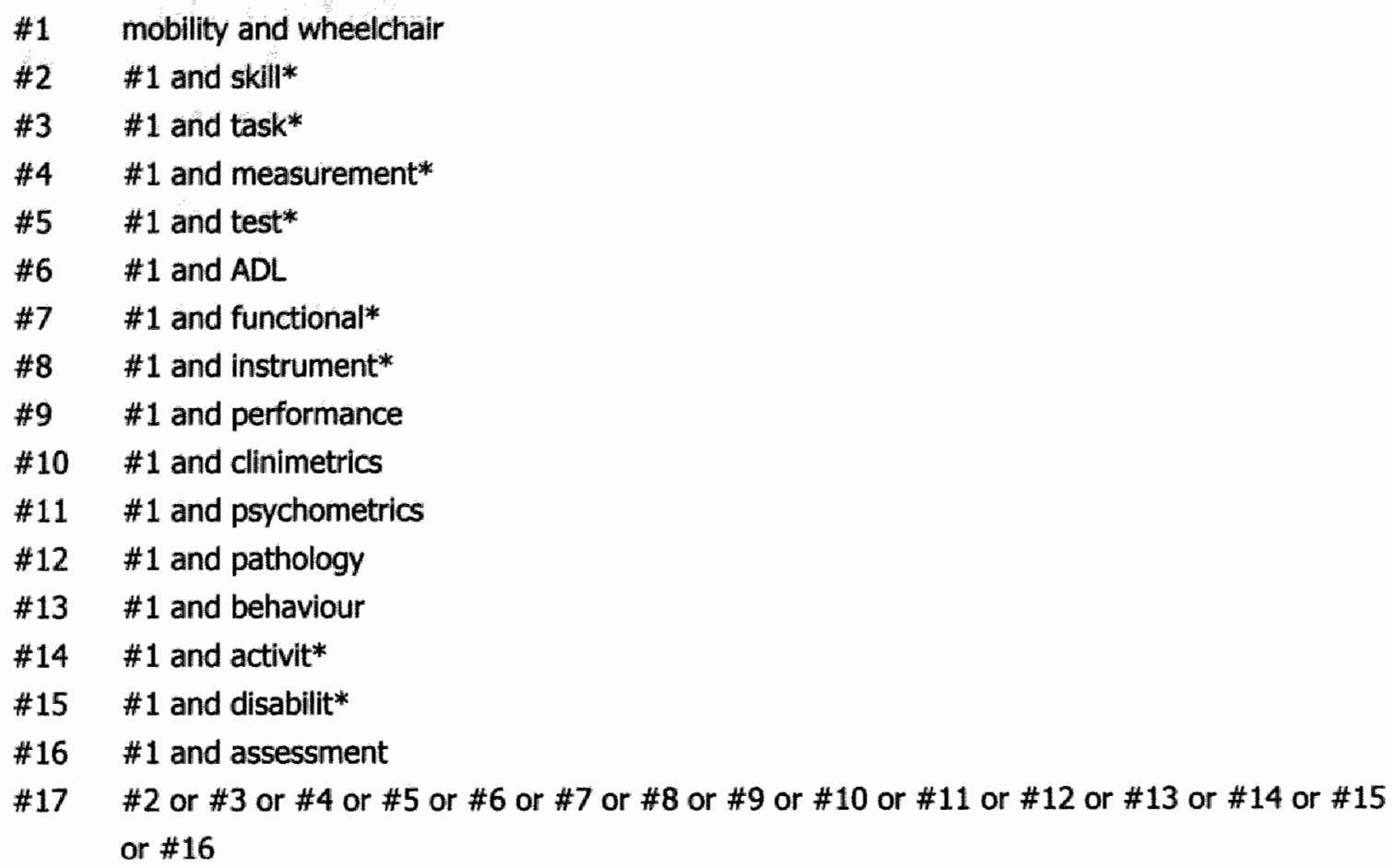




\section{3}

The Wheelchair Circuit:

Reliability of a test to assess mobility in persons with spinal cord injuries

Olga Kilkens, Marcel Post, Luc van der Woude, Annet Dallmeijer and Wim van den Heuvel Archives of Physical Medicine and Rehabilitation 2002; 83 (12): 1783 - 8 


\section{Summary}

Objective: To assess the reliability of a 9-task Wheelchair Circuit.

Design: Three test trials per participant were conducted by 2 raters. Inter- and intrarater reliability were examined.

Setting: Eight rehabilitation centers in the Netherlands.

Patients: Convenlence sample of 27 patients (age $\geq 18$ years) with spinal cord injury (SCI), all of whom were in the final stage of their inpatient rehabilitation.

Intervention: A Wheelchair Circuit was developed to assess mobility in subjects with SCI. The circuit consisted of 9 tasks:" figure-of- 8 shape, doorstep crossing, mounting a platform, sprint, walking, driving up treadmill slopes of $3 \%$ and $6 \%$, wheelchair driving, and transfer.

Main Outcome Measures: Task feasibility, task performance time, and peak heart rates.

Results: The number of tasks that participants could perform varied from 3 to 9 . Feasibility intrarater reliability was 0.98 and the interrater reliability intraclass correlation coefficient (ICC) was 0.97 .

Performance time ICCs ranged from 0.70 to 0.99 (mean, 0.88 ) for intrarater reliability and from 0.76 to 0.98 (mean, 0.92 ) for interrater reliability. Heart rate ICCs ranged from 0.64 to 0.96 (mean, 0.81 ) for intrarater reliability and from 0.82 to 0.99 (mean, 0.89 ) for interrater reliability.

Conclusions: The reliability of the Wheelchair Circuit was good. More research is needed to assess test validity and responsiveness. 


\section{Introduction}

Because approximately $82 \%$ of persons with a spinal cord injury ( $\mathrm{SCI}$ ) are dependent on wheelchairs for mobility (1), wheelchairs are important in achieving independent mobility. Wheelchair propulsion is an inefficient and strenuous method of locomotion (2). As a result of a reduction in active muscle mass, the physical capacity of persons with $\mathrm{SCI}$ is often very low. This leads to high physical strain during wheelchair performance (3). A thorough mastery of wheelchair skills, combined with an optimal physical capacity, can enhance mobility. Increasing physical capacity and specific wheelchair skills therefore are important goals of rehabilitation after SCI (4).

For this study, mobility was defined as the process of moving oneself and of changing and maintaining postures (5). The most common way to assess the mobility of persons with SCI is through observation. The FIM ${ }^{T M}$ instrument and the Modified Barthel Index are two frequently used observational measurement instruments $(6,7)$. Currently, the FIM is the most widely accepted and most commonly used measure to evaluate the mobility of persons with $\mathrm{SCI}(8)$. However, these observational methods have some disadvantages. First, they are not sensitive enough to detect small changes in mobility (9-13) because they only record whether a person can perform a particular task or whether the task is performed independently. Small improvements in the quality of the task performance can often not be scored. Nonetheless, these small changes can be of great importance. Second, these methods do not provide information about the physical strain involved in performing a particular task.

To skirt these disadvantages, several researchers $(9,10,14-20)$ have used functional tests, including the performance of wheelchair tasks, to assess mobility gain or physical strain during wheelchair tasks. Cardus et al. (20) designed an open-air test circuit. In such a situation, standardization of environmental parameters is not possible, which limits the reliability of this circuit as a measurement instrument. Harvey et al. (10) used 6 functional tasks to assess mobility in wheelchair-dependent paraplegic persons. Tasks used were supine to long sitting, horizontal and vertical transfer, wheelchair propulsion on a flat surface, driving up a ramp, and negotiating curbs. A 6-point scoring system was used that considered only the level of assistance needed during task performance. Performance time and physical strain were not assessed, which makes this test less suitable for detecting small changes in mobility. In the Netherlands, Michels et al. (16) and Meijs et al. (19) developed a wheelchair circuit with 6 tasks. Each task was performed for 3 minutes to reach a steady-state condition. However, this circuit proved highly impractical for use in different rehabilitation centers. Both Janssen et al. (15) and Dallmeijer et al. (14) used several diverse functional activity of daily living (ADL) tasks to assess physical strain during task performance. Some tasks specifically referred to mobility, such as ascending a ramp and transferring from a wheelchair to a toilet. Other tasks were related to other $A D L s$, such as changing sheets, preparing lunch, and washing hands. Until now, there has been no uniformly sensitive measurement instrument with which to assess functional wheelchair skills.

An ongoing longitudinal, multicenter prospective cohort study was initiated in 1999 in the Netherlands in which people with acute $\mathrm{SCI}$ are followed during and after clinical rehabilitation. Within the scope of this study, a functional test - the Wheelchair Circuit - was developed. Its purpose is to assess mobility during and after clinical rehabilitation. The Wheelchair Circuit is primarily designed for research purposes but may also be used in a clinical setting. The reliability of any new measurement instrument is important to ensure that the measurement error is small enough to detect actual 
changes in what is being measured (21). The aim of this study was to assess the feasibility and the inter- and intrarater reliability of this Wheelchair Circuit.

\section{Methods}

\section{Participants}

Twenty-seven wheelchair users with SCI (convenience sample) were recruited from among patients admitted to any 1 of 8 rehabilitation centers that specialize in SCI rehabilitation in the Netherlands. All participants were in the final stage of their clinical rehabilitation program, used a hand-rim wheelchair, and were between 18 and 65 years of age. Potential participants were not included if they had a current cardiorespiratory disorder or orthopedic or other medical complications that restricted them in performing the tasks required for the Wheelchair Circuit. Participant characteristics are summarized in table 3.1.

All participants completed a consent form after they were given information about the testing procedures. All tests and protocols were approved by the Medical Ethics Commiltee of the Institute for Rehabilitation Research, Hoensbroek, the Netherlands.

Table $3.1 \quad$ Subject characteristics

\begin{tabular}{|l|l|l|l|l|}
\hline Type of injury & Completeness of injury & n & Mean Age \pm SD & M / F \\
\hline Paraplegla & Complete & 9 & $39.7 \pm 11.5$ & $5 / 4$ \\
\hline Paraplegla & Incomplete & 5 & $29.8 \pm 8.2$ & $3 / 2$ \\
\hline Tetraplegla & Complete & 5 & $25.4 \pm 4.8$ & $4 / 1$ \\
\hline Tetraplegla & Incomplete & 8 & $37.9 \pm 15.9$ & $6 / 2$ \\
\hline Total $\mathbf{n}$ & & 27 & $34.7 \pm 12.5$ & $18 / 9$ \\
\hline
\end{tabular}

$M=$ male; $F=$ female.

\section{Testing procedure}

The study involved 3 performance trials of the Wheelchair Circuit. To minimize a learning effect, a practice session was performed before the test trials. Eleven research assistants conducted the tests; 8 worked in the 8 participating rehabilitation centers ( 6 physical therapists, 1 occupational therapist, 1 qualified nurse), and 3 were students in human movement sciences. All 8 research assistants received extensive training in how to administer the tests.

Persons were tested in the rehabilitation centers in which they were inpatients. The practice session was supervised by the research assistant working in that center (internal research assistant). Two test trials were directed by the internal research assistant and the third by an external research assistant (Figure 3.1). The sequential order of the trials supervised by the internal or external research assistant was varied arbitrarily. 
Figure 3.1 Assessment of intra- and interrater reliability

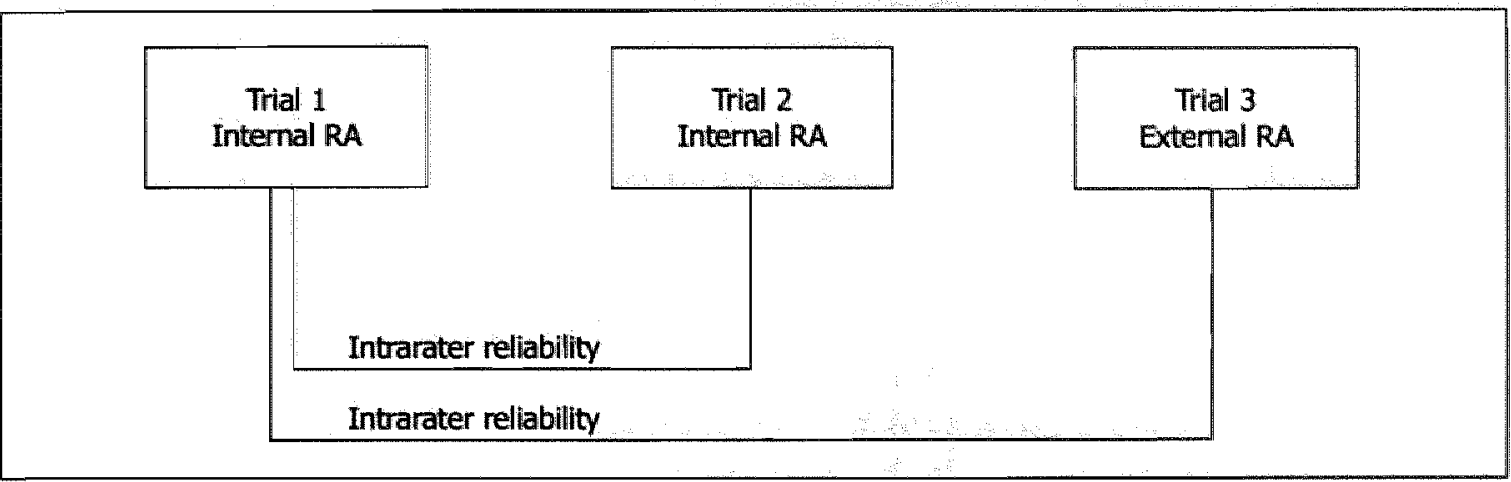

RA = research assistant

During all test trials, heart rate was monitored with a heart rate monitor (Polar Sport Tester Vantage NV, Polar Electro Inc., Finland). Performance time was measured with a stopwatch and task feasibility (the ability to perform the tasks as required - yes or no) was subjectively assessed by the research assistants.

Time between each trial was at least 1 day and not more than 3 days. The whole testing period per participant thus ranged from 8 to 13 days. Persons performed the test trials at the same time of the day. To avoid influencing the test results, participants were asked to refrain from smoking and drinking alcohol and coffee for at least 2 hours before each trial. They were also asked to void just before testing.

Not all participants performed all 3 test trials. Because of a scheduling problem, one participant did not perform the test trial conducted by an external research assistant. A second participant recelved another wheelchair after he had completed the first trial (conducted by the internal research assistant). That trial was not included in the statistical analyses. Because of pressure ulcers, a third participant was unable to perform the last 2 test trials, and in one participant, the heart rate monitoring devices failed during the third test trial with an external research assistant, because of transmitter displacement.

\section{The Wheelchair Circuit}

The Wheelchair Circuit consisted of 9 standardized tasks related to ADLs; they were all conditional to mobility in persons with an SCI. The tasks used in the circuit were adapted from the mobility-related tasks used by Dallmeijer et al. (14), Janssen et al. (15), and Harvey et al. (10). Because the tasks vary in difficulty, the circuit can be used to assess the mobility of persons with different competency levels.

The 9 tasks of the Wheelchair Circuit are described as follows.

Figure-of- 8 shape. Three markers were placed in a straight line, $1.5 \mathrm{~m}$ apart. Participants started at the first marker and drove the wheelchair in a figure-of- 8 shape around the 2 other markers. Time was recorded from the moment the persons began to drive until the front wheels of the wheelchair passed the first marker again. Maximum time allotted to perform this task was 1 minute. 
Crossing a doorstep. A wooden doorstep, $0.04 \mathrm{~m}$ high, $0.15 \mathrm{~m}$ wide, and $1.20 \mathrm{~m}$ long, was placed in a doonway. A marker $1 \mathrm{~m}$ in front of and $1 \mathrm{~m}$ behind the doorstep was placed on the floor. Persons started at the first marker and crossed the doorstep. Time was recorded from the moment persons started to drive until the front wheels passed the marker on the other side of the doorstep.

Participants were allowed to make several attempts within a maximum of 2 minutes. In doing so, the maximum run-up allowed was the $1 \mathrm{~m}$ indicated by the marker on the floor:

Mounting a platform. A wooden platform, $0.10 \mathrm{~m}$ high, $1.20 \mathrm{~m}$ wide, and $1.20 \mathrm{~m}$ long, was placed against a wall. Two meters before the platform, a marker was placed on the floor. Participants started at this marker and drove up onto the platform. Time was recorded from the moment the persons started to drive until all 4 wheels were on the platform. Participants were allowed to make several attempts within a maximum time of 2 minutes. In doing so, the maximum run-up allowed was the $2 \mathrm{~m}$, as indicated by the marker on the floor. This task was not considered to have been completed if a person did not succeed in crossing the doorstep.

$15 \mathrm{~m}$ Sprint. Two markers were placed on the floor, $15 \mathrm{~m}$ apart. Participants started at the first marker and drove as fast as possible to the second marker. Time was recorded from the moment persons started to drive until the front wheels passed the second marker. Maximum time to perform this task was 1 minute.

Walking. Two markers were placed on the floor, $15 \mathrm{~m}$ apart. Participants who were able to ambulate walked up and down between these markers for 2 minutes, from a standing start. They were permitted to use the walking aids they normally used when walking. Participants were asked to walk at their own personal and safe pace. If they were unable to walk for 2 minutes, the time recorded was that from the moment they started walking until they stopped. The distance covered was measured and rounded off to the nearest meter. At all times, the research assistant walked alongside the participant to help prevent a fall.

Note that walking is a task that does not seem to fit into the Wheelchair Circuit. It is, however, an important aspect of mobility for people with incomplete lesions who are able to walk. We decided, therefore, to include this task in the Wheelchair Circuit.

3\% slope. This task was performed while driving on a treadmill (Treadmill Giant, Bonte BV, Zwolle, the Netherlands). The treadmill started with the speed set at $0.56 \mathrm{~m} / \mathrm{s}$. After 10 seconds, the slope was raised to $3 \%$ (which took $12 \mathrm{~s}$ ) and after this inclination was reached, the persons had to keep driving for 10 seconds before the inclination was returned to $0 \%$ (which also took $12 \mathrm{~s}$ ). The test stopped when the treadmill reached the horizontal position again. Performance time of this test was constant.

$6 \%$ slope. This task was the same as the $3 \%$ slope, except that the slope was increased to $6 \%$. Increasing the slope to $6 \%$ took 23 seconds, as did decreasing the slope back to $0 \%$. This task was not attempted if the person did not succeed in performing the $3 \%$ slope task. Performance time of this test was constant.

Wheelchair driving. The persons drove for 5 minutes on a treadmill, at a speed of $0.83 \mathrm{~m} / \mathrm{s}$.

Transfer. A line was placed on the floor $1 \mathrm{~m}$ from a treatment table and parallel to it. Participants were asked to transfer from the wheelchair to the table, beginning from the line. First they had to drive up to the table and put the wheelchair in position to make a transfer. Then, they transferred from the wheelchair to the table, with their legs hanging over the edge and finally they lifted them onto the table while remaining seated. The table was set at the same height as the top of the seat cushion in the wheelchair. This task was not attempted if a person had a score lower than 3 on the 
FIM item transfer bed/chair/wheelchair (8). The research assistants could not lift any part of the participant's body to help them to perform the task. The participants were allowed to use the assistive device(s) they normally used in performing a transfer. Time was recorded from the moment persons started to move until they were sitting with their legs on the bed. Maximum time to perform this task was 5 minutes.

All tasks were performed in the sequence described earlier on a hard and smooth floor surface. The participants performed the tasks in their own wheelchairs. During each task, task feasibility, performance time, and peak heart rate were recorded. Immediately after each task, persons sat quietly in their wheelchairs for 2 minutes as their heart rates returned to resting levels.

The 9 tasks described previously relate mainly to 3 different aspects of mobility: tempo, technical skills, and physical capacity. The figure-of- 8 shape and the sprint mainly focus on tempo. Crossing a doorstep, mounting a platform, and making a transfer are tasks that require the highest level of technical skills; the tasks of wheelchair driving, ascending slopes, and walking mostly reflect a person's physical capacity. This segmentation between the tasks is, of course, not as strict as stated earlier. Walking, for instance, also reflects technique and tempo. Ascending a slope requires technique. It is, however, clear that the different tasks of the Wheelchair Circuit represent the different aspects of wheelchair mobility.

\section{Statistical analysis}

Intrarater reliability was assessed by using trials 1 and 2 , both of which were conducted by the internall research assistant. For the assessment of the Interrater rellability, trial 1 and trial 3 (with external research assistant) were used (Figure 3.1). The Intraclass correlation coefficient (ICC) was used as a measure of reliability. For both the inter-and intrarater rellability, a 1=way random effects model was applied (22). A priori an ICC of 0.80 or higher was defined as an indication of good reliability.

To calculate the intra- and interrater reliability of the feasibility of the different tasks, we used the sum of the number of tasks that each person was able to perform.

\section{Results}

Because of various task difficulties, not all persons were able to perform all 9 tasks of the Wheelchair Circuit. This, in combination with the missing trials reported in the Methods section, resulted in a variation of the number of participants for whom heart rate and/or performance times were available. Table 3.2 and 3.3 display, respectively, performance times and peak heart rates recorded during the performance on the different tasks. The walking, 3\% and $6 \%$ slope, and wheelchair driving tasks had a fixed duration, and are therefore not shown in table 3.2. Figure 3.1 shows that trial 1 was used for the assessment of both inter- and intrarater reliability. For the intrarater reliability, only participants who had a complete data set for trials 1 and 2 were included, whereas the assessment of the interrater reliability required a complete data set for trials 1 and 3 . As a result, the group composition of participants in trial 1 differs slightly for the intra- and the interrater reliability. 
Table 3.2 Performance times of the tasks of the Wheelchair Circuit for the 3 test trials

\begin{tabular}{|l|l|l|l|l|l|l|}
\hline & \multicolumn{4}{l}{ Intratrater } & \multicolumn{2}{l|}{ Interrater } \\
\hline Task & $\mathbf{n}$ & Trial 1 & Trial 2 & $\mathbf{n}$ & Trial 1 & Trial 3 \\
\hline Figure-of-8 shape & 25 & $16.3 \pm 8.6$ & $15.6 \pm 8.1$ & 25 & $16.1 \pm 8.7$ & $16.3 \pm 9.6$ \\
\hline Crossing doorstep & 16 & $4.7 \pm 4.1$ & $4.8 \pm 3.6$ & 17 & $5.2 \pm 4.7$ & $6.4 \pm 7.5$ \\
\hline Mounting platform & 8 & $7.1 \pm 4.8$ & $6.6 \pm 9.5$ & 8 & $11.6 \pm 12.4$ & $12.3 \pm 14.1$ \\
\hline 15m Sprint & 25 & $11.7 \pm 5.5$ & $11.5 \pm 6.0$ & 25 & $11.6 \pm 5.6$ & $11.4 \pm 6.0$ \\
\hline Transfer & 19 & $47.4 \pm 49.8$ & $42.2 \pm 38.3$ & 18 & $35.9 \pm 34.7$ & $42.4 \pm 45.7$ \\
\hline
\end{tabular}

Values are mean $\pm \mathrm{sd}$

Table 3.3 Peak heart rates during the tasks of the Wheelchair Circuilt for the 3 test trials

\begin{tabular}{|l|l|l|l|l|l|l|}
\hline & \multicolumn{4}{l}{ Intrarater } & \multicolumn{2}{l|}{ Interrater } \\
\hline Task & $\mathbf{n}$ & Trial 1 & Trial 2 & $\mathbf{N}$ & Trial 1 & Trial 3 \\
\hline Figure-of-8 shape & 24 & $107.4 \pm 17.6$ & $103.8 \pm 17.2$ & 23 & $110.2 \pm 16.2$ & $107.1 \pm 15.7$ \\
\hline Crossing doorstep & 16 & $100.5 \pm 20.2$ & $95.9 \pm 18.7$ & 16 & $104.9 \pm 16.9$ & $106.1 \pm 16.8$ \\
\hline Mounting platform & 8 & $114.3 \pm 19.2$ & $106.3 \pm 18.8$ & 8 & $113.8 \pm 18.7$ & $107.9 \pm 27.1$ \\
\hline 15m Sprint & 25 & $107.5 \pm 18.3$ & $107.2 \pm 15.8$ & 24 & $109.8 \pm 16.9$ & $109.2 \pm 16.6$ \\
\hline Walking & $\mathbf{8}$ & $130.4 \pm 22.0$ & $131.5 \pm 23.9$ & 8 & $130.4 \pm 22.0$ & $132.4 \pm 22.9$ \\
\hline 3\% slope & 20 & $99.4 \pm 16.4$ & $94.7 \pm 15.6$ & 19 & $102.1 \pm 14.8$ & $99.1 \pm 13.0$ \\
\hline 6\% slope & 15 & $108.3 \pm 17.2$ & $103.9 \pm 17.6$ & 14 & $111.7 \pm 15.1$ & $111.79 \pm 15.6$ \\
\hline Wheelchair driving & 21 & $103.1 \pm 17.3$ & $99.7 \pm 16.5$ & 21 & $105.1 \pm 14.5$ & $105.9 \pm 13.3$ \\
\hline Transfer & 18 & $112.7 \pm 16.4$ & $106.1 \pm 13.4$ & 17 & $115.7 \pm 17.0$ & $114.7 \pm 17.7$ \\
\hline
\end{tabular}

Values are mean \pm sd

\section{Task feasibility}

The results of trial 1 were used to describe task feasibility. The number of tasks that each participant was able to perform varied from $3(n=2)$ to $9(n=3)$. The remaining persons completed $8(n=7), 7$ $(n=4), 6(n=4), 5(n=4)$, or $4(n=3)$ tasks.

Figure 3.2 shows the number of participants who were able to perform the different tasks. All 27 persons were able to perform the figure-of- 8 shape and sprint tasks, whereas only 8 participants were able to walk for 2 minutes.

Note that the number of participants shown in figure 3.2 does not always correspond to the available data in tables 3.2 through 3.4 because of missing data attributable to measurement failure. 
Figure 3.2 Number of persons who were able to perform the different tasks (trial 1).

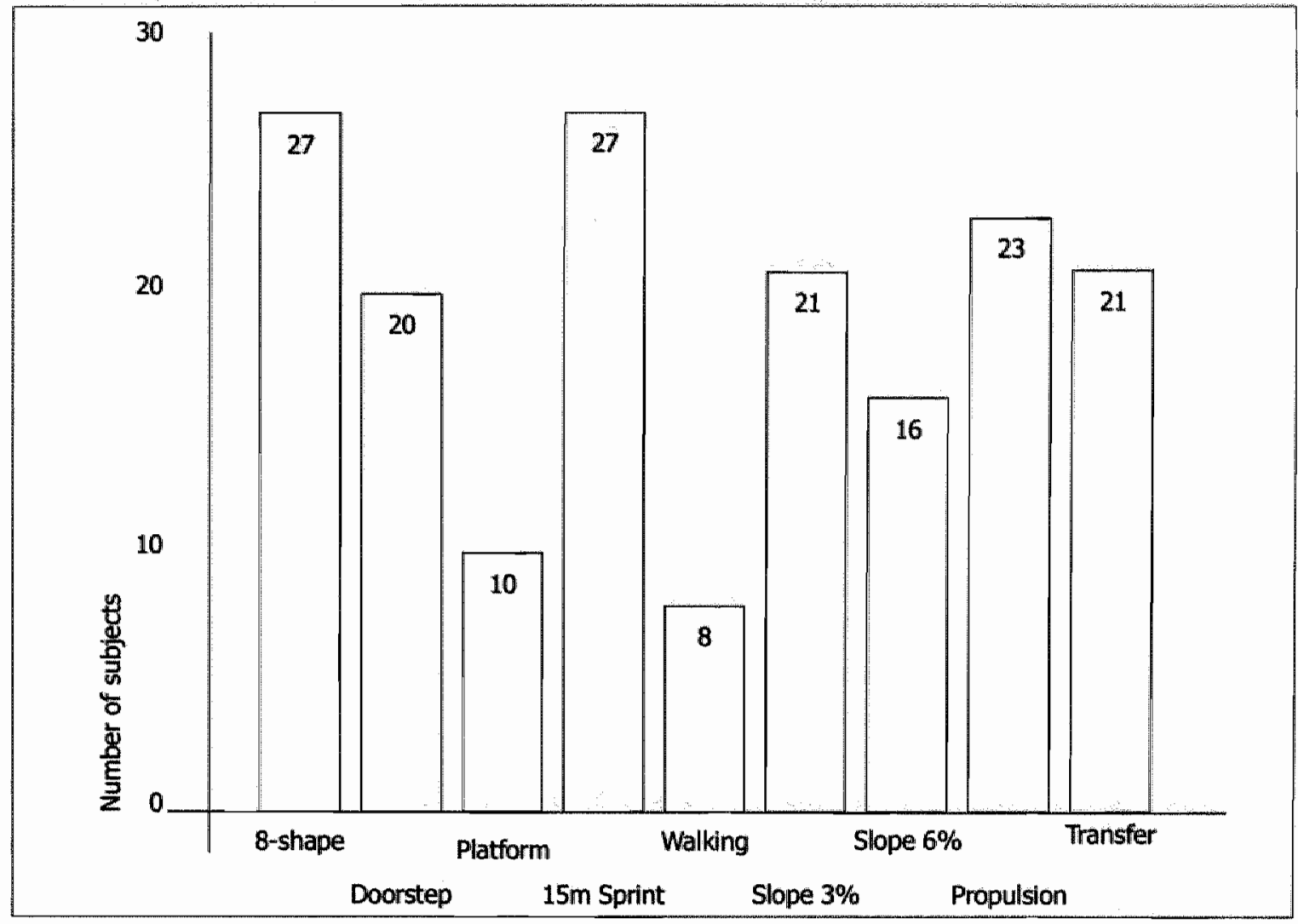

\section{Inter- and intrarater reliability}

The ICC of the intrarater reliability of the sum of tasks that each participant was able to perform was $0.98(n=25 ; 95 \%$ confidence interval $[C 1], 0.96-0.99)$. The interrater reliability showed an ICC of $0.97(n=25 ; 95 \%$ CI, $0.94-0.99)$.

The inter- and intrarater reliability results of task performance time are shown in table 3.4.

Table 3.4 Intra- and interrater reliability of the time needed to perform the tasks of the Wheelchair Circuit

\begin{tabular}{|l|l|l|l|l|l|l|}
\hline & \multicolumn{3}{|l|}{ Intrarater } & \multicolumn{2}{l|}{ Interrater } \\
\hline Task & $\mathbf{n}$ & $\mathbf{I C C}$ & $\mathbf{9 5 \%} \mathbf{C I}$ & $\mathbf{n}$ & $\mathbf{I C C}$ & $\mathbf{9 5 \%} \mathbf{C I}$ \\
\hline 8-shape & 25 & 0.97 & $0.94-0.99$ & 25 & 0.97 & $0.93-0.99$ \\
\hline Crossing doorstep & 16 & 0.71 & $0.19-0.90$ & 17 & 0.76 & $0.36-0.91$ \\
\hline Mounting platform & 8 & 0.78 & $0.00-0.96$ & 8 & 0.96 & $0.82-0.99$ \\
\hline 15m Sprint & 25 & 0.99 & $0.97-0.99$ & 25 & 0.98 & $0.96-0.99$ \\
\hline Transfer & 19 & 0.94 & $0.84-0.98$ & 18 & 0.95 & $0.87-0.98$ \\
\hline
\end{tabular}

ICC = intraclass correlation coefficient; $95 \% \mathrm{CI}=95 \%$ confidence interval 
Because of the fixed duration of the walking, the $3 \%$ and $6 \%$ slope, and the 5-minute wheelchairdriving tasks, they are not presented here. For the figure-of-8 shape, sprint, and transfer both interand intrarater reliability were high, with ICCs ranging from 0.94 to 0.99 . The interrater reliability of mounting the platform was good, with an ICC of 0.96 whereas the intrarater reliability was slightly below threshold, with an ICC of 0.78 . Both inter- and intrarater reliability for crossing the doorstep were below the desired value of 0.80 (ICC $=0.76,0.71$ respectively).

Table 3.5 shows the inter- and intrarater reliability results of the recorded peak heart rate during the different tasks. Intrarater reliability was good for the figure-of- 8 shape, crossing doorstep, mounting platform, sprint, walking, slope $6 \%$, and wheelchair driving (ICC range, $0.83-0.96$ ). The $3 \%$ slope and transfer showed lower ICCs (ICC $=0.69,0.68$ respectively). All tasks showed high interrater reliability with ICCs ranging from 0.82 to 0.99 .

Table 3.5 Intra- and interrater reliability of the maximum heart rates recorded during the tasks of the Wheelchair Circuit

\begin{tabular}{|l|l|l|l|l|l|l|}
\hline & \multicolumn{4}{l}{ Intrarater } & \multicolumn{2}{l|}{ Interrater } \\
\hline Task & $\mathbf{n}$ & ICC & $\mathbf{9 5} \% \mathbf{C I}$ & $\mathbf{n}$ & $\mathbf{I C C}$ & $\mathbf{9 5 \%}$ CI \\
\hline Figure-of-8 shape & 24 & 0.85 & $0.67-0.94$ & 23 & 0.87 & $0.69-0.94$ \\
\hline Crossing doorstep & 16 & 0.90 & $0.74-0.97$ & 16 & 0.93 & $0.81-0.98$ \\
\hline Mounting platform & $\mathbf{8}$ & 0.84 & $0.27-0.97$ & 8 & 0.83 & $0.22-0.97$ \\
\hline $\mathbf{1 5 m}$ Sprint & 25 & 0.83 & $0.61-0.92$ & 24 & 0.82 & $0.58-0.92$ \\
\hline Walking & 8 & 0.96 & $0.84-0.99$ & 8 & 0.99 & $0.93-1.00$ \\
\hline Slope 3\% & 20 & 0.69 & $0.24-0.88$ & 19 & 0.82 & $0.54-0.93$ \\
\hline Slope 6\% & 15 & 0.85 & $0.57-0.95$ & 14 & 0.91 & $0.72-0.97$ \\
\hline Wheelchair driving & 21 & 0.84 & $0.62-0.94$ & 21 & 0.88 & $0.71-0.95$ \\
\hline Transfer & 18 & 0.68 & $0.16-0.88$ & 17 & 0.97 & $0.92-0.99$ \\
\hline
\end{tabular}

ICC $=$ Intraclass correlation coefficlent; $95 \% \mathrm{CI}=95 \%$ confidence interval

\section{Discussion}

This study examined the inter- and intrarater reliability of the Wheelchair Circuit designed to assess the mobility of persons with SCI. This study included only persons in their last stage of clinical rehabilitation. This was done to avoid learning and training effects during the testing period, which might have negatively influenced reliability. There was no indication that the reliability results were not representative for persons with SCI in earlier phases of clinical rehabilitation or who were living at home after rehabilitation.

Results showed that not all participants could perform all tasks; therefore, some ICC values were based on a small number of persons. This must be considered when interpreting the reported ICC values. 


\section{Feasibility}

To enhance test sensitivity, the tasks each had different difficulty levels. The fact that the number of feasible tasks varied between participants confirms that the tasks were not equally difficult to perform. Mounting a platform and walking were the most difficult tasks to perform. The easiest tasks where the figure-of- 8 shape and the sprint, which all participants performed. Most persons $(n=22)$ were able to complete 5 or more tasks, indicating that the difficulty level was not set too high. The fact that the ability to perform tasks varied between persons suggests that the Wheelchair Circuit has a discrimination validity.

\section{Inter- and intrarater reliability}

Overall, the inter- and intrarater reliability of the Wheelchair Circuit was satisfactory. The doorstepcrossing task showed an inter- and intrarater reliability of the performance time just below threshold. The intrarater reliability of the performance time of mounting a platform also was just below threshold. The reason for these lower ICC values may be that performance time on these tasks is more dependent on coincidence. Any failed attempt (e.g. because of a miss hit of the hand rims) costs many seconds and may thus result in large differences between trials. Because of this, performance time is not an adequate outcome measure in these 2 tasks and will not be considered in future tests.

Our results show that peak heart rates can be reliably measured during the performance of the different tasks of the Wheelchair Circuit. This was also found by Janssen et al. (23), Nijhoff et al. (17), and Bhambhani et al. (24), who stated that heart rate responses can be reliably recorded in persons with $\mathrm{SCI}$, even in non-steady-state conditions. The intrarater reliability of the heart rates was high in all tasks, except the 3\% slope and the transfer. These 2 tasks showed ICCs below the cutoff point of 0.80 , a fact that we cannot explain.

To assess whether the circuit is sensitive to changes in mobility, further longitudinal research is needed in which persons take the test at different times during clinical rehabilitation. Studies to date look promising because Janssen et al. $(15,25)$, have shown that there is a relation between physical strain during standardised $\mathrm{ADL}$ tasks and physical capacity in men many years after SCI.

The Wheelchair Circuit was primarily designed to be used in a longltudinal study design to assess changes in mobility during and after rehabilitation. In cross-sectional study designs, it can be useful to chart the mobility of wheelchair-dependent persons with SCI. At this point, the different tasks of the Wheelchair Circuit are scored and reviewed separately, resulting in 3 different scores per task. In the current validation of the circuit, the aim is to design a scoring system that reflects a person's wheelchair mobility in a comprehensible way. Depending on the data, this may result in 1 score per task that combines task feasibility, performance time and physical strain during task performance, or it may result in 1 total score for the test as a whole. 


\section{Conclusion}

The overall reliability of the Wheelchair Circuit was good. Performance time of the crossing doorstep and mounting platform tasks were not reliable and therefore cannot be considered determinants of mobility. The Wheelchair Circuit seems to be an adequate instrument with which to assess mobility in persons with $\mathrm{SCl}_{i}$, however more research is needed to assess its responsiveness and validity. 


\section{References}

1. Post MWM, Asbeck van FW, Dijk van AJ, Schrijvers AJ. Services for spinal cord injured: Availability and satisfaction. Spinal Cord 1997;35(2):109-15.

2. Woude van der LHV, Hendrich KMM, Veeger HEJ, Ingen Schenau van GJ, Rozendal RH, Groot de $G$, et al. Manual wheelchair propulsion: Effects of power output on physiology and technique. Med Sci Sports Exerc 1988;20:70-8,

3. Janssen TWJ, Oers van CAJM, Woude van der LHV, Hollander AP. Physical strain in daily life of wheelchair users with spinal cord injuries. Medicine and Science in Sports and Exercise 1994:661-70.

4. Noreau L, Shephard RJ. Spinal cord injury, exercise and quality of life. Sports Med 1995;20(4):226-50.

5. Bussmann JBJ, Stam HJ. Techniques for measurement and assessment of mobility in rehabilitation: A theoretical approach. clinical rehabilitation 1998;12:455-64.

6. Graves DE, Frankiewicz RG, Carter RE. Gain in functional ability during medical rehabilitation as related to rehabilitation process indices and neurologic measures. Arch Phys Med Rehabil 1999;80:1464-70.

7. Noreau L. Relationship of impairment and functional ability to habitual activity and fitness following spinal cord injury. Int J Rehabil Res 1993;16(4):265-75.

8. Hall KM, Cohen ME, Wright J, Call M, Werner P. Characteristics of the Functional Independence Measure in traumatic spinal cord injury. Arch Phys Med Rehabil 1999;80:14716.

9. Bollin I, Bodin P, Kreuter M. Sitting position - posture and performance in C5 - C6 tetraplegla. Spinal Cord 2000;38(7):425-34.

10. Harvey LA, Batty J, Fahey A. Reliability of a tool for assessing mobility in wheelchairdependent paraplegics. Spinal Cord 1998;36(6):427-31.

11. Ota $T$, Akaboshi $K$, Nagata $M$, Sonoda $S$, Domen $K$, Seki $M$, et al. Functional assesment of patients with spinal cord injury: Measured by the motor score and the functional independence measure. Spinal Cord 1996;34(9):531-5.

12. Taricco M, Apolone G, Colombo $C$, Filardo G, Telaro E, Liberati A. Functional status in patients with spinal cord injury: A new standardized measurement scale. Gruppo Interdisciplinare Valutazione Interventi Riabilitativi. Arch Phys Med Rehabil 2000;81(9):1173-80.

13. Catz A, Itzkovich M, Agranov E, Ring H, Tamir A. SCIM - spinal cord independence measure: A new disability scale for patients with spinal cord lesions. Spinal Cord 1997;35:850-6.

14. Dallmeijer AJ, Woude van der LHV, Hollander AP, As van HH. Physical performance during rehabilitation in persons with spinal cord injuries. Med Sci Sports Exerc 1999;31(9):1330-5.

15. Janssen TWJ, Oers van CAJM, Veeger HE, Hollander AP, Woude van der LHV, Rozendal RH. Relationship between physical strain during standardised ADL tasks and physical capacity in men with spinal cord injuries. Paraplegia 1994;32(12):844-59.

16. Michels $\mathrm{KJ}$, Meijs PJM, Pons $\mathrm{C}$. Bepaling van rolstoelgebonden functionaliteit tijdens het revalidatieproces. Nederlands Tijdschrift voor Geneeskunde. 1993;137(20):1029-30.

17. Nijhoff TA, Hollander AP, Dallmeijer AJ, Hofman JW. The relation between heart rate and oxygen uptake during non-steady state arm exercise. In: Woude van der LHV, Hopman MTE, 


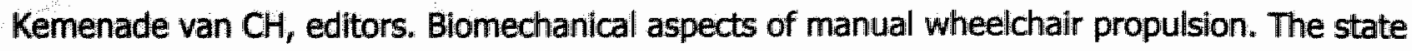
of the art II. Amsterdam: IOS Press; 1999. p. 16-25.

18. Mattison PG, Hunter J, Spence S. Development of a realistic method to assess wheelchair propulsion by disabled people. Int J Rehabil Res 1989;12(2):137-45.

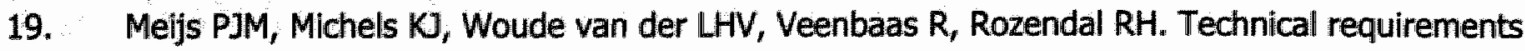
of wheelchair exercise testing in rehabilitation field research. In: Woude van der LHV, Meijs PJM, Grinten van der BA, Boer de YA, editors. Ergonomics of manual wheelchair propulsion. Amsterdam: IOS Press; 1993. p. 61 - 70.

20. Cardus D, McTaggart WG, Ribas-Cardus F, Donovan WH. Energy requirements of gamefield exercises designed for wheelchair-bound persons. Arch Phys Med Rehabil 1989;70(2):124-7.

21. Rankin G, Stokes M. Reliability of assessment tools in rehabilitation: An illustration of appropriate statistical analyses. Clinical Rehabilitation 1998;12:187-99.

22. Nichols DP. Choosing an intraclass correlation coefficient. SPSS Keywords 1998;67. Availlable at: http://www.spss.com/tech/stat/articles/whichicc.txt. Accessed May 13, 2002.

23. Janssen TWJ, Oers van CAJM, Woude van der LHV, Hollander AP. Reliability of heart rate responses to non-steady-state activities of daily living in men with spinal cord injuries. Scand ] Rehabil Med 1994;26(2):71-8.

24. Bhambhani YN, Eriksson P, Steadward RD. Reliability of peak physiological responses during wheelchair ergometry in persons with spinal cord injury. Arch Phys Med Rehabil 1991;72:55962.

25. Janssen TWJ, Oers van CAIM, Rozendaal EP, Willemsen EM, Hollander AP, Woude van der LHV. Changes in physical strain and physical capacity in men with spinal cord injuries. Med Sci Sports Exerc 1996;28(5):551-9. 
The Wheelchair Circuit:

Construct validity and responsiveness of a test to assess manual wheelchair mobility in persons with a spinal cord injury

Olga Kilkens, Annet Dallmeijer, Luc de Witte, Luc van der Woude and, Marcel Post Archives of Physical Medicine and Rehabilitation 2004; 85 (3): 424-31 


\section{Summary}

Objective: To assess the validity and responsiveness of the Wheelchair Circuit, a test to assess manual wheelchair mobility in persons with spinal cord injury (SCI).

Design: Longitudinal. Participants performed the Wheelchair Circuit at the start (T1) and at the end (T3) of inpatient functional rehabilitation. Construct validity and responsiveness were assessed.

\section{Setting: Eight rehabilitation centers in the Netherlands.}

Patients: Seventy-four participants with SCI admitted for inpatient rehabilitation.

Main Outcome Measures: The Wheelchair Circuit consists of 8 wheelchair skills, and results in 3 test scores: ability, performance time and physical strain. The construct validity of the Wheelchair Circuit was assessed by testing whether the test scores were significantly related to the participants' functional status, physical capacity, lesion level, motor completeness of the lesion, and age. To prove the test's responsiveness it was assessed whether the test scores had significantly improved between T1 and T3.

Results: For construct validity, 4 of the 5 hypotheses were confirmed. For test responsiveness, all 3 test scores had significantly improved during rehabilitation, and the standlardized response mean values ranged from 0.6 to 0.9 .

Conclusions: The Wheelchair Circuit is a valid and responsive instrument with which to measure manual wheelchair mobility in persons with SCI. 


\section{Introduction}

An important aspect of daily life in the majority of persons with spinal cord injury (SCI) is their dependence on a wheelchair. In the Netherlands approximately $82 \%$ of persons with SCI who were admitted for inpatient rehabilitation are wheelchair users, and $60 \%$ are completely wheelchair dependent (1). For these persons wheelchair use is conditional to achieve independent mobility. To function independently, manual wheelchair users must possess a variety of wheelchali skills, enabling them to deal with the physical barriers they will inevitably encounter in various environments (2). Mastering wheelchair skills can make the difference between dependence and independence in daily life $(3,4)$. Training of these skills is therefore a vital part of the rehabilitation process. Within the scope of a longitudinal multicenter cohort study, a test to assess manual wheelchair mobility was developed: the Wheelchair Circuit. The interrater and intrarater reliability of the Wheelchair Circuit is good (5). The aim of the present study was to assess the construct validity and responsiveness of the Wheelchair Circuit. Construct validity is the degree to which the scores of the Wheelchair Circuit are related to variables that are hypothesized or known to be related to manual wheelchair mobility (6). From the literature we know that physical capacity, functional status, lesion level, motor completeness of the lesion and age are directly related to the performance of wheelchair skills in persons with SCI (7-19). We hypothesized that, when the construct validity of the Wheelchair Clrcuit is good, these determinants will be significantly associated with the test scores. Responsiveness, which is an aspect of validity (20), indicates the ability of a measurement tool to detect functional change over time (6, 21). The responsiveness of the Wheelchair Circuit was assessed by comparing the scores achieved by persons with $\mathrm{SCI}$ at the beginning of their inpatient rehabilitation period with the scores these persons attained at the end of their inpatient rehabilitation period. We hypothesized that a person's wheelchair skills would significantly improve during his/her rehabilitation period.

The aim of our study was to test the following 6 hypotheses:

1) The functional status of persons with SCI - assessed by the FIM ${ }^{\mathrm{TM}}$ Instrument mobility score and peak power output during a maximum wheelchair exercise test - is significantly related to the scores of the Wheelchair Circuit; 2) the physical capacity (expressed as peak oxygen consumption) of persons with SCI is significantly related to their scores in the Wheelchair Circuit; 3) persons with paraplegia perform better on the Wheelchair Circuit than persons with tetraplegia; 4) persons with motor incomplete lesions perform better on the Wheelchair Circuit than persons with motor complete lesions; 5) age is inversely associated with the scores of the Wheelchair Circuit; and 6) scores of the Wheelchair Circuit improve significantly between T1 and T3.

\section{Methods}

\section{Participants}

Our study was part of the Dutch research program 'Physical Strain, Work Capacity, and Mechanisms of Restoration of Mobility in the Rehabilitation of Persons with Spinal Cord Injuries' (22). In this program individuals with an acute SCI are being followed during clinical rehabilitation. Participants are eligïble to enter the program if they have an acute $\mathrm{SCI}$, are between 18 and 65 years; are categorized as $\mathrm{A}$, $B, C$ or D on the American Spinal Injury Association impairment scale (ASIA)(23); are wheelchair 
dependent; do not have a progressive disease or psychiatric problem; and have enough knowledge of the Dutch language to understand the goal of the study and the testing methods.

Participants were not allowed to perform physically strenuous tests (i.e. the Wheelchair Circuit and the maximum wheelchair exercise test) if they had 1) cardiovascular disorders (the absolute contraindications as they are stated by the ACSM 2000 guidelines (24), or a resting diastolic blood pressure $>90 \mathrm{~mm} \mathrm{Hg}$ or a resting systollc blood pressure $>180 \mathrm{~mm} \mathrm{Hg}$ ), and/or 2) severe musculoskeletal complaints of the upper extremities, neck or back. After inclusion in the cohort, participants were examined by their rehabilitation physician to check for any of these contraindications.

Eight Dutch rehabilitation centers specializing in the rehabilitation of persons with SCI participate in this research program. Eight trained research assistants conduct the measurements, according to a standardized protocol. Participants are assessed at 3 moments during inpatient rehabilitation: at the start of functional rehabilitation, defined as the moment that participants are just able to sit in their wheelchair for (at least) 3 consecutive hours (T1); three months later (T2); and at the time of discharge from inpatient rehabilitation (T3).

For the study described in this paper, only the results of T1 and T3 were used. This study was based on 74 participants who participated in both measurements. Mean time between T1 and T3 was $177 \pm$ 87 days (range 15-454 days). Participants' mean age at T1 was $40.5 \pm 14.5$ years (range $18-65$ years), and 51 participants (69\%) were men. There were 53 participants with paraplegia, including 18 persons with a motor incomplete lesion, and 21 persons with tetraplegia, including 9 persons with a motor incomplete lesion.

\section{Procedure}

The measurements for our study assessed the main lesion characteristics, the participants' physical capacity and the participants' functional abilities. Tests were performed on 2 different days (at the same time of the day, no more than Iwk apart). To avoid influencing test results, participants were asked to consume only a light meal; to refrain from smoking, drinking coffee and drinking alcohol at least 2 hours before each measurement; and to void their bladder directly before testing. All participants completed a consent form after they had been given information about the test procedures. All tests and protocols were approved by the Medical Ethics Committee of the Institute for Rehabilitation Research, Hoensbroek, the Netherlands.

\section{Measurements}

On the first test day, the participants' lesion characteristics were assessed and the participants performed the Wheelchair Circuit. On day 2 the FIM was assessed and participants performed the maximum wheelchair exercise test (including a wheelchair drag test). 


\section{Lesion characteristics}

Lesion characteristics were assessed by a physician according to the International Standards for Neurological Classification of Spinal Cord Injury (25): the AIS classifications A and B were defined as motor complete and classes $C$ and $D$ as motor incomplete. Neurologic lesion levels at or caudal to the $\mathrm{T} 1$ vertebra were defined as paraplegia, and lesions cranial to the $T 1$ vertebra were defined as tetraplegia.

\section{The Wheelchair Circuit}

The Wheelchair Circuit (5) consists of 8 different standardized items that are conditional to achieve independent wheelchair mobility. The items used in the circuit were adapted from the mobility-related tasks used by Dallmeijer et al. (8), Janssen et al. (12), and Harvey et al. (26). Items of varying difficulties were selected to make the circuit suitable to assess the wheelchair sklls of persons with different competence levels. The appendix provides a detailed description of instructions and scoring for each test item. The items were performed in a fixed sequence, on a hard and smooth floor surface or on a motor-driven treadmill, all using a standard test wheelchair. During the performance of the circuit, the ability to perform the test items, the performance time of the figure-of- 8 shape and the $15 \mathrm{~m}$ sprint, and the peak heart rates reached during the $3 \%$ and $6 \%$ slope items on the treadmill were recorded.

The main score of the Wheelchair Circuit is the ability score. All items that can be performed adequately and independently are assigned 1 point. There are 3 items that can also be scored as partially able (crossing a doorstep, mounting platform, transfer) and can then be assigned half a point. All points are summed to give an overall ability score. The ability score ranges from 0 to 8 , is easy to calculate and provides information about the ability of participants to perform the varlous test items.

Besides the ability score 2 other scores express participants' performance on the Wheelchair Circuit: 1) the performance time score and 2) the physical strain score. The performance time score is the sum of the performance times of the figure-of- 8 shape and the $15 \mathrm{~m}$ sprint. Participants were instructed to perform these 2 tasks at their maximum speed. The physical strain score provides information on the physical strain induced by the performance of the $3 \%$ and $6 \%$ slope items. These items are performed on the treadmill with the same belt velocity for all persons $(0.56 \mathrm{~m} / \mathrm{s})$ and have a fixed performance time. The physical strain score can be expressed in 2 ways. First, it is expressed as the mean of the peak heart rates (in beats $/ \mathrm{min}$ ) reached during each of the 2 slope items. This scale can be used when persons' performances are compared longitudinally. In our study the mean heart rate was used to assess the responsiveness of the physical strain score. Second, it is expressed as the mean of the peak heart rates reached during each of the 2 slope items, which is expressed as percentage heart rate reserve (\%HRR). The HRR is the difference between the maximum heart rate (Hrpeak)(in beats/min) and the heart rate at rest (HRrest)(in beats/min) (27). The \%HRR is calculated according to the formula

$$
\% \text { HRR }=(\text { HRslopes }- \text { HRrest }) /(\text { HRpeak-HRrest }) \times 100 \%
$$


HRpeak was assessed during a maximum wheelchair exercise test (described below), and HRrest was measured after 5 minutes of rest, with the participants sitting quietly in the wheelchair.

The heart rate response expressed relative to the HRR is used when comparisons between participants are performed. The \%HRR provides a relative measure to estimate physical strain because a correction is made for inter-individual differences in HRpeak and HRrest $(12,28)$. In our expanded study the \%HRR will be used when relationships between the physical strain score and other variables are studied.

The $\mathbf{2}$ additional scores of the Wheelchair Circuit can be used to further differentiate wheelchair skill performance or to detect changes in test performance in those persons who have attained the maximum ability score.

\section{Functional Independence Measure}

On the second day, participants' functional status was measured using the FIM (Dutch version 5.0) (29). For our study only 4 items of mobility and locomotion were taken into account (transfer bed, chair, wheelchair; transfer toilet; transfer tub and shower; walk and/or wheelchair). Each item in the FIM has a range of 1 (complete dependence) to 7 (complete independence). The scores of the 4 FIM items were summed to retrieve a score that we called the FIM mobility score. FIM ratings were based on the observations of research assistants trained in the use of the FIM.

\section{Wheelchair drag test}

Prior to the maximum wheelchair exercise test, the wheelchair drag force for the wheelchair user combination on the treadmill was recorded in a drag test (30). These force measurements were used to calculate the power output for each angle of inclination on the treadmill, according to Fdrag (i.e. dragforce in Newtons) multiplied by belt velocity (in $\mathrm{m} / \mathrm{s}$ ). During this measurement, the person sat passively in a wheelchair that was attached by a rope to a force transducer fixed to the frame of the treadmill. The velocity of the belt was set equal to the velocity at which the maximum exercise test would be performed, and subsequently the slope was raised from $0^{\circ}$ to $3.6^{\circ}$ in 10 steps of $0.36^{\circ}$. The results were stored on a computer.

\section{Maximum exercise test}

After a 5-minute rest and a subsequent 2-minute warm up, two 3-minute submaximal exercise periods were performed, separated by 2 -minute rest intervals. The first 3-minute period was performed with the belt in horizontal position, the second with a slope of $0.36^{\circ}$. After the submaximal exercise periods and a 2-minute rest, the workload was increased every minute by increasing the slope of the belt with $0.36^{\circ}$. During the entire test the velocity of the belt was held constant at $0.56,0.83$ or $1.11 \mathrm{~m} / \mathrm{s}$, depending on the person's ability. The test was terminated when the person could no longer maintain his/her position on the belt. Throughout the test, oxygen consumption $\left(\mathrm{VO}_{2} ; \mathrm{in} \mathrm{l} / \mathrm{min}\right)$ was recorded continuously, and heart rate (in beats/min) was measured at a 5 second storage interval. The highest 
mean value over 30 seconds of $\mathrm{VO}_{2}$ measured during the entire test was defined as $\mathrm{VO}_{2}$ peak. The HRpeak measure was the highest heart rate recorded during the test. Peak power output (in watts), derived from the dragtest, was defined as the power output that corresponded to the highest slope level that had been maintained for at least 30 seconds during the maximum exercise test.

\section{Testing equipment}

The Wheelchair Circuit and the maximum exercise test were performed in a test hand-rim rigid-frame wheelchair, which was available in 2 seat widths, $0.42 \mathrm{~m}$ and $0.46 \mathrm{~m}$, and was equipped with solid tires (Sopur Starlight 622, Sunrise Medical GmbH, Malsch/Heidelberg, Germany). Three items of the Wheelchair Circuit ( $3 \%$ and $6 \%$ slope and wheelchair propulsion) and the maximum exercise test were performed on a treadmill (Treadmill Giant (width, $1.20 \mathrm{~m}$; length, $2.60 \mathrm{~m}$ ), Bonte BV, Zwolle, the Netherlands). The slope of the belt is adjustable from $0^{\circ}$ to $9^{\circ}$, in 25 steps of $0.36^{\circ}$. Maximum velocity of the belt was $5 \mathrm{~m} / \mathrm{s}$, adjustable in 180 steps of $0.028 \mathrm{~m} / \mathrm{s}$. To measure the drag force, the treadmill was modified with a force transducer (KAP-E, AST GmbH, Dresden, Germany) mounted on ai heightadjustable horizontal crossbar at the front of the frame of the treadmill to measure the forces exerted on the person-wheelchair combination during the separate dragtest. Static calibration of the force transducer was performed regularly with reference weights. Heart rate was monitored with a polar sport tester (Polar Vantage NV, Polar Electro Oy, Kempele, Finland). Data were saved to a computer with the Polar Tester interface and software. Oxygen uptake (in $1 / \mathrm{min}$ ) was continuously measured with an Oxycon instrument (Oxycon Delta, Jaeger Toennies, Breda, the Netherlands). Data were stored on a computer with the concomitant software program. Before each test, a calibration was performed with reference gases. Equipment needed to perform the Wheelchair Circuit, apart from the treadmill and the sport tester, were a treatment table, a wooden doorstep (height, $0.04 \mathrm{~m}$; width, $0.15 \mathrm{~m}$; length, $1.20 \mathrm{~m}$ ), a wooden platform (height, $0.10 \mathrm{~m}$; width, $1.20 \mathrm{~m}$; length $1.20 \mathrm{~m}$ ) a stopwatch and 3 markers.

\section{Statistical analysis}

Construct validity. A Mann-Whitney $U$ test for 2 independent samples was used to test for differences in ability scores due to lesion level (paraplegia vs tetraplegia) and motor completeness of the lesion (complete vs incomplete). To assess whether lesion level and motor completeness of the lesion significantly influenced performance time scores (in seconds) and mean physical strain scores (\%HRR) independent samples t-tests were used. To determine the relation between the ability score and age, FIM mobility score, $\mathrm{VO}_{2}$ peak (in $1 / \mathrm{min}$ ) and peak power output (in watts) we calculated Spearman correlations. Pearson correlations were calculated to determine the relation between the performance time score and the physical strain score on the Wheelchair Circuit and age, $\mathrm{VO}_{2}$ peak and peak power output, while Spearman correlations were calculated to determine the relation between these scores on the Wheelchair Circuit and FIM mobility score.

Responsiveness. Responsiveness was assessed through 2 methods. The first method assessed the changes in the Wheelchair Circuit scores between T1 and T3. We used the Wilcoxon signed-rank test to assess whether the ability score had improved significantly between T1 and T3. Paired Students 
t-tests were used to evaluate changes in performance time scores and physical strain scores (in beats/min) (31). The second method involved calculating the standardized response mean (SRM) (20). The SRM is a standardized measure of change callculated by dividing the mean change score by the standard deviation (SD) of this change score $(20,31)$. An SRM of 0.8 or higher is considered large, a value between 0.5 and 0.8 is regarded as moderate, and lower values are considered small (32).

All values are described as mean \pm SD. The level of significance was set at $P$ less than 0.05 . For the construct validity, which was assessed using multiple comparisons, the level of significance was adjusted using the Bonferroni adjustment $(P<0.0083)$.

\section{Results}

\section{Participants}

Not all 74 participants included in the project performed the Wheelchair Circuit. At T1, 12 persons did not perform the Wheelchair Circuit $(\mathrm{N}=62)$. Nine persons were still wearing a halo or a brace at the time of the measurement, and 3 persons had a contraindication. At T3, 5 persons did not perform the Wheelchair Circuit $(N=69)$. Three had a contraindication, 1 had a pressure ulcer and was not allowed to sit in a wheelchair, and 1 person did not want to perform the Wheelchair Circuit.

\section{Maximum exercise test}

Of the 62 participants that performed the Wheelchair Circuit at $T 1,43$ were physically able to perform the maximum exercise test. At T3, 54 of the 69 participants were able to perform the maximum exercise test. During T3, the oxygen uptake measurement failed in 2 persons, and in 2 other persons the power output was not measured correctly. Mean values, SDs and ranges of peak power output and peak oxygen uptake values, measured at the 2 measurement times are shown in table 4.1.

\section{FIM mobility scores}

FIM mobility scores were available for all participants who performed the Wheelchair Circuit at T1. At T3, the FIM mobility score was missing for 1 person. Mean values, SDs and ranges of FIM mobility scores at $\mathrm{T} 1$ and $\mathrm{T} 3$ are displayed in table 4.1. 


\begin{tabular}{|c|c|c|c|c|c|c|c|c|c|c|}
\hline & & \multicolumn{3}{|c|}{ FIM Mobility Score } & \multicolumn{3}{|c|}{$\begin{array}{l}\text { Peak Power Output } \\
\text { (Watt) }\end{array}$} & \multicolumn{3}{|c|}{$\begin{array}{l}\text { Peak Oxygen Uptake } \\
(1 / \mathrm{min})\end{array}$} \\
\hline & & $\mathbf{N}$ & $\begin{array}{l}\text { mean } \\
\pm \text { sd }\end{array}$ & e & $\mathbf{N}$ & $\begin{array}{l}\text { mean } \\
\pm \text { sd }\end{array}$ & range & $\mathbf{N}$ & $\begin{array}{l}\text { mean } \\
\pm \text { sd }\end{array}$ & range \\
\hline \multirow[t]{5}{*}{ T1 } & Total & 62 & $13.2 \pm 7.0$ & $4-28$ & 43 & $37.4 \pm 22.1$ & $10.9-124.1$ & 43 & $1.10 \pm 0.42$ & $0.52-3.15$ \\
\hline & Paraplegia & 45 & $14.0 \pm 7.2$ & $4-28$ & 36 & $41.0 \pm 22.3$ & $15.7-124.1$ & 36 & $1.15 \pm 0.43$ & $0.70-3.15$ \\
\hline & Tetraplegia & 17 & $11.0 \pm 6.2$ & $4-25$ & 7 & $9.0 \pm 6.9$ & $10.9-30.8$ & 7 & $0.85 \pm 0.22$ & $0.52-1.23$ \\
\hline & Incomplete & 25 & $14.6 \pm 7.4$ & $4-27$ & 20 & $36.8 \pm 26.0$ & $10.9-124.1$ & 20 & $1.16 \pm 0.53$ & $0.52-3.15$ \\
\hline & Complete & 37 & $12.3 \pm 6.7$ & $4-28$ & 23 & $37.9 \pm 18.7$ & $14.4-70.1$ & 23 & $1.05 \pm 0.29$ & $0.70-1.57$ \\
\hline \multirow[t]{5}{*}{ T3 } & Total group & 68 & $21.4 \pm 6.6$ & $4-28$ & 52 & $46.5 \pm 24.5$ & $4.6-117.5$ & 52 & $1.29 \pm 0.47$ & $0.55-2.90$ \\
\hline & Paraplegia & 50 & $22.4 \pm 5.4$ & $9-28$ & 41 & $51.0 \pm 24.7$ & $4.6-117.5$ & 41 & $1.33 \pm 0.49$ & $0.57-2.90$ \\
\hline & Tetraplegila & 18 & $18.7 \pm 8.8$ & $4-28$ & 11 & $29.8 \pm 15.4$ & $11.7-65.2$ & 11 & $1.14 \pm 0.36$ & $0.55-1.61$ \\
\hline & Incomplete & 24 & $23.3 \pm 5.0$ & $10-28$ & 21 & $50.1 \pm 26.8$ & $13.7-117.5$ & 21 & $1.42 \pm 0.60$ & $0.60-2.90$ \\
\hline & Complete & 44 & $20.4 \pm 7.2$ & $4-28$ & 31 & $44.1 \pm 23.0$ & $4.6-94.0$ & 31 & $1.21 \pm 0.35$ & $0.55-1.91$ \\
\hline
\end{tabular}

\section{Wheelchair Circuit}

Ability score. At T1, 6 of the 62 participants were unable to perform any of the items of the circuit and had an ability score of zero; 3 persons were able to perform all 8 items and obtained the maximum score of 8 . At T3, 3 persons scored zero and 22 persons achieved the maximum score of 8 . Descriptive figures are displayed in table 4.2.

Performance time score. Performance time scores were only available for those participants who were able to perform both the figure-of- 8 shape and the $15 \mathrm{~m}$ sprint. At $T 1,52$ persons had a performance time score, and at T3 65 persons performed both tasks (Table 4.2).

Physical strain score. Physical strain scores (\%HRR) could only be given to participants who had performed both slope items and from whom both HRrest and HRpeak were available. At T1 and T3, 38 and 47 persons respectively could be assigned a physical strain score. At T3 the peak heart rate reached during the $3 \%$ slope item was lower than the heart rate at rest in 1 person. This resulted in a negative HRR for the $3 \%$ slope item. The physical strain score of this person was not taken into account in the statistical analyses and was not included in tables 4.2 or 4.3 . Table 4.2 displays the mean physical strain scores at $\mathrm{T} 1$ and $\mathrm{T} 3$.

\section{Construct validity}

Ability score. At T1 and T3 the ability scores differed significantly for both lesion levels; persons with paraplegia scored significantly higher than persons with tetraplegia. No differences existed between the ability scores of persons with motor complete and those with motor incomplete lesions at any of the measurement times (Table 4.2). 


\begin{tabular}{|c|c|c|c|c|c|}
\hline \multicolumn{6}{|c|}{ Ability Score } \\
\hline & 3 & N & Mean \pm sd & range & p-value \\
\hline \multirow[t]{5}{*}{$\mathrm{T1}$} & Total group & 62 & $4.9 \pm 2.4$ & $0-8$ & \\
\hline & Paraplegia & 45 & $5.7 \pm 1.8$ & $0-8$ & $<0.001^{*}$ \\
\hline & Tetraplegia & 17 & $2.7 \pm 2.4$ & $0-6.5$ & \\
\hline & Incomplete & 25 & $5.0 \pm 2.2$ & $0-8$ & 0.718 \\
\hline & Complete & 37 & $4.8 \pm 2.5$ & $0-8$ & \\
\hline \multirow[t]{5}{*}{ T3 } & Total group & 69 & $6.2 \pm 2.2$ & $0-8$ & \\
\hline & Paraplegla & 50 & $6.7 \pm 2.0$ & $0-8$ & $0.004 *$ \\
\hline & Tetraplegia & 19 & $5.1 \pm 2.6$ & $0-8$ & \\
\hline & Incomplete & 25 & $6.7 \pm 1.6$ & $3-8$ & 0.696 \\
\hline & Complete & 44 & $6.0 \pm 2.5$ & $0-8$ & \\
\hline
\end{tabular}

\begin{tabular}{|c|l|l|l|l|l|}
\hline \multicolumn{2}{|l|}{ Performance Time Score (s) } & Mean \pm sd & range & p-value \\
\hline \multirow{4}{*}{ T1 } & Total group & 52 & $30.6 \pm 16.1$ & $12.0-83.0$ & \\
\cline { 2 - 6 } & Paraplegla & 43 & $28.7 \pm 15.4$ & $12.0-83.0$ & 0.055 \\
& Tetraplegia & 9 & $40.0 \pm 17.3$ & $19.0-69.0$ & \\
\cline { 2 - 6 } & Incomplete & 21 & $34.1 \pm 20.5$ & $12.0-83.0$ & 0.206 \\
& Complete & 31 & $28.3 \pm 12.2$ & $13.0-63.0$ & \\
\hline \multirow{4}{*}{ T3 } & Total group & 65 & $22.0 \pm 10.6$ & $11.0-64.0$ & \\
\cline { 2 - 7 } & Paraplegla & 48 & $19.4 \pm 7.7$ & $11.0-51.0$ & $<0.001^{*}$ \\
& Tetraplegla & 17 & $29.5 \pm 13.8$ & $14.0-64.0$ & \\
\cline { 2 - 7 } & Incomplete & 25 & $23.2 \pm 11.6$ & $12.0-64.0$ & 0.489 \\
& Complete & 40 & $21.3 \pm 1.0$ & $11.0-60.0$ & \\
\hline
\end{tabular}

\begin{tabular}{|l|l|l|l|l|l|}
\hline \multicolumn{2}{|l|}{ Physical Strain Score (\%HRR) } & N & Mean \pm sd & range & p-value \\
\hline \multirow{4}{*}{ T1 } & Total group & 38 & $43.8 \pm 17.8$ & $13.9-74.6$ & \\
\cline { 2 - 6 } & Paraplegla & 34 & $41.3 \pm 16.8$ & $13.9-71.2$ & 0.010 \\
& Tetraplegia & 4 & $56.0 \pm 11.4$ & $50.0-74.6$ & \\
\cline { 2 - 6 } & Incomplete & 17 & $44.2 \pm 15.3$ & $18.2-66.7$ & 0.907 \\
& Complete & 21 & $43.5 \pm 20.0$ & $13.9-74.6$ & \\
\hline \multirow{1}{*}{ 33 } & Total group & 46 & $35.4 \pm 17.5$ & $8.4-77.0$ & \\
\cline { 2 - 6 } & Paraplegia & 37 & $31.0 \pm 14.4$ & $8.4-72.1$ & $<0.001^{*}$ \\
\cline { 2 - 6 } & Tetraplegla & 9 & $53.2 \pm 18.6$ & $22.9-77.0$ & \\
\cline { 2 - 6 } & Incomplete & 18 & $38.1 \pm 18.1$ & $15.8-72.9$ & 0.397 \\
& Complete & 28 & $33.6 \pm 17.3$ & $8.4-77.0$ & \\
\hline
\end{tabular}

$* p<0.0083$ 
At $\mathrm{T} 1$, age did not correlate significantly with the ability score, and at $\mathrm{T} 3$ there was an inverse relation between age and ability score: older persons scored lower than younger persons. The ability score was correlated positively with the FIM mobility score, peak power output, and $\mathrm{VO}_{2}$ peak at both measurement times, with the highest correlation for peak power output (Table 4.3).

Performance time score. At $\mathrm{T} 1$, no differences existed between the performance time scores of persons with tetraplegia and those with paraplegia, and at T3 persons with paraplegia were significantly faster than persons with tetraplegia. There were no differences in the performance time scores due to motor completeness of the lesion at any of the measurement times (Table 4.2). At both measurement times age, FIM mobility score, peak power output, and peak oxygen uptake were related to the performance time score, showing the highest correlation for peak power output (Table 4.3).

Physical strain score. At T3, persons with tetraplegia had significantly higher levels of physical strain during the performance of the slope items. At T1 no differences existed in physical strain scores due to lesion level (Table 4.2). At none of the measurement times was there a difference in the physical strain scores due to the motor completeness of the lesion, age, or the FIM mobility score. Peak power output and peak oxygen uptake were inversely related to physical strain at both measurement times, again showing the highest mean correlation for peak power output (Table 4.3).

Table 4.3 Correlation coefficients $(r)$ of the ability score, performance time score, and physical strain score

\begin{tabular}{|c|c|c|c|c|c|c|c|c|c|c|c|c|}
\hline & \multicolumn{4}{|c|}{ Ability Score } & \multicolumn{4}{|c|}{$\begin{array}{l}\text { Performance Time Score } \\
\text { (s) }\end{array}$} & \multicolumn{4}{|c|}{$\begin{array}{l}\text { Physical Strail Score } \\
\text { (\%HRR) }\end{array}$} \\
\hline & \multicolumn{2}{|l|}{ T1 } & \multicolumn{2}{|l|}{$T 3$} & \multicolumn{2}{|l|}{ T1 } & \multicolumn{2}{|c|}{$T 3$} & \multicolumn{2}{|l|}{ T1 } & \multicolumn{2}{|l|}{$\mathbf{T 3}$} \\
\hline & $N$ & $r$ & $\mathbf{N}$ & $r$ & $\mathbf{N}$ & $r$ & $\mathbf{N}$ & $\mathbf{r}$ & $\mathbf{N}$ & $r$ & $\mathbf{N}$ & ir \\
\hline Age (years) & 62 & -0.216 & 69 & $-0.322^{*}$ & 52 & $0.397^{*}$ & 65 & $0.383^{*}$ & 38 & 0.067 & 46 & 0.365 \\
\hline $\begin{array}{l}\text { FIM mobility } \\
\text { score }\end{array}$ & 62 & $0.517^{*}$ & 68 & $0.519^{*}$ & 52 & $-0.466^{*}$ & 64 & $-0.396^{*}$ & 38 & -0.398 & 46 & -0.139 \\
\hline $\begin{array}{l}\text { Peak power } \\
\text { output (Watt) }\end{array}$ & 43 & $0.824^{*}$ & 52 & $0.762^{*}$ & 43 & $-0.628^{*}$ & 51 & $-0.719^{*}$ & 38 & $-0.678 *$ & 45 & $-0.692^{*}$ \\
\hline $\begin{array}{l}\mathrm{VO}_{2} \text { peak } \\
(1 / \mathrm{min})\end{array}$ & 43 & $0.674^{*}$ & 52 & $0.572^{*}$ & 43 & $-0.425^{*}$ & 51 & $-0.563^{*}$ & 38 & $-0.560^{*}$ & 45 & $-0.490^{*}$ \\
\hline
\end{tabular}

$* p<0.0083$

\section{Responsiveness}

Fifty-eight participants performed the Wheelchair Circuit both at T1 and T3. For this participant-group the mean time between $\mathrm{T} 1$ and $\mathrm{T} 3$ was $172 \pm 87$ days (range, 35-454 days). Fifty-one participants had a performance time score (in seconds) at both measurement times, and 33 participants had a physical strain score (in beats $/ \mathrm{min}$ ) at $\mathrm{T} 1$ and at $\mathrm{T} 3$. Table 4.4 shows that all 3 scores of the Wheelchair Circuit showed strong significant improvements between T1 and T3. The SRM ranged from 0.6 to 0.9 (moderate to large effect). 


\begin{tabular}{|l|l|l|l|l|l|l|}
\hline & N & T1 & T3 & Change Score & p-value & SRM \\
\hline Ability score & & mean \pm sd & mean \pm sd & mean \pm sd & & \\
\hline $\begin{array}{l}\text { Performance time score } \\
\text { (s) }\end{array}$ & 58 & $5.1 \pm 2.2$ & $6.3 \pm 2.2$ & $1.2 \pm 2.0$ & $<0.001$ & 0.6 \\
\hline $\begin{array}{l}\text { Physical strain score } \\
\text { (beats/min) }\end{array}$ & 31 & $30.7 \pm 16.3$ & $20.2 \pm 8.1$ & $10.5 \pm 11.0$ & $<0.001$ & 0.9 \\
\hline
\end{tabular}

SRM = standardized response mean

\section{Discussion}

\section{Construct validity}

Five different hypotheses were tested to assess construct validity.

Hypothesis 1. Persons with paraplegia perform better than persons with tetraplegia. This hypothesis was confirmed for the ability score at $\mathrm{T} 1$ and $\mathrm{T} 3$, and for the 2 additional scores at $\mathrm{T} 3$. The literature provides little information about the relation between lesion level on the one hand and wheelchair mobility on the other hand. Our findings are in agreement with those of Janssen et al. (12), who studled physical strain during the performance of wheelchair tasks in persons with long-standing SCI and found that persons with tetraplegla experienced significantly higher levels of strain during task performance than persons with paraplegia.

Hypothesis 2. Persons with motor incomplete lesions perform better than persons with motor complete lesions. Motor completeness of the lesion was not associated with any of the test scores at any of the measurement times. There are 2 possible explanations for this result. First, all participants were wheelchair dependent. This implies that, in participants with incomplete lesions, the spinal cord was nevertheless severely damaged. The distinction in functioning between persons with motor complete and persons with motor incomplete lesions is therefore less evident. Second, we did not take the lesion level into account in these analyses. Among participants with tetraplegia, motor completeness of the lesion may be a more important predictor of the performance of manual wheelchair tasks than in persons with paraplegia. Because of the small percentage of participants with tetraplegla in our study group, we did not perform subgroup analyses. In their study on persons with longstanding SCI, Janssen et al. (12), could not show an effect of completeness of the lesion on physical strain during the performance of wheelchair skills and activity of daily living (ADL) tasks. Hypothesis 3. Age is inversely related to manual wheelchair mobility. A small but significant inverse correlation existed between age and the ability score at T3, and a positive correlation existed between age and the performance time score at both measurement times, but age did not correlate with the physical strain score. Kirby et al. (11) tested the same hypothesis to assess the construct validity of the Wheelchair Skills Test (WST) in wheelchair users with different disabilities who had on average been wheelchair dependent for 1 year. In their study population, they also found a small inverse relation between persons' age and the test scores (reflecting test ability). Our inability to show a relation between age and the ability score at $\mathrm{T} 1$ may reflect the participants inexperience with 
wheelchair skill performance at that measurement time: all participants were early in their rehabilitation after a SCI, and at this measurement time the impairment itself may have had much more a general impact than did age.

Jebsen et al. (10) found that older persons (age $\geq 50$ years) performed the wheelchair tasks significantly more slowly than younger persons, which is in accordance with our findings on performance time. Regarding physical strain during wheelchair skill performance, Mattison et al. (33) also could not show a relation between age and physical strain during wheelchair propulsion in persons performing a wheelchair test circuit. A possible explanation might be that the characteristics of the spinal injury influence physical capacity to a larger extent than age.

Hypothesis 4. Participants' functional abilities are positively associated with wheelchair skill performance. The FIM mobility score and peak power output (reached during a maximum exercise test) were used as parameters of functional ability. The FIM mobility score was indeed positively related to the ability score and the performance time score at both T1 and T3. No relation existed between the FIM mobility score and the physical strain score. Like Duran et al. (9), who studied persons with paraplegia, we found that FIM scores were positively associated with functional abllity and the performance time of wheelchair tasks. A strong inverse relationship existed between peak power and all 3 scores of the Wheelchair Circuit at both measurement times. Janssen et al. (34) studied the performance of ADL tasks (including a number of wheelchair skills) in persons with an SCI at 2 occasions (on average 35 months apart). They found strong indications for a positive relationship between peak power output and the ability to perform ADL tasks. Janssen et al. $(12,34)$ also found that peak power output was the most important predictor of physical strain during task performance. Hypothesis 5. Physical capacity $\left(\mathrm{VO}_{2}\right.$ peak) is positively related to wheelchair skill performance. This hypothesis proved true for all 3 scores at both measurement times. Janssen et al. (34) found strong indications for a positive relationship between physical capacity and the ability to perform tasks.

Regarding physical strain during task performance, Janssen et al. $(12,34)$ and Dallmeijer et al. (19) also showed that physical capacity was inversely related to physical strain during a wide array of ADL. tasks, both in persons with a longstanding SCI as well as in persons during and after rehabilitation, both cross-sectionally and longitudinally.

Summarizing, 4 of the 5 hypotheses - all but hypothesis 2 - have been confirmed. This confirmation supports the view that the Wheelchair Circuit is a valid test to assess wheeichair skill performance during inpatient rehabilitation.

\section{Responsiveness}

To assess the responsiveness of the Wheelchair Circuit, we examined whether the 3 test scores had significantly improved between T1 and T3 and calculated the SRM for each score. The responsiveness was good: all scores had significantly improved between T1 and T3, and the SRM values ranged from moderate to large. Evaluating the responsiveness of a test should ideally involve 3 measurement times: 2 baseline measurements and 1 follow-up measurement. In the present study only one baseline measurement was performed, which may have limited the value of the responsiveness (20). 


\section{Wheelchair tests}

The results show that the Wheelchair Circuit is a reliable test (5), and has construct validity. Along with being valid, it is also a responsive instrument to assess manual wheelchair mobility in persons with SCI. It can be used in scientific studies as well as in clinical practice. The ability score and the performance time score can be simply obtained from the performance of the Wheelchair Circuit. To acquire the physical strain score, a heart rate monitor is required. Only when groups of persons with $\mathrm{SCI}$ are compared is the performance of a maximum exercise test necessary to calculate the heart rate reserve.

A number of tests are available to evaluate manual wheelchair mobility (35). The majority, however, have not been evaluated on reliability, validity or responsiveness. There are 2 tests that exceed the others: the test of Harvey et al. (26) and the WST of Kirby et al. (11).

Harvey et al. (26) designed a tool to assess mobility in wheelchair-dependent persons with paraplegia. The scoring system, a 6-point scale, resembles that of the FIM and takes into account the level of assistance and the time required to complete the tasks. The incorporated tasks are fundamental to the mobility of wheelchair users, the test does not require special equipment, and it can be performed in only 15 minutes. The main disadvantage of this test is the scoring system: it requires a subjective evaluation of the rater, which may result in less objective results (36). The interrater reliability of the test is good; its validity has not been assessed.

The WST (11) includes the performance of 33 skills. The skills concern the handling of the wheelchair itself (e.g. brakes, footrests, armrests), transfers to and from the wheelchair, maneuvering the wheelchair, and negotiating obstacles. All skills are scored on a 3-point scale $(0$, failure; 1 , partial completion; 2, successful and safe completion). The time required to administer the WST is 30 minutes. The reliablity and the validity of the WST are good. The WST provides a very detailed view of the ability of a person to use his/her wheelchair. The WST does, however, have 1 major drawback: only 15 of the 33 items directly concern wheelchair mobility.

Nelther the Harvey assessment tool nor the WST provide any concrete information on the time needed to perform a task and the physical strain induced by the tasks. These variables can, however, provide valuable and more detailed information in addition to the ability score. It is important to note that the coherence between the 3 test scores was significant, as shown in the calculations of the Spearman correlation coefficients. At T1, the correlations were -0.765 (ability score and performance time score), -0.540 (ability score and physical strain score), and 0.655 (performance time score and physical strain score). At T3 these correlations, respectively, were $-0.680,-0.635$, and 0.666 . The range of correlations between the 3 scores showed both conceptual coherence, and each score provides information additional to that of the other scores. The scores must be viewed as highly complementary to each other.

When a person is able to perform a certain wheelchair skill but requires a disproportionately long amount of time to do it, the performance of this skill will probably not be practicable in the person's daily live. The same applies to the physical strain attained during the performance of a wheelchair skill. The 2 additional scores of the Wheelchair Circuit make it possible to include these considerations into the test results.

Another advantage of the additional scores is that they make it possible to detect changes in wheelchair skill performance in persons who have achieved the maximum ability score of 8 , or did have the same ability score at 2 successive measurement times. 


\section{Conclusion}

The Wheelchair Circuit, is a complete and compact measurement, has an objective scoring method, and is a valid and responsive test to assess manual wheelchair mobility in persons with SCI. The ability score is easy to retrieve and provides information on a person's ability to perform wheelchair skills. If desired, the 2 additional scores (performance time score, physical strain score) can provide more detailed information on wheelchair related performance. 


\section{References}

1. Post MWM, Asbeck van FWA, Dijk van AJ, Schrijvers AJ. Services for spinal cord injured: Availability and satisfaction. Spinal Cord 1997;35(2):109-15.

2. Pierce $\mathrm{LL}$. Barriers to access: Frustrations of people who use a wheelchair for full-time mobility. Rehabil Nurs $1998 ; 23(3): 120-5$.

3. Somers M. Spinal cord injury, functional rehabilitation. Connecticut: Appleton \& Lange; 1992.

4. Britell CW. Wheelchair prescription. In: Lehmann JF, Kottke FJ, editors. Krusen's Handbook of Physical Medicine and Rehabilitation. 4 ed. Philadelphia: W.B. Company Saunders; 1990. p. 548-63.

5. Kilkens OJE, Post MWM, Woude van der LHV, Dallmeijer AJ, Heuvel van den WJA. The wheelchair circuit: Reliability of a test to assess mobility in persons with spinal cord injuries. Arch Phys Med Rehabil 2002;83(12):1783-8.

6. Streiner DL, Norman GR. Health measurements scales: A practical guide to their development and use. 2 ed. New York: Oxford University Press; 1995.

7. Woude van der LHV, Bakker WH, Elkhuizen JW, Veeger HE, Gwinn T. Propulsion technique and anaerobic work capacity in elite wheelchair athletes: Cross-sectional analysis. Am J Phys Med Rehabil 1998;77(3):222-34.

8. Dallmeijer AJ, Woude van der LHV, Hollander AP, As van HH. Physical performance during rehabilitation in persons with spinal cord injuries. Med Sci Sports Exerc 1999;31(9):1330-5.

9. Duran FS, Lugo L, Ramirez L, Lic EE. Effects of an exercise program on the rehabilitation of patients with spinal cord injury. Arch Phys Med Rehabil 2001;82(10):1349-54.

10. Jebsen RH, Trieschmann RB, Mikulic MA, Hartley RB, McMillan JA, Snook ME. Measurement of time in a standardized test of patient mobility. Arch Phys Med Rehabil 1970;51(3):170-5.

11. Kirby RL, Swuste J, Dupuis DJ, MacLeod DA, Monroe R. The Wheelchair Skills Test: A pilot study of a new outcome measure. Arch Phys Med Rehabil 2002;83(1):10-8.

12. Janssen TWJ, Oers van CAJM, Veeger $H_{\text {, }}$, Hollander AP, Woude van der LHV, Rozendal RH. Relationship between physical strain during standardised ADL tasks and physical capacity in men with spinal cord injuries. Paraplegia 1994;32(12):844-59.

13. Lehmann JF, Warren CG, Halar E, Stonebridge JB, DeLateur BJ. Wheelchair propulsion in the quadriplegic patient. Arch Phys Med Rehabil 1974;55(4):183-6.

14. Taricco M, Colombo C, Adone R, Chiesa G, Di Carlo S, Borsani M, et al. The social and vocational outcome of spinal cord injury patients. Paraplegia 1992;30(3):214-9.

15. Sawka MN, Glaser RM, Laubach LL, Al-Samkari O, Suryaprasad AG. Wheelchair exercise performance of the young, middle-aged, and elderly. J Appl Physiol 1981;50(4):824-8.

16. Morrison SA, Melton-Rogers SL, Hooker SP. Changes in physical capacity and physical strain in persons with acute spinal cord injury. Topics Spinal Cord Inj Rehabil 1997;3(1):1-15.

17. Janssen TWJ, Dallmeijer AJ, Veeger DJ, Woude van der LHV. Normative values and determinants of physical capacity in individuals with spinal cord injury. J Rehabil Res Dev 2002;39(1):29-39.

18. Noreau L. Relationship of impairment and functional ability to habitual activity and fitness following spinal cord injury. Int J Rehabil Res 1993;16(4):265-75. 


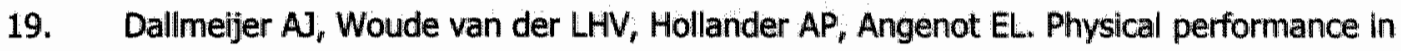
persons with spinal cord injuries after discharge from rehabilitation. Med Sci Sports Exerc 1999;31(8):1111-7.

20. Stratford PW, Binkley FM, Riddle DL. Health status measures: Strategies and analytic methods for assessing change scores. Phys Ther 1996;76(10):1109-23.

21. Davidson $M$, Keating JL. A comparison of five low back disability questionnaires: Reliability and responsiveness. Phys Ther 2002;82(1):8-24.

22. Woude van der LHV, Dallmeijer AJ, Killkens OJE, Post MWM, Witte de LP, Asbeck van FWA, et al. Physical strain, work capacity and mechanisms of restoration of mobility in the rehabilitation of individuals with spinal cord injury: Outline of a multi-center study. In: 1st World Congress of the International Society of Physical and Rehabilitation Medicine; 2001 7-13 July; Amsterdam (Netherlands). Bologna (Italy): Monduzzi Editore; 2001. p 162.

23. American Spinal Injury Association (ASIA): Reference manual for the International Standards for Neurological Classification of Spinal Cord Injury. Marino RJ, Ed. Chicago: American Spinal Injury Association, 2000

24. American College of Sports Medicine. ACSM's guidelines for exercise testing and prescription. 6th ed. Philadelphia: Lippincott Williams \& Wilkins; 2000.

25. Maynard FM, Jr., Bracken MB, Creasey G, Ditunno JF, Jr., Donovan WH, Ducker TB, et al. International standards for neurological and functional classification of spinal cord injury. American Spinal Injury Association. Spinal Cord 1997;35(5):266-74.

26. Harvey LA, Batty J, Fahey A. Reliability of a tool for assessing mobility in wheelchairdependent paraplegics. Spinal Cord 1998;36(6):427-31.

27. Karvonen $M$, Kentala $E$, Mustala $O$. The effects of training on heart rate. A longitudinal study. Annals of Medicine and Experimental Biology Fenn 1957(35):307-15.

28. Dallmeijer AJ, Hopman MT, Angenot EL, Woude van der LHV. Effect of training on physical capacity and physical strain in persons with tetraplegia. Scand J Rehabil Med 1997;29(3):1816.

29. Hall KM, Cohen ME, Wright J, Call M, Werner P. Characteristics of the Functional Independence Measure in traumatic spinal cord injury. Arch Phys Med Rehabil 1999;80:14716.

30. Woude van der LHV, Groot de G, Hollander AP, Ingen Schenau van GJ, Rozendal RH. Wheelchair ergonomics and physiological testing of prototypes. Ergonomics 1986;29(12):1561-73.

31. Hays $\mathrm{RD}$, Hadorn D. Responsiveness to change: An aspect of validity, not a separate dimension. Qual Life Res 1992;1(1):73-5.

32. Cohen J. Statistical Power Analysis for the Behavioral Sciences. New York: Academic Pr; 1977.

33. Mattison PG, Hunter J, Spence S. Development of a realistic method to assess wheelchair propulsion by disabled people. Int J Rehabil Res 1989;12(2):137-45.

34. Janssen TWJ, Oers van CAJM, Rozendaal EP, Willemsen EM, Hollander AP, Woude van der LHV. Changes in physical strain and physical capacity in men with spinal cord injuries. Med SCi Sports Exerc 1996;28(5):551-9.

35. Kilkens OJE, Post MWM, Dallmeijer AJ, Seelen HAM, Woude van der LHV. Wheelchair skills tests: A systematic review. Clin Rehabil 2003;17(4):418-30. 
36. Newton AM, Kirby RL, Macphee AH, Dupuis DJ, Macleod DA. Evaluation of manual wheelchair skills: Is objective testing necessary or would subjective estimates suffice? Arch Phys Med Rehabil 2002;83(9):1295-9. 


\section{Appendix Chapter 4}

\section{Description and scoring procedure of the Wheelchair Circuit}

\section{Item 1: Figure-of-8 Shape}

Three markers are placed on the floor, in a straight line and $1.50 \mathrm{~m}$ apart. The person sits in the wheelchair, front casters behind the first marker and turned backwards. At the starting signal, the person propels the wheelchair as fast as possible in a shape of 8 around the other 2 markers. Time is recorded from the moment the person starts until the front casters pass the first marker again. Ability score 0 : the person cannot perform this item within 60 s.

Ability score 1: the person performs this item correctly within 60 s.

Performance time: time needed to perform this item.

\section{Item 2: Crossing a Doorstep}

A wooden doorstep (height, $0.04 \mathrm{~m}$ ) is placed in an otherwise level doorway. One meter in front and $1 \mathrm{~m}$ behind the doorstep a marker is placed on the floor. The person sits in the wheelchair, front casters behind the first marker and turned backwards. At the starting signal, the person propels the wheelchair forward, negotiates the doorstep, and propels further forward onto the second marker. Time is recorded from the moment he/she starts until the front casters pass the second marker. Ability score 0 : the person cannot perform this item within 120 s.

Ability score 0.5: the person is able to cross the doorstep with the front casters (within 120s) but cannot pass the doorstep with the rear wheels.

Ability score 1 : the person performs this item correctly within 120 s.

\section{Item 3: Mounting a Platform}

A wooden platform (height, $0.10 \mathrm{~m}$ ) is placed on the floor, 1 side against a wall. Two meters in front of the platform, a marker is placed on the floor. The person sits in the wheelchair, front casters behind the first marker and turned backwards. At the starting signal, the person propels the wheelchair forward and mounts the platform. Time is recorded from the moment he/she starts untill all 4 wheels are on the platform.

Note: this item is only performed when the person was able to cross the doorstep (ability score, 1 ). Ability score 0: the person cannot perform this item within 120 s.

Ability score 0.5: the person is able to mount the platform with the front casters (within 120s) but cannot mount the platform with the rear wheels.

Ability score 1: the person performs this item correctly within 120 s.

\section{Item 4: $15 \mathrm{~m}$ sprint}

Two markers are placed on the floor, $15 \mathrm{~m}$ apart. The person sits in the wheelchair, with the front casters behind the first marker and turned backwards. At the starting signal, the person propels the wheelchair toward the second marker as fast as possible. Time is recorded from the moment he/she starts until the front casters pass the second marker.

Ability score 0 : the person cannot perform this item within 60 s.

Ability score 1: the person performs this item correctly within 60 s.

Performance time: time needed to perform this item. 


\section{Item 5: 3\% Slope}

This item is carried out with the person propelling the wheelchair on a wheelchair-adjusted treadmill. At the starting signal, the velocity of the belt is set at $0.56 \mathrm{~m} / \mathrm{s}, 10$ seconds later the slope is raised to $3 \%$ (which takes 125 ), and when this inclination is reached the person keeps propelling the wheelchair for another 10 seconds before the inclination is returned to $0 \%$ (which again takes $12 \mathrm{~s}$ ). The test ends when the treadmill has returned to horizontal position.

Ability score 0: the person cannot perform this item.

Ability score 1: the person performs this item correctly.

Strain: the maximum heart rate reached during the performance of the item.

\section{Item 6: 6\% Slope}

This item is exactly the same as the $3 \%$ slope item, except for the inclination of the slope, which is increased to $6 \%$. Both the increasing and decreasing of the slope take 23 seconds.

Note: this item is only performed if the person was able to perform the $3 \%$ slope item

(ability score, 1)

Ability score 0 : the person cannot perform this item.

Ability score 1: the person performs this item correctly.

Strain: the maximum heart rate reached during the performance of the item.

\section{Item 7: Wheelchair Propulsion}

This item is carried out with the person propelling the wheelchair on a wheelchair-adjusted treadmill. At the starting signal, the velocity of the belt is set at $0.56,0.83$, or $1.11 \mathrm{~m} / \mathrm{s}$, depending on the person's ability. The person propels the wheelchair for 180 seconds.

Ability score 0: the person cannot perform this item.

Abillty score 1: the person performs this item correctly for 180 s.

\section{Item 8: Transfer}

A line is placed on the floor $1 \mathrm{~m}$ from a treatment table and parallel to it; the table is set at the same height as the top of the seat cushion in the wheelchair. The person sits in the wheelchair, front casters behind the line and turned backwards. At the starting signal, the person performs a transfer from the wheelchair to the table. First he/she drives up to the table and puts the wheelchair in position, then he/she makes a transfer, with the legs hanging over the edge of the table, and finally he/she places his/her legs on the table, while remaining seated. The person is allowed to use the assistive device(s) he/she normally uses to perform a transfer. Time is recorded from the moment the person starts until the person sits on the table with both legs lying on the table.

Note: this item is not carried out if the person has a score less than 3 on the FIM transfer item bed/chair/wheelchair. The research assistant is not allowed to lift any part of the person's body to help in performing the item.

Ability score 0 : the person cannot perform this item within 300 s.

Ability score 0.5: the person is able to perform a transfer (within 300s), but cannot do this in the manner described above.

Ability score 1 : the person performs this item correctly within 300 s. 


\section{5}

\section{Personal characteristics and injury related factors}

influencing the course of manual wheelchair skill performance during initial inpatient rehabilitation of persons with a spinal cord injury 


\section{Summary}

Objective: To study changes in wheelchair skills in persons with spinal cord injury (SCI) during rehabilitation, to determine whether changes in wheelchair skill performance are related to personal-, and lesion characteristics, secondary complications and upper extremity pain, and to investigate if wheelchair skill performance at discharge can be predicted from these features.

Design: Longitudinal. Participants performed the Wheelchair Circuit three times during rehabilitation: at admission (T1), three months later (T2), and at discharge (T3).

Setting: Eight rehabilitation centers in the Netherlands.

Patlents: One hundred and twenty-one persons with SCI.

Main outcome measures: The Wheelchair Circuit consists of eight wheelchair skills, and results in three test scores: ability, performance time and physical strain.

Results: All the scores of the Wheelchair Circuit improved significantly between $T 1$ and $T 2$, and between $\mathrm{T} 2$ and $\mathrm{T} 3$. The scores were related to age and lesion level, while changes in scores were related to age, gender, lesion level and secondary complications. Age and Body Mass Index are the most important variables to predict the wheelchair skill performance after inpatient rehabilitation.

Conclusions: Wheelchair skill performance improves during rehabilitation. Personal- and lesion characteristics are most important for the development of wheelchair skill performance and the prediction of wheelchair skill performance. 


\section{Introduction}

The majority of persons with a spinal cord injury (SCI) is dependent on wheelchair use for mobility (1). This may impact overall functioning, primarily at the level of activities, but also in participation (2). Environmental and personal factors, as well as lesion characteristics, will impact wheelchair skill performance during and after inpatient rehabilitation. The current study is the first that deals with an analysis of the complex of relationships within this conceptual model.

To function independently, manual wheelchair users must possess a variety of wheelchair skills to deal with the physical barriers they will encounter in various environments (3). Mastering wheelchair skills can make the difference between dependence and independence in dally life $(4,5)$, and wheelchair skill training therefore is a major part of inpatient rehabilitation after $\mathrm{SCI}$ (6). During rehabilltation, recently injured persons with an SCI have to learn a completely new way of locomotion. When persons with acute $\mathrm{SCI}$ are discharged from inpatient rehabilitation, indeed most of them are capable of performing various wheelchair skills, such as making transfers, negotiating curbs and ramps. It seems obvious that the performance of wheelchair skills improves during inpatient rehabilitation as a direct consequence of practice and learning. MacPhee et al. (7) found considerable improvements in wheelchair skills after a training program aimed at improving wheelchair skills during inpatient rehabilitation of wheelchair users with different neurological and musculoskeletal disorders. However, there is only little research that describes the improvement of wheelchair skill performance during inpatient rehabilitation of persons with SCI (8). From the literature, investigating disability in general or functional limitations, or in cross sectional studies, it can be derived that wheelchair skill performance is related to personal- and lesion characteristics and the prevalence of secondary complications and upper extremity pain (8-17).

In the literature there is evidence for an inverse relationship between age and functional outcomes (14, 18-21). Warschausky et al. (20) found that gender was a significant predictor for changes in functional outcome during rehabilitation, while Greenwald et al. (19) stated that gender did not influence the functional outcome of rehabilitation of SCI patients. Literature concerning the relationship between wheelchair mobility and body mass index (BMI) is lacking, but it is plausible to hypothesize that wheelchair skill performance and BMI are related because activities that require moving or lifting the whole body, which are the essence of wheelchair mobillty, are more difficult with a higher body weight $(14,22)$.

Lesion level and lesion completeness are known to be related to wheelchair mobility $(10,11,17)$. Persons with tetraplegia are in general more limited in their ability to propel a wheelchair than individuals with paraplegia, and persons with motor complete lesions are expected to experience more difficulties in wheelchair skill performance than persons with motor incomplete lesions. Persons that suffer from secondary complications (l.e. pressure sores, urinary tract infections, and/or respiratory tract infections) may also experience a limitation in their daily physical activity. This can indirectly affect a patient's progress in rehabilitation $(23,24)$. Musculoskeletal pain in the upper extremities is a common problem among individuals with $\mathrm{SCI}$ who use manual wheelchairs for their mobility $(13,25-$ 28). This pain interferes with daily activities and may lead to a decrease in independence and mobility $(13,14,28)$.

The influence of personal- and lesion characteristics, secondary complications and upper extremity pain on changes in manual wheelchair skills during inpatient rehabilitation has however never been studied in detail. Understanding the influence of these variables is important for the planning and 
allocation of treatment resources, and for setting realistic rehabilitation goals and prognosis. The objectives of the present research were therefore 1) to study changes in manual wheelchair skills in persons with SCI during inpatient rehabilitation, 2) to determine whether changes in wheelchair skills are related to personal characteristics, lesion characteristics, secondary complications, and upper extremity pain, and 3) to investigate to what degree the level of wheelchair skill performance at the time of discharge from inpatient rehabilitation (T3) can be predicted from personal characteristics, lesion characteristics, secondary complications, and upper extremity pain at the start of the inpatient rehabilitation ( $\mathrm{T} 1)$.

\section{Methods}

\section{Participants and procedures}

The present study was part of the Dutch research program 'physical strain, work capacity and mechanisms of restoration of mobility in the rehabilitation of persons with spinal cord injuries'. In this prospective cohort study individuals with an acute SCI were followed during inpatient rehabilitation. Participants were measured three times: at the start of functional rehabilitation, defined as the moment that participants were able to sit in their wheelchair for (at least) three consecutive hours $(\mathrm{T} 1)$, three months later (T2), and at the time of discharge from inpatient rehabilitation (T3). Eight Dutch rehabilitation centers specialized in the rehabilitation of persons with SCI participated in this research program. Eight trained research assistants conducted the measurements, according to a standardized protocol.

Participants were eligible to enter the project if they had an acute $\mathrm{SCI}$, were between 18 and 65 years of age, were dassified as A, B, C or D on the American Splnal Injury Association (ASIA) impairment scale (29), were wheelchair dependent, did not have a progressive disease or psychiatric problem, and had enough knowledge of the Dutch language to understand the goal of the study and the testing methods. Participants were not allowed to perform physically strenuous tests (i.e. the Wheelchair Circuit and the maximum wheelchair exercise test) if they had 1) cardiovascular disorders (the absolute contra-indications as they are stated by the American College of Sports Medicine 2000 guidelines (30), and/or a resting diastolic blood pressure $>90 \mathrm{~mm} \mathrm{Hg}$ or a resting systolic blood pressure $>180 \mathrm{~mm} \mathrm{Hg}$ ), and/or 2) severe musculoskeletal complaints of the upper extremities, neck or back. After inclusion in the cohort, participants were examined by their rehabilitation physician to check for any of these contraindications.

To avoid influence on the test results, participants were asked to consume a light meal only, to refrain from smoking, drinking coffee and drinking alcohol for at least two hours prior to each measurement, and to void their bladder directly before testing. All participants completed a consent form after they had been given information about the testing procedures. All tests and protocols were approved by the Medical Ethics Committee of the Institute for Rehabilitation Research, Hoensbroek, the Netherlands. 


\section{Measures}

\section{The Wheelchair Circuit}

Wheelchair skills were measured with the Wheelchair Circuit $(15,31)$, a standardized test in which the capacity to perform wheelchair skills was measured. The Wheelchair Circuit consists of eight different standardized tasks. The tasks are performed in a fixed sequence, on a hard and smooth floor surface and on a motor driven treadmill (Treadmill Glant, Bonte BV, Zwolle, the Netherlands). To avoid using different wheelchairs over time, all participants used an individually adjusted standard test wheelchair, which was available in two seat widths, $0.42 \mathrm{~m}$ and $0.46 \mathrm{~m}$, and was equipped with solid tires (Sopur Starlight 622, Sunrise Medical GmbH, Malsch/Heidelberg, Germany).

The eight tasks of the Wheelchair Circuit are: 1) Figure-of-8 shape: the participants propel their wheelchair, as fast as possible, in a shape of eight around two markers. 2) Crossing a doorstep: a doorstep (height $0.04 \mathrm{~m}$ ) is placed in an otherwise level doorway, the participants sit in their wheelchair, one meter in front of the doorstep, and propel the wheelchair forwards and negotiate the doorstep. 3) Mounting a platform (height $0.10 \mathrm{~m}$ ) that is placed on the floor. This task is only performed when participants were able to cross the doorstep. 4) $15 \mathrm{~m}$ sprint: participants propel their wheelchairs over a distance of 15 meters as fast as possible. 5-6) $3 \%$ and $6 \%$ slope performed on a wheelchair-adjusted treadmill. 7) 3 Minute wheelchair propulsion carried out on a treadmill at a constant velocity of $0.56,0.83$, or $1.11 \mathrm{~m} / \mathrm{s}$, depending on the persons' ability. 8) Transfer from the wheelchair to a treatment table, allowing to use the assistive device(s) normally used to perform a transfer. For a further detailed description, see Kilkens et al. $(15,31)$.

During the performance of the Wheelchair Circuit heart rate is measured with a heart rate monitor (Polar Vantage NV, Polar Electro Oy, Kempele, Finland).

The performance of the Wheelchair Circuit leads to three different test scores: ability score, performance time score, ${ }_{r}$ and physical strain score.

The ability score contains all eight test items, assigned $0,0.5$ or 1 point, all points are summed to give an overall score ranging from $0-8$. Items that are performed adequately and independently are assigned one point. Crossing a doorstep, mounting platform, and transfer can also be scored partially able ( 0.5 points). All participants are given an ability score, irrespective of whether they are able to perform all eight tasks of the circuit.

The performance time score is the sum of the performance times of the figure-of-eight shape and the $15 \mathrm{~m}$ sprint, and is available in only those persons that are able to perform both tasks.

The physical strain score provides information on the physical strain induced by the performance of the 3- and 6\% slope items, and is available only in those participants that are able to perform these tasks. The physical strain score is defined as the mean of the peak heart rates reached during each of the two slope items expressed as percentage heart rate reserve (\%HRR) $(15,31,32)$.

The development, and the assessment of the clinimetric properties of the Wheelchair Circuit have been described earlier $(15,31)$, and the reliability, construct validity and responsiveness of the Wheelchair Circuit have proven to be good. 


\section{Participant characteristics}

At each measurement occasion the participant characteristics age, gender, and BMI were registered. BMI was calculated as body mass divided by the square of the height of the participants.

\section{Lesion characteristics}

At each measurement occasion the lesion characteristics were assessed by a physician according to the International Standards for Neurological Classification of Spinal Cord Injury (33): the ASIA impairment scale classifications $A$ and $B$ were defined as motor complete, $C$ and $D$ as motor incomplete, and neurological lesion levels below T1 were defined as paraplegia, while lesion levels at or above $\mathrm{T} \mathbb{1}$ were defined as tetraplegia.

\section{Secondary complications}

The rehabilitation physicians reported whether persons had suffered from pressure sores, urinary tract infections, or respiratory tract infections between the admission to the rehabilitation center and $\mathrm{T} 1$, between $\mathrm{T} 1$ and $\mathrm{T} 2$, and between $\mathrm{T} 2$ and $\mathrm{T} 3$. They also registered whether participants had been prescribed bed rest due to the prevalence of these secondary complications. In the present study we wanted to select persons that might experience a limitation in their daily physical activity due to secondary complications. The variable secondary complications was therefore defined as follows: persons did have pressure sores, urinary tract infections, or respiratory tract infections and had been prescribed bed rest for at least one of these conditions, for at least one day.

\section{Upper extremity pain}

Participants were asked whether they had pain in the muscles and/or joints of the upper extremities (i.e. fingers, elbows, and shoulders) between the admission to the rehabilitation center and $\mathrm{T} 1$, between $\mathrm{T} 1$ and $\mathrm{T} 2$, and between $\mathrm{T} 2$ and $\mathrm{T} 3$.

\section{Statistical analysis}

Descriptive statistics (means \pm SD) were applied to all variables. For longitudinal analysis multilevel analysis was used (MiwiN, version 1.10; Center for Multilevel Modeling, Institute of Education, London, UK). The benefits of this method are 1) that it accounts for the dependency of repeated measures within the same person, 2) that it accounts for the hierarchical nature of the longitudinal data of the present study, and 3) that, in contrast to traditional methods of longitudinal data analysis (i.e. MANOVA for repeated measures), the number of observations per individual may vary $(34,35)$. Three levels of hierarchy are present: the repeated measurements are nested within the participants and the participants are nested within rehabilitation centers. 
The three outcome variables of the Wheelchair Circuit (i.e. ability score, performance time score, and physical strain score) were related to time, which was entered into the analyses as a categorical variable; i.e. converted into dummy variables with the second measurement as reference (dummy T1$\mathrm{T} 2: \mathrm{T} 1=1, \mathrm{~T} 2=0, \mathrm{~T} 3=0$; dummy $\mathrm{T} 2-\mathrm{T} 3: \mathrm{T} 1=0, \mathrm{~T} 2=0, \mathrm{~T} 3=1)$.

To answer the first research question, only the time dummies were included in the model. For the second research question we first analyzed which of the independent variables were, in addition to the time-based model, univariately related to either one of the three outcome measures. Apart from time, the independent variables used in the analyses were: age (years), gender (male $=1$, female $=0$ ), BMI $\left(\mathrm{kg} / \mathrm{m}^{2}\right)$, lesion level (paraplegia $=1$, tetraplegia $=0$ ), motor completeness of the lesion (complete $=1$, incomplete $=0$ ), secondary complications (yes $=1$, no $=0$ ), and upper extremity pain $\left(y e s=1, n_{0}=0\right)$. It was also investigated whether there was a significant interaction of all the independent variables listed above with the time indicator variables (T1-T2 and T2-T3). All independent variables and interaction terms with a univariate $p$-value below 0.10 were subsequently included in a multivariate multilevel model. A backward elimination technique (35) was used to filter significant main relationships $(p \leq 0.05)$. All analyses were performed separately for each of the three scores of the Wheelchair Circuit.

To answer the third research question (predicting the wheelchair scores at discharge, using independent varlables measured at the start of active rehabilitation), all participants that performed a measurement both at $\mathrm{T} 1$ and at $\mathrm{T} 3$ were included. Because the time variables were not included in this study, only two levels of hierarchy in the data were considered: the participants who are nested within the rehabilitation centers. To predict the scores of the Wheelchair Circuit at discharge (T3) a model was built which only includes the independent variables measured at $T 1$ as predictor varlables, using the same procedure as described above.

\section{Results}

\section{Participants}

This study was based on 121 participants who performed the Wheelchair Clrcuit at least twice. Not all participants performed the tests at all three the measurement occasions: fourteen persons did not perform the $T 1$ measurement because they were wearing a halo or a brace at the time of the measurement. Thirty-one persons did not perform a $\mathrm{T} 2$ measurement because their entire inpatient rehabilitation period lasted three months or less, these participants skipped the $\mathrm{T} 2$ measurement and thus performed only the $\mathrm{T} 1$ and the $\mathrm{T} 3$ measurement.

Above that, not all participants were able to obtain all three the scores of the Wheelchair Circuit: 121 persons had at least two ability scores, 110 persons had at least two performance time scores, and 71 persons had at least two physical strain scores.

For the construction of the predictive models (research question 3) the number of participants that had an ability score, performance time score or physical strain score at both $\mathrm{T} 1$ and $\mathrm{T} 3$ were 107, 92 and 52 respectively.

The mean number of days ( \pm standard deviation) between T1 and T3 was $192 \pm 127$ for all participants (those with paraplegia: $157 \pm 92$; those with tetraplegia: $254 \pm 155$ days). 
Table 5.1 shows the three test scores of the Wheelchair Circuit, personal characteristics, lesion characteristics, and secondary complications at the different measurement occasions. The mean age of the participants at T1 was $39.8 \pm 14.5$ years, and $74 \%$ was male.

Table 5.1 Scores of the Wheelchair Circuit, personal- and lesion characteristics, secondary complications and upper extremity pain at $\mathrm{T} 1, \mathrm{~T} 2$ and $\mathrm{T} 3$

\begin{tabular}{|c|c|c|c|c|c|c|}
\hline & \multicolumn{2}{|l|}{$\mathbf{T 1}$} & \multicolumn{2}{|l|}{ T2 } & \multicolumn{2}{|l|}{ T3 } \\
\hline & $\overline{\mathbf{N}}$ & & $\mathbf{N}$ & & $\mathbf{N}$ & \\
\hline Abllity score (mean $\pm S D)$ & 107 & $4.9 \pm 2.4$ & 86 & $5.6 \pm 2.5$ & 121 & $6.3 \pm 2.1$ \\
\hline Performance time score $(s$, mean \pm SD) & 92 & $31.6 \pm 17.5$ & 79 & $26.9 \pm 13.4$ & 115 & $22.4 \pm 10.7$ \\
\hline Physical strain score (\%HRR, mean \pm SD) & 62 & $44.6 \pm 18.3$ & 53 & $42.1 \pm 18.9$ & 81 & $37.3 \pm 19.0$ \\
\hline $\mathrm{BMI}\left(\mathrm{kg} / \mathrm{m}^{2}\right.$, mean $\left.\pm \mathrm{SD}\right)$ & 115 & $23.0 \pm 4.1$ & 79 & $23.5 \pm 4.2$ & 113 & $23.7 \pm 4.1$ \\
\hline$\%$ Paraplegla & 120 & 63 & 85 & 61 & 118 & 64 \\
\hline$\%$ Motor complete & 120 & 69 & 83 & 66 & 116 & 61 \\
\hline$\%$ Secondary complications & 121 & 24 & 86 & 35 & 121 & 13 \\
\hline$\%$ Pain upper extremities & 121 & 51 & 86 & 54 & 121 & 49 \\
\hline
\end{tabular}

Motor complete = ASIA Impairment scale A and B; paraplegia = lesion level caudal to $\mathrm{T} 1$.

\section{Changes over time in the scores of the Wheelchair Circuit}

Between T1 and T2 the ability score improved on average 1.1 points ( $95 \% \mathrm{CI}: 0.8-1.4, \mathrm{p}<0.001$ ), and between $\mathrm{T} 2$ and $\mathrm{T} 30.4$ points (95\% CI: $0.1-0.7, \mathrm{p}=0.014$ ) (Figure 5.1.).

The performance time score improved significantly between T1 and T2 (a mean drop of $7.0 \mathrm{~s}$, $95 \%$ CI: $4.7-9.4, p<0.001$ ), and between T2 and T3 (a mean decrease of 4.1 s., $95 \% \mathrm{CI}: 1.9-6.3, \mathrm{p}<$ $0.001)$.

The physical strain score showed a significant decrease of $7.1 \% \mathrm{HRR}(95 \% \mathrm{CI}: 3.0-11.2, \mathrm{p}=0.001)$ between $\mathrm{T} 1$ and $\mathrm{T} 2$, and between $\mathrm{T} 2$ and $\mathrm{T} 3$ a significant decrease of $2.9 \% \mathrm{HRR}$ was found $(95 \% \mathrm{CI}$ : $1.9-9.6, \mathrm{p}=0.003$ ).

In all three the scores of the Wheelchair Circuit, the hierarchical level 'rehabilitation center' did not contribute to the explanation of variance. 
Figure 5.1 The results of the multilevel analysis to describe the changes in the Wheelchair Circuit scores over time
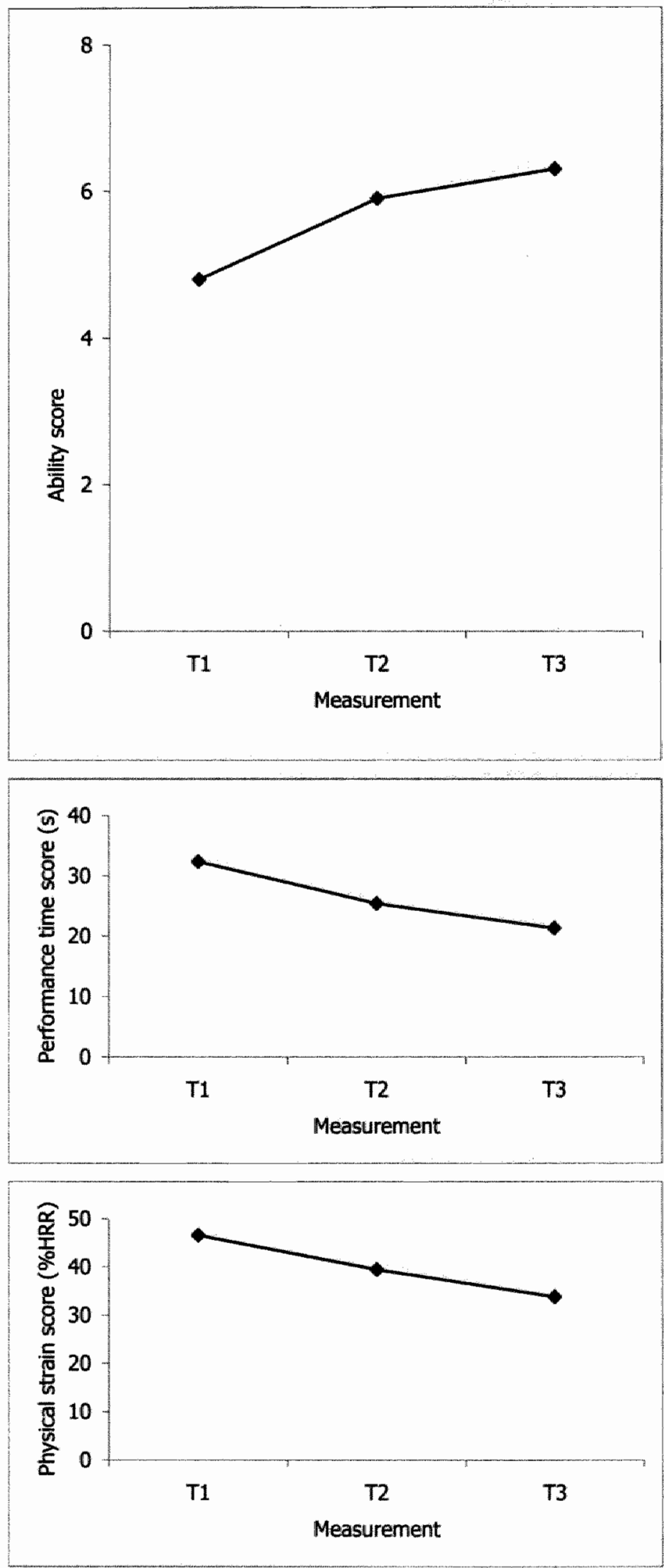


\title{
The relationship between personal- and lesion characteristics, secondary complications and upper extremity pain, and the scores of the Wheelchair Circuit.
}

\begin{abstract}
Ability score
Age was inversely related to the ability score: older persons had lower ability scores than younger persons. Persons with paraplegia performed the Wheelchair Circuit significantly better than individuals with tetraplegia. The significant negative interaction between lesion level and T2-T3 indicates that between $T 2$ and $T 3$ persons with tetraplegia on average improved 0.96 points more than persons with paraplegia, thus reducing the difference in ability score between persons with paraplegia and persons with tetraplegia. The significant interaction between secondary complications and T1-T2 shows that between $\mathrm{T} 1$ and $\mathrm{T} 2$ persons that suffered from secondary complications improved on average 1.05 points less than persons who did not have secondary complications. There was a significant negative interaction between gender and T1-T2, indicating that between $\mathrm{T} 1$ and $\mathrm{T} 2$ men improved on average 0.81 points more than women.
\end{abstract}

\section{Performance time score}

There was a significant relation between age and performance time, indicating that younger participants had better performance time scores than older participants, with an average difference of 0.28 seconds per year (Table 5.2 ). Lesion level was also significantly related to the performance time score. Persons with paraplegia were on average 10.8 seconds faster than individuals with tetraplegia. The significant interaction between lesion level and T2-T3 demonstrates that between T2 and T3, participants with tetraplegia on average improved 6 seconds more than participants with paraplegia, thus decreasing the difference in performance time score between participants with paraplegia and participants with tetraplegia at time of discharge.

\section{Physical strain score}

Lesion level was significantly related to the physical strain score: for persons with paraplegia the performance of the two slope tasks was less strenuous than for persons with tetraplegia, with an average difference of $24 \%$ HRR (Table 5.2). The significant interaction between age and T2-T3 demonstrates that between $\mathrm{T} 2$ and $\mathrm{T} 3$, younger persons improved more than older persons. 
Table 5.2 Results of the multilevel analysis to assess the longitudinal relationship of the ability score, performance time score and physical strain score with personal- and lesion characteristics, secondary complications and upper extremity pain $(\mathrm{N}=121)$.

\begin{tabular}{|c|c|c|c|c|c|c|}
\hline & \multicolumn{2}{|l|}{ Ability score } & \multicolumn{2}{|c|}{ Performance time score } & \multicolumn{2}{|c|}{ Physical strain score } \\
\hline & $\beta(95 \% \mathrm{CI})$ & p-value & $\beta(95 \% \mathrm{CI})$ & p-value & $\beta(95 \% \mathrm{CI})$ & $p$-value \\
\hline Constant & $\begin{array}{l}5.29 \\
(3.94,6.64)\end{array}$ & & $\begin{array}{l}21.40 \\
(14.23,28.57)\end{array}$ & & $\begin{array}{l}65.66 \\
(53.00,78.31)\end{array}$ & \\
\hline $\mathrm{T} 1-\mathrm{T} 2 *$ & $\begin{array}{l}-1.06 \\
(-1.90,-0.22)\end{array}$ & 0.013 & $\begin{array}{l}9.40 \\
(5.02,13.77)\end{array}$ & $<0.001$ & $\begin{array}{l}4.52 \\
(-7.19,16.23)\end{array}$ & 0.449 \\
\hline $\mathrm{T} 2-\mathrm{T} 3 * *$ & $\begin{array}{l}1.02 \\
(0.21,1.83)\end{array}$ & 0.014 & $\begin{array}{l}-8.24 \\
(-12.23,-4.26)\end{array}$ & $<0.001$ & $\begin{array}{l}-18.57 \\
(-29.88,-7.27)\end{array}$ & 0.001 \\
\hline Age (years) & $\begin{array}{l}-0.04 \\
(-0.06,-0.01)\end{array}$ & 0.004 & $\begin{array}{l}0.28 \\
(0.15,0.40)\end{array}$ & $<0.001$ & $\begin{array}{l}-0.19 \\
(-0.48,0.10)\end{array}$ & 0.199 \\
\hline Gender (men=1) & $\begin{array}{l}0.81 \\
(-0.09,1.71)\end{array}$ & 0.078 & - & Ns & - & Ns \\
\hline $\begin{array}{l}\text { Lesion levell } \\
\text { (paraplegia=1) }\end{array}$ & $\begin{array}{l}2.39 \\
(1.64,3.14)\end{array}$ & $<0.001$ & $\begin{array}{l}-10.83 \\
(-15.72,-5.94)\end{array}$ & $<0.001$ & $\begin{array}{l}-24.47 \\
(-31.70,-17.24)\end{array}$ & $<0.001$ \\
\hline $\begin{array}{l}\text { Secondary } \\
\text { Complications (yes }=1 \text { ) }\end{array}$ & $\begin{array}{l}-0.33 \\
(-0.95,0.29)\end{array}$ & 0.294 & - & Ns & - & Ns \\
\hline Age $\times \mathrm{T} 1-\mathrm{T} 2$ & - & Ns & - & Ns & $\begin{array}{l}0.09 \\
(-0.22,0.39)\end{array}$ & 0.581 \\
\hline Age $\times \mathrm{T} 2-\mathrm{T} 3$ & - & Ns & - & Ns & $\begin{array}{l}0.34 \\
(0.05,0.63)\end{array}$ & 0.020 \\
\hline Gender $\times$ T1-T2 & $\begin{array}{l}-0.81 \\
(-1.59,-0.02)\end{array}$ & 0.044 & - & Ns & - & Ns \\
\hline Gender $\times$ T2-T3 & $\begin{array}{l}-0.20 \\
(-0.95,0.55)\end{array}$ & 0.602 & - & Ns & - & Ns \\
\hline Lesion level $\times$ T1-T2 & $\begin{array}{l}-0.41 \\
(-0.28,1.10)\end{array}$ & 0.246 & $\begin{array}{l}-2.56 \\
(-7.81,2.69)\end{array}$ & 0.339 & - & Ns \\
\hline Lesion level $\times$ T2-T3 & $\begin{array}{l}-0.96 \\
(-1.36,-0.02)\end{array}$ & 0.043 & $\begin{array}{l}6.07 \\
(1.12,11.01)\end{array}$ & 0.016 & - & Ns \\
\hline $\begin{array}{l}\text { Secondary } \\
\text { Complications } \times \text { T1-T2 }\end{array}$ & $\begin{array}{l}1.05 \\
(0.20,1.89)\end{array}$ & 0.015 & - & Ns & - & Ns \\
\hline $\begin{array}{l}\text { Secondary } \\
\text { Complications x T2-T3 }\end{array}$ & $\begin{array}{l}-0.63 \\
(-1.58,0.32)\end{array}$ & 0.194 & - & Ns & - & Ns \\
\hline
\end{tabular}

$\beta=$ regression coefficient; $95 \% \mathrm{CI}=95 \%$ confidence interval; $\mathrm{Ns}=$ not significant; $*$ = The regression coefficient of the time dummies $\mathrm{T} 1-\mathrm{T} 2$ and $\mathrm{T} 2-\mathrm{T} 3$ represent the change between $\mathrm{T} 1$ and $\mathrm{T} 2$, respectively $\mathrm{T} 2-\mathrm{T} 3$, bearing in mind that $T 2$ is the reference $(0)$ in both; for instance the negative $\beta$ of $T 1-T 2$ for the Ability score indicates an average value of 5.29 at $T 2$, an improvement of $(1 * 1.06)$ compared to $T 1 ; * *=$ The positive $\beta$ for T2-T3 for the Ability score for instance indicates a 1 point improvement over this time interval $(1.02 * 1)$ at T3. 


\section{Predictive models}

Table 5.3 shows the results of the multiple multilevel analyses to predict the ability score, performance time score and physical strain score at T3. The ability score at $\mathrm{T} 1$, age and BMI proved to be the significant predictors of the ability score at T3, clarifying $60 \%$ of the variance. Performance time at T1 and age, best predicted performance time at T3, explaining $61 \%$ of the variance.

Physical strain score at T1, and BMI were significant predictors of the physical strain score at $T 3$, explaining $45 \%$ of the variance.

Table 5.3 Results of the multilevel analysis to predict the ability score, performance time score and physical strain score at $\mathrm{T3}$, using independent variables measured at $\mathrm{T1}(\mathrm{N}=107)$

\begin{tabular}{|c|c|c|c|c|c|c|}
\hline & $\begin{array}{l}\text { Ability score } \\
\text { at T3 }\end{array}$ & & $\begin{array}{l}\text { Performance } \\
\text { time score at } \\
\text { T3 }\end{array}$ & & \begin{tabular}{|l|} 
Physical \\
strain score at \\
T3
\end{tabular} & \\
\hline & $\beta(95 \%$ CI $)$ & p-value & $\beta(95 \%$ CI $)$ & p-value & $\beta(95 \% \mathrm{CI})$ & p-value \\
\hline Constant & $\begin{array}{l}5.78 \\
(4.05,7.52)\end{array}$ & & $\begin{array}{l}5.25 \\
(2.49,8.02)\end{array}$ & & $\begin{array}{l}-14.98 \\
(-38.23,8.27)\end{array}$ & \\
\hline $\begin{array}{l}\text { Ability } \\
\text { score T1 }\end{array}$ & $\begin{array}{l}0.55 \\
(0.45,0.65)\end{array}$ & $<0.001$ & Not entered & & Not entered & \\
\hline $\begin{array}{l}\text { Performance time } \\
\text { score T1 }\end{array}$ & Not entered & & $\begin{array}{l}0.28 \\
(0.22,0.33)\end{array}$ & $<0.001$ & Not entered & \\
\hline $\begin{array}{l}\text { Physical strain } \\
\text { score T1 }\end{array}$ & Not entered & & Not entered & & $\begin{array}{l}0.55 \\
(0.38,0.72)\end{array}$ & $<0.001$ \\
\hline Age & $\begin{array}{l}-0.02 \\
(-0.04,-0.002)\end{array}$ & 0.026 & $\begin{array}{l}0.16 \\
(0.10,0.23)\end{array}$ & $<0.001$ & - & Ns \\
\hline BMI & $\begin{array}{l}-0.07 \\
(-0.13,-0.004)\end{array}$ & 0.037 & - & Ns & $\begin{array}{l}0.97 \\
(0.06,1.88)\end{array}$ & 0.037 \\
\hline
\end{tabular}

$\beta=$ regression coefficient; $95 \% \mathrm{CI}=95 \%$ confidence interval; $\mathrm{Ns}=$ not significant

\section{Discussion}

In this study, the wheelchair skill performance of 121 persons with SCI was assessed three times during their inpatient rehabilitation. The inpatient rehabilitation period is an essential period for persons with SCI to learn to be independent in daily life. There are only very few studies that have examined wheelchair skill performance during initial rehabilitation. Except for Dallmeijer et al. (8) and MacPhee et al. (7), most studies that did investigate wheelchair skills only included participants that were already discharged from inpatient rehabilitation $(8,12,36,37)$. 


\section{Changes in the scores of the Wheelchair Circuit}

The scores of the Wheelchair Circuit all improved significantly between $T 1$ and $T 2$, and between $T 2$ and T3. For all three scores, the largest improvement occurred during the first three months of the inpatient rehabilitation period $(T 1-T 2)$. The multilevel analyses showed that the level 'rehabilitation center" did not contribute to the clarification of variance. From this we may conclude that the changes in wheelchair skill performance are not different in different rehabilitation centers.

There are no other studies that describe the longitudinal development of wheelchair skills during inpatient rehabilitation. A number of authors have studied the change in functional status during rehabilitation after SCI, using FIM scores or parameters of physical capacity as outcome variables (8, 17, 38-42). Most studies only assessed persons once or twice during their rehabilitation period (i.e. at admission, and/or at the time of discharge from the rehabilitation center) $(8,17,38,39)$. There is only little literature available that examines the course of improvement during rehabilitation and assesses functional status at least three times during rehabilitation (40-42). Furthermore these studies include small numbers of participants, which makes the interpretation of the results difficult. The results of the present study are in accordance with those of Bode et al. (40) and Hjeltnes et al. (42). Hjeltnes et al. measured the physical capacity of persons with SCI three times during their primary rehabilitation period. They found that the largest improvement in physical capacity occurred during the first 6 to 8 weeks of the active rehabilitation period. During the whole rehabilitation period, Bode et al. (40) weekly assessed the FIM to examine functional improvement of persons with SCI. They found that functional status improved linearly during inpatient rehabilitation. Future studies will have to focus on changes that occur after discharge from rehabilitation as well.

\section{The relationship between personal- and lesion characteristics, secondary complications and upper extremity pain, and the scores of the Wheelchair Circuit}

Age and lesion level were associated to the scores of the Wheelchair Circuit during inpatient rehabilitation. There was an interaction between time and age, gender, lesion level, and secondary complications, indicating that these variables did influence the rate of change in wheelchair skill performance over time.

Only a few studies have examined wheelchair skill performance during inpatient rehablittation in persons with SCI $(8,43)$, furthermore most of the studies that have been performed only include small numbers of participants. Therefore we can only compare the results of the present study with the results of studies that examined changes in FIM scores during inpatient rehabilitation.

Warschausky et al. (20) examined the recovery of the FIM motor score in 142 persons with SCI during inpatient rehabilitation. In agreement with our results, they also found that the rate of change over time was significantly influenced by gender. The results of the present study showed that both the ability score and the performance time score were significantly related to age. These results are in accordance with those of other authors, who found that age is inversely related to functional status after SCI $(20,44)$. Many studies have demonstrated a relationship between lesion level and motor completeness of the lesion and functional outcome after inpatient rehabilitation $(10,11,17)$. In our study we also found that lesion level was significantly associated with the three scores of the Wheelchair Circuit. The analyses also demonstrated that between $T 2$ and $T 3$ persons with tetraplegia 
showed a larger improvement of the ability score and the performance time score than persons with paraplegia. This difference may be explained by the fact that persons with tetraplegia did have a longer inpatient rehabilitation period than persons with paraplegia, resulting in a longer time period between $\mathrm{T} 2$ and $\mathrm{T} 3$. We could not demonstrate a relation between the scores of the Wheelchair Circuit and the motor completeness of the lesion. This may be explained by the fact that all participants had to be wheelchair dependent to be included in the cohort. This implies that, in persons with incomplete lesions, the spinal cord was nevertheless severely damaged. The distinction in functioning between persons with motor complete and persons with motor incomplete lesions may therefore be less evident.

\section{Predictive models}

From our results it can be concluded that the measurement at the start of active rehabilitation, age, and BMI are the most important variables to predict the wheelchair skill performance after inpatient rehabilitation.

The models that were built to predict the physical strain score at T3 explained substantially less variance than the models that were made to predict the ability - and the performance time score. This is most likely due to the fact that only 52 participants did have a physical strain score at $\mathrm{T} 1$ and at $\mathrm{T} 3$, whereas respectively 107 and 92 participants did have an ability score or a performance time score at $\mathrm{T} 1$ and $\mathrm{T} 3$.

In medical practice, these prediction models can be used to obtain an insight in the possible future wheelchair skill performance of the patient. This can be useful for the formulation of the rehabilitation goals and the treatment plan concerning wheelchair mobility. However, the patient has to be able to perform the Wheelchair Circuit at T1.

\section{Limitations of the study}

To be included into the cohort, persons had to meet several inclusion criteria: they had to be between 18 and 65 years of age, and they had to be wheelchair dependent. When, during the rehabilitation period, persons were no longer wheelchair dependent they were at that point excluded from the cohort. Participants that for whatever reason performed the Wheelchair Circuit only once were not included in the present study. Because of these criteria, our participants are a positive selection out of the complete population of persons with an acute $\mathrm{SCI}$ who are admitted to a rehabilitation center, which should be kept in mind when the results of the present study are interpreted.

At all measurement times, all participants that performed the Wheelchair Circuit did have an ability score, but only those participants that were able to perform both the figure-of-eight shape and the $15 \mathrm{~m}$ sprint were assigned a performance time score. Further, to be given a physical strain score participants had to be able to perform the $3 \%$ and $6 \%$ slope task and the maximum exercise test which is needed to compute the physical strain score. Because of this the analyses regarding the performance time score and the physical strain score concern a positive selection of the research population, consisting of persons with a relatively good wheelchair skill performance. 
Fourteen participants were not able to perform the T1 measurement because they were wearing a halo or a brace at the time of the measurement. It could be possible that these persons negatively influenced the results at $T 2$ and $T 3$. To check for this selection bias we performed secondary analyses, which showed that the wheelchair skill performance of these persons at $T 2$ and $T 3$ was not different from the wheelchair skill performance of the persons that were able to perform the Wheelchair Circuit at T1.

Not all participants performed the Wheelchair Circuit at all three measurement times, which led to missing values in the database. Missing values occurred also when participants were not able to perform parts of the Wheelchair Circuit, or the maximum exercise test. These missing values consequently can not be defined as 'missing at random'. We did not use imputation to replace these missing values because that is not necessary when multi-level analyses are used (45).

The length of the inpatient rehabilitation period considerably varies between persons. This may have affected the results that concern the period between $T 2$ and $T 3$. The T3 measurement is performed at the time of discharge from the rehabilitation center. However, sometimes the time of discharge is delayed for reasons that do not concern the functional status of patients, for instance when the necessary adaptations to their house are not completed yet, or when they have to wait for placement in a nursing home. During the period between the moment that persons are functionally ready to be discharged and the moment that they actually leave the rehabilitation center, theraples are continued at a lower frequency. In these persons the $\mathrm{T} 3$ measurement may not reflect the actual discharge status.

\section{Conclusions}

The scores of the Wheelchair Circuit all improved significantly between $T 1$ and $T 2$, and between $T 2$ and T3. The largest improvement occurred during the first three months of the inpatient rehabilitation.

Personal characteristics, lesion characteristics and secondary complications do significantly influence the wheelchair skill performance during rehabilitation, while upper extremity pain did not affect wheelchair skills during inpatient rehabilitation in the current study.

The personal characteristics age and BMI are the most important predictors, in addition to the baseline score for wheelchair skills at the end of inpatient rehabilitation.

Future studies should include the post rehabilitation phase and should analyze modifiable characteristics such as physical fitness and muscle force. The role of wheelchair skill performance in participation needs further attention as well. 


\section{References}

1. Post MWM, Asbeck van FWA, Dijk van AJ, Schrijvers AJ. Services for spinal cord injured: Availability and satisfaction. Spinal Cord 1997;35(2):109-15.

2. WHO. International Classification of Functioning, Disability and Health. ICIDH-2 final draft. Geneva: WHO, 2001.

3. Plerce LL. Barriers to access: Frustrations of people who use a wheelchair for full-time mobillty. Rehabil Nurs 1998;23(3):120-5.

4. Noreau L, Shephard RJ. Spinal cord injury, exercise and quality of life. Sports Med 1995;20(4):226-50.

5. Somers M. Spinal cord injury, functional rehabilitation. Connecticut: Appleton \& Lange; 1992.

6. Sparrow WA. The Efficiency of Skilled Performance. J. Mot. Behav. 1983;15(3):237-61.

7. MacPhee AH, Kirby RL, Coolen AL, Smith C, MacLeod DA, Dupuis DJ. Wheelchair skills training program: A randomized clinical trial of wheelchair users undergoing initial rehabilitation. Arch Phys Med Rehabil 2004;85(1):41-50.

8. Dallmeijer AJ, Woude van der LHV, Hollander AP, As van HH. Physical performance during rehabilitation in persons with spinal cord injuries. Med Sci Sports Exerc 1999;31(9):1330-5.

9. Ballinger DA, Rintala DH, Hart KA. The relation of shoulder pain and range-of-motion problems to functionall limitations, disability, and perceived health of men with spinal cord injury: A multifaceted longitudinal study. Arch Phys Med Rehabil 2000;81(12):1575-81.

10. Beekman CE, Miller-Porter L, Schoneberger M. Energy cost of propulsion in standard and ultralight wheelchairs in people with spinal cord injuries. Phys Ther 1999;79(2):146-58.

11. Dahlberg $A$, Kotila $M$, Kautiainen $H$, Alaranta $H$. Functional independence in persons with spinal cord injury in Helsinki. J Rehabil Med 2003;35(5):217-20.

12. Dallmeijer AJ, Woude van der LHV, Hollander AP, Angenot EL. Physical performance in persons with spinal cord injuries after discharge from rehabilitation. Med Sci Sports Exerc 1999;31(8):1111-7.

13. Dalyan M, Cardenas DD, Gerard B. Upper extremity pain after spinal cord injury. Spinal Cord 1999;37(3):191-5.

14. Gerhart KA, Bergstrom E, Charlifue SW, Menter RR, Whiteneck GG. Long-term spinal cord injury: Functional changes over time. Arch Phys Med Rehabil 1993;74(10):1030-4.

15. Kilkens OJE, Dallmeijer AJ, Witte de LP, Woude van der LHV, Post MWM. The Wheelchair Circuit: Construct validity and responsiveness of a test to assess manual wheelchair mobility in persons with spinal cord injury. Arch Phys Med Rehabil 2004;85(3):424-31.

16. McKinley WO, Jackson AB, Cardenas DD, DeVivo MJ. Long-term medical complications after traumatic spinal cord injury: A regional model systems analysis. Arch Phys Med Rehabil 1999;80(11):1402-10.

17. Schönherr MC, Groothoff JW, Mulder GA, Eisma WH. Functional outcome of patients with spinal cord injury: Rehabilitation outcome study. Clin Rehabil 1999;13(6):457-63.

18. Kirby $\mathrm{RL}$, Ethans KD, Duggan RE, Saunders-Green LA, Lugar JA, Harrison ER. Wheelchair propulsion: Descriptive comparison of hemiplegic and two- hand patterns during selected activities. Am J Phys Med Rehabil 1999;78(2):131-5. 
19. Greenwald BD, Seel RT, Cifu DX, Shah AN. Gender-related differences in acute rehabilitation lengths of stay, charges, and functional outcomes for a matched sample with spinal cord injury: A multicenter investigation. Arch Phys Med Rehabil 2001;82(9):1181-7.

20. Warschausky S, Kay JB, Kewman DG. Hierarchical linear modeling of FIM instrument growth curve characteristics after spinal cord injury. Arch Phys Med Rehabil 2001;82(3):329-34.

21. Yarkony GM, Roth EJ, Heinemann AW, Lovell LL. Spinal cord injury rehabilitation outcome: The impact of age. J Clin Epidemiol 1988;41(2):173-7.

22. Janssen TWJ, Oers van CAJM, Rozendaal EP, Willemsen EM, Hollander AP, Woude van der LHV. Changes in physical strain and physical capacity in men with spinal cord injuries. Med Sci Sports Exerc 1996;28(5):551-9.

23. Ellenberg M, MacRitchie M, Franklin B, Johnson S, Wrisley D. Aerobic capacity in early paraplegia: Implications for rehabilitation. Paraplegia 1989;27(4):261-8.

24. Müller EA. Influence of training and of inactivity on muscle strength. Arch Phys Med Rehabil 1970;51(8):449-62.

25. Dyson-Hudson TA, Kirshblum SC. Shoulder pain in chronic spinal cord injury. Part 1: Epidemiology, etiology, and pathomechanics. J Spinal Cord Med 2004;27(1):4-17.

26. Samuelsson KA, Tropp $\mathrm{H}$, Gerdle B. Shoulder pain and its consequences in paraplegic spinal cord injured wheelchair users. Spinal Cord 2004;42(1):41-6.

27. Subbarao JV, Klopfstein J, Turpin R. Prevalence and impact of wrist and shoulder pain in patients with spinal cord injury. J Spinal Cord Med 1995;18(1):9-13.

28. Widerstrom-Noga EG, Felipe-Cuervo E, Yezierski RP. Chronic pain after spinal injury: Interference with sleep and daily activities. Arch Phys Med Rehabil 2001;82(11):1571-7.

29. American Spinal Injury Association (ASIA): Reference manual for the international standards for neurological classification of spinal cord injury. Marino RJ, Ed. Chicago: American Spinal Injury Association,2000.

30. American College of Sports Medicine. ACSM's guidelines for exercise testing and prescription. 6th ed. Philadelphia: Lippincott, Williams \& Wilkins; 2000.

31. Kilkens OJE, Post MWM, Woude van der LHV, Dallmeijer AJ, Heuvel van den WJA. The Wheelchair Circuit: Reliability of a test to assess mobility in persons with spinal cord injuries. Arch Phys Med Rehabil 2002;83(12):1783-8.

32. Karvonen $M$, Kentala $E$, Mustala $O$. The effects of training on heart rate. A longitudinal study. Annals of Medicine and Experimental Biology Fenn 1957(35):307-15.

33. Maynard FM, Jr., Bracken MB, Creasey G, Ditunno JF, Jr., Donovan WH, Ducker TB, et al. International standards for neurological and functional classification of spinal cord injury. American Spinal Injury Association. Spinal Cord 1997;35(5):266-74.

34. Goldstein H. Multilevel statistical models. New York: John Wiley \& Sons; 1995.

35. Twisk JWR. Applied longitudinal data analysis for epidemiology, A practical guide. Amsterdam: Cambridge University Press; 2003.

36. Taricco M, Colombo C, Adone R, Chiesa G, Di Carlo S, Borsani M, et all. The social and vocational outcome of spinal cord injury patients. Paraplegia 1992;30(3):214-9.

37. Janssen TWJ, Oers van CAJM, Rozendaal EP, Willemsen EM, Woude van der LHV, Hollander AP. Changes in physical capacity and physical strain during ADL in men with spinal cord injuries. Med Sci Sports Exerc 1994;28(5):551-9. 
38. Tooth $L$, McKenna $K$, Geraghty $T$. Rehabilitation outcomes in traumatic spinal cord injury in Australia: Functional status, length of stay and discharge setting. Spinal Cord 2003;41(4):22030.

39. Woolsey RM. Rehabilitation outcome following spinal cord injury. Arch Neurol 1985;42(2):1169.

40. Bode RK, Heinemann AW. Course of functional improvement after stroke, spinal cord injury, and traumatic brain injury. Arch Phys Med Rehabil 2002;83(1):100-6.

41. Ota T, Akaboshi K, Nagata M, Sonoda S, Domen K, Seki M, et al. Functional assessment of patients with spinal cord injury: Measured by the motor score and the functional independence measure. Spinal Cord 1996;34(9):531-5.

42. Hjeltnes $\mathbf{N}$. Changes in cardiovascular responses to graded armergometry in tetra- and paraplegic patients during primary rehabilitation. In: Woude van der LHV, Meijs PJM, Boer de YA, editors. Ergonomics of manual wheelchair propulsion: State of the art. Amsterdam: IOS Press; 1991. p. 51-60.

43. Duran FS, Lugo L, Ramirez L, Lic EE. Effects of an exercise program on the rehabilitation of patients with spinal cord injury. Arch Phys Med Rehabil 2001;82(10):1349-54.

44. Cifu DX, Seel RT, Kreutzer JS, McKinley WO. A multicenter investigation of age-related differences in lengths of stay, hospitalization charges, and outcomes for a matched tetraplegia sample. Arch Phys Med Rehabil 1999;80(7):733-40.

45. Twisk J, Vente de W. Attrition in longitudinal studies. How to deal with missing data. J Clin Epidemiol 2002;55(4):329-37. 


\section{6}

The longitudinal relationship between physical capacity and wheelchair skill performance during inpatient rehabilitation of persons with spinal cord injuries 


\section{Summary}

Objective: To study the longitudinal relationship between physical capacity and wheelchair skill performance in persons with spinal cord injury (SCI) during rehabilitation.

Design: Observational prospective cohort study. Participants performed the measurements three times during rehabilitation.

Setting: Eight rehabilitation centers in the Netherlands.

Patients: Ninety-seven persons with SCI.

Main outcome measures: Parameters of physical capacity were upper extremity muscle strength (Manual Muscle Testing (MMT) sum score), peak oxygen uptake, and peak power output (POpeak). The Wheelchair Circult consists of eight wheelchair skills, and results in three test scores: ability, performance time and physical strain.

Results: POpeak was related to all three scores of the Wheelchair Circuit, and the MMT sum score was related to the ability score and the performance time score. The results indicate 1) that participants with higher values of POpeak and/or MMT sum score had better scores on the Wheelchair Circuit than participants with lower values; and 2) when a person increased his/her POpeak and/or MMT sum score, this was associated with better wheelchair skill scores.

Conclusions: There is a significant longitudinal relationship between wheelchair skill performance and POpeak and MMT sum score during the rehabilitation of persons with SCI. To optimize wheelchair skill performance, attention should be directed towards manual wheelchair exercise training and strength training of the upper body. 


\section{Introduction}

The majority of persons with a spinal cord injury (SCI) are dependent on wheelchair use for mobility (1). For these persons wheelchair use is conditional to achieve independent mobility. To function independently, manual wheelchair users must possess a variety of wheelchair skills, enabling them to deal with the physical barriers they will inevitably encounter in various environments (2). Mastering wheelchair skills can make the difference between dependence and independence in daily life $(3,4)$. Training of these skills is therefore a vital part of the rehabilitation process. From the literature physical capacity is known to be related to the performance of wheelchair skills and wheelchair-related activities of daily living in persons with SCI (5-11). Most studies however included small numbers of participants $(5-7,9)$, and/or participants who were already discharged from inpatient rehabilitation $(5$, 7-9, 11).

Due to muscle paralysis and deficient autonomic regulation of the cardiovascular system, persons with an SCI have a low physical capacity. In the first months following injury, their physical capacity is even lower due to bed rest and physical inactivity (12-14). Increasing physical capacity is therefore another important goal of inpatient rehabilitation after SCI (15).

The mastering of wheelchair skills combined with an optimal physical capacity, will enhance the mobility of wheelchair dependent persons, which is essential to reach an optimal level of independence in daily life. Different studies have shown that rehabilitation of persons with SCI has a positive effect on physical capacity $(6,10,16)$, and on wheelchair skill performance(10, 17-20). Up till now however no research has been done to study the longitudinal relationship between manual wheelchair skill performance and physical capacity during inpatient rehabilitation. Knowledge about this relationship might however be useful to gain insight in, and to optimize the effectiveness of the inpatient rehabilitation process after SCI. Therefore the objective of the present study was to examine the relationship between longitudinal changes in manual wheelchair skill performance and parameters of physical capacity during inpatient rehabilitation of persons with SCI.

\section{Methods}

\section{Participants and procedure}

The present study was part of the Dutch research program 'Physical Strain, Work Capacity, and Mechanisms of Restoration of Mobility in the Rehabilitation of Persons with Spinal Cord Injuries'. In this observational longitudinal cohort study individuals with an acute SCI were followed during inpatient rehabilitation. Participants were measured three times: at the start of active rehablitation (T1), three months later (T2), and at the time of discharge from inpatient rehabilitation (T3). Eight Dutch rehabilitation centers specialized in the rehabilitation of persons with SCI participated in this research program. Eight trained research assistants conducted the measurements, according to a standardized protocol.

Participants were eligible to enter the cohort if they had an acute SCI, were between 18 and 65 years of age, were classified as A, B, C or D on the American Spinal Injury Association (ASIA) (21) impairment scale, were wheelchair dependent, did not have a progressive disease or psychiatric problem, and had enough knowledge of the Dutch language to understand the goal of the study and 
the testing methods. Participants were not allowed to perform physically strenuous tests (i.e. the Wheelchair Circuit and the maximum wheelchair exercise test) if they had 1) cardiovascular disorders (the absolute contra-indications as they are stated by the ACSM 2000 guidelines (22), or a resting diastolic blood pressure $>90 \mathrm{~mm} \mathrm{Hg}$ or a resting systolic blood pressure $>180 \mathrm{~mm} \mathrm{Hg}$ ), and/or 2) severe musculoskeletal complaints of the upper extremities, neck or back. After inclusion in the cohort, participants were examined by their rehabilitation physician to check for any of these contraindications.

Consequently not all participants performed the tests at all three measurement occasions because they were excluded due to medical contra indications (as described above) or the test was too heavy for them at a certain test occasion.

For some participants the length of stay in inpatient rehabilitation did not exceed three months, in these cases the T3 measurement was performed at the time of discharge, meaning that of those persons no data were available at $\mathrm{T} 2$.

Participants were tested in the rehabilitation centers in which they were inpatients. The tests were performed on two different days (at the same time of the day, no more than 1 week apart). On the first test day, participants' lesion characteristics were assessed, and participants performed the Wheelchair Circuit. On day two the upper extremity strength was assessed, and participants performed the maximum wheelchair exercise test. To avoid influence on the test results participants were asked to consume a light meal only, to refrain from smoking, drinking coffee, and drinking alcohol to at least two hours prior to each measurement, and to void their bladder directly before testing. All participants completed a consent form after they had been given information about the testing procedures. All tests and protocols were approved by the Medical Ethics Committee of the Institute for Rehabilitation Research, Hoensbroek, the Netherlands.

\section{Lesion characteristics}

At each measurement occasion the lesion characteristics were assessed by a physician according to the International Standards for Neurological Classification of Spinal Cord Injury (23): the ASIA impairment scale classifications $A$ and $B$ were defined as motor complete and classes $C$ and $D$ as motor incomplete. Neurologic lesions at or above the T1 vertebra were defined as tetraplegia, and lesions below the $\mathrm{T} 1$ vertebra were defined as paraplegla.

\section{Physical capacity}

As parameters of physical capacity, upper extremity muscle strength, peak oxygen uptake $\left(\mathrm{VO}_{2}\right.$ peak), and peak power output (POpeak) were measured at the three measurement occasions. 


\section{Upper extremity muscle strength}

The strength of six muscle groups of the upper extremities (wrist extensors, elbow flexors-extensors, shoulder internal and external rotators, shoulder abductors) was assessed by manual muscle testing (MMT). These muscle groups were chosen because they are known for their important contribution in functional activities, such as wheelchair propulsion and transfers $(24,25)$. The MMT was performed in standardized positions (26). For each muscle group, the person was asked to perform the movement with or without gravity, or against a resistance. The research assistants subjectively measured the muscle force on a scale of 0-5 as follows: 0) no muscle contraction, 1) palpable or visible muscle contraction, 2) active movement through full range of motion (ROM) with gravity eliminated, 3) active movement through full ROM against gravity, 4) active movement through full ROM against resistance, 5) normal muscular strength. The muscle group scores of the right and left upper extremities were summed to obtain an MMT sum score, which ranges from $0-60$.

\section{Peak oxygen uptake and peak power output}

$\mathrm{VO}_{2}$ peak and POpeak were assessed through the performance of a maximal wheelchair exercise test on the treadmill (Treadmill Giant, Bonte BV, Zwolle, the Netherlands). Before the maximal exercise test, the wheelchair drag force (Fdrag in Newton) for the wheelchair-user combination on the treadmill was recorded in a drag test (27). During this measurement, the participant sat passively in the wheelchair that was connected with a rope to a force transducer (KAP-E, AST GmbH, Dresden, Germany), which was attached to the frame of the treadmill. The velocity of the belt of the treadmill was set equal to the velocity at which the maximum exercise test would be performed, and subsequently the slope was raised from $0^{\circ}$ to $3.6^{\circ}$ in ten steps of $0.36^{\circ}$. The results were stored on a computer. The force measurement was used to calculate the power output for each angle of inclination on the treadmill, according to Fdrag multiplied by treadmill belt velocity (in $\mathrm{m} / \mathrm{s}$ ).

After a 2-minute warm up, two 3-minute submaximal exercise periods were performed, separated by 2-minute rest intervals. The first 3-minute period was performed with the belt in horizontal position, the second with a slope of $0.36^{\circ}$. After the submaximal exercise periods and a 2-minute rest, the workload was raised every minute by increasing the slope of the belt with $0.36^{\circ}$. The test was terminated when the person could no longer maintain his/her position on the belt. During the entire test the velocity of the belt was held constant at $0.56,0.83$ or $1.11 \mathrm{~m} / \mathrm{s}$, depending on the lesion level as well as the ability of the person.

Throughout the test, oxygen uptake $\left(\mathrm{VO}_{2}, \mathrm{l} / \mathrm{min}\right)$ was recorded continuously with an Oxycon instrument (Oxycon Delta, Jaeger Toennies, Breda, the Netherlands). Mean values over 30 seconds were used for the analyses. Calibration was performed prior to each test with a known reference gas mixture. The highest mean value of $\mathrm{VO}_{2}$ measured over 30 seconds during the entire test was defined as $\mathrm{VO}_{2}$ peak. POpeak, derived from the dragtest, was defined as the power output that corresponded to the highest slope of the belt that had been maintained for at least 30 seconds during the maximum exercise test.

$\mathrm{VO}_{2}$ peak and POpeak were expressed both in absolute values and relative to body mass (in kilogram). 


\section{The Wheelchair Circuit}

The Wheelchair Clrcuit $(19,28)$ is a test to assess manual wheelchair skill performance. It consists of eight different standardized tasks that were performed in a fixed sequence, on a hard and smooth floor surface and on a motor driven treadmill. The eight tasks are 1) Figure-of-8 shape; 2) Crossing a doorstep (height, 0.04m); 3) Mounting a platform (height, 0.10m); 4) $15 \mathrm{~m}$ Sprint; 5) 3\% Slope; 6) 6\% Slope; 7) 3 minute wheelchair propulsion; 8) Transfer. All participants used an individually adjusted standard test wheelchair that was available in two seat widths: $0.42 \mathrm{~m}$ and $0.46 \mathrm{~m}$ (Sopur Starlight 622, Sunrise Medical GmbH, Malsch/Heidelberg, Germany).

During the performance of the circuit, the ability to perform the test items, the performance time of the figure-of- 8 shape and the $15 \mathrm{~m}$ sprint, and the peak heart rates during the $3 \%$ and $6 \%$ slope items on the treadmill were recorded. The heart rate (beats/min) was registered with a Polar sport tester Vantage NV at a 5-second storage interval (Polar Vantage NV, Polar Electro Oy, Kempele, Finland). The performance of the Wheelchair Circuit leads to three different test scores: ability score, performance time score, and physical strain score.

Ability score: all test items that are performed adequately and independently are assigned one point. Three items (crossing a doorstep, mounting a platform, and transfer) can also be scored partially able and can be given half a point. All points are summed to give an overall ability score. The ability score ranges from 0-8.

Performance time score: the sum of the performance times of the figure-of-eight shape and the $15 \mathrm{~m}$ sprint. Participants are instructed to perform these two tasks at their maximum speed. Persons that were not able to perform both the figure-of-eight shape and the $15 \mathrm{~m}$ sprint could not be assigned a performance time score.

Physical strain score: the mean of the peak heart rates reached during each of the two slope items expressed as percentage heart rate reserve (\%HRR), with the HRR being the difference between the maximum heart rate and the heart rate at rest (29). The maximum heart rate was the highest heart rate recorded during the maximum wheelchair exercise test (described above), while the resting heart rate was measured after 5 minutes of rest, with the participants sitting quietly in the wheelchair. Participants who were not able to perform both the 3- and 6\% slope items, and/or the maximum wheelchair exercise test could not be assigned a physical strain score.

The content and the development of the Wheelchair Circuit have been described in detail in previous studies, and the reliability, construct validity and responsiveness of the Wheelchair Circuit have been assessed and are good $(19,28)$.

\section{Statistical analysis}

Descriptive statistics were used to describe wheelchair skill performance and parameters of physical capacity during the inpatient rehabilitation. To determine the correlations between the ability score and parameters of physical capacity at the different measurement times we calculated Spearman correlations. Pearson correlations were calculated to determine the relation between the other scores of the Wheelchair Circuit (i.e. performance time and strain) and parameters of physical capacity. These analyses were performed using the statistical package for the social sciences (SPSS, version 11.0). 
For the regression analyses multilevel models were used (MLWin version 1.10; Center for Multilevel Modeling, Institute of Education, London, UK). Multilevel analysis is suitable for the analysis of longitudinal data because 1) it considers the dependency of repeated measures within the same person; 2) it accounts for the hierarchical nature of the longitudinal data of the present study (the repeated measurements (level $1=1$ ) are nested within the persons (level $2=j$ ) and the persons are nested within rehabilitation centers (level $3=k$ )); and 3 ) in contrast to traditional methods of longitudinal data analysis (i.e. MANOVA for repeated measures), the number of observations per individual may vary $(30,31)$.

Multillevel analyses were used 1) to assess the changes of the scores of the Wheelchair Circuit and the parameters of physical capacity during inpatient rehabilitation, and 2) to estimate the relationship between manual wheelchair skill performance and parameters for physical capacity during the course of inpatient rehabilitation of persons with $\mathrm{SCI}$.

Because of the interest in the relationship between the change over time of the Wheelchair Circuit scores and the parameters of physical capacity, only participants who performed at least two measurements were taken into account in the analyses.

For the assessment of the change over time of the Wheelchair Circuit scores and the parameters of physical capacity, only time was included in the model.

Time was modeled as a categorical variable, using two dummy variables (Timedummy1 and Timedummy2) (30), with $\mathrm{T} 2$ as the reference. Consequently, the regression coefficient of Timedummy 1 indicated the effect of the time period between $\mathrm{T} 1$ and $\mathrm{T} 2$, and the regression coefficient of Timedummy 2 indicated the effect of the time period between 12 and T3. The dependent variables were successively the three scores of the Wheelchalr Circuit, and the three parameters of physical capacity.

To investigate the longitudinal relationship between wheelchair skill performance and parameters for physical capacity, the following multilevel model was built:

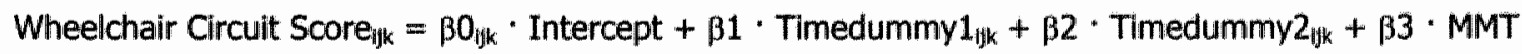
sum score ljk $+\beta 4 \cdot \mathrm{VO}_{2}$ peak $_{\mathrm{jfk}}+\beta 5 \cdot$ POpeak $_{\mathrm{jjk}}+\beta 6 \cdot$ age $_{\mathrm{jk}}+\beta 7 \cdot$ gender $_{\mathrm{jk}}+\beta 8 \cdot \mathrm{BMI}_{\mathrm{ijk}}+\beta 9 \cdot$ lesion level $\left.\right|_{j k}+\beta 10 \cdot$ completeness $_{j k}$

A separate model was built for each of the scores of the Wheelchair Circuit. All parameters were fixed, except the intercept which was allowed to vary randomly at all three levels. The parameters of physical capacity, used as independent variables in the analyses, were: MMT sum score, $\mathrm{VO}_{2}$ peak, and POpeak. A backward elimination technique was performed to filter significant relationships ( $p \leq 0.05)$. Additionally we tested whether age (years), gender (female $=0$; male $=1)$, body mass index $\left(\mathrm{kg} / \mathrm{m}^{2}\right)$, lesion level (tetraplegia $=0$; paraplegia $=1$ ), and motor completeness of the lesion (incomplete $=0$; complete $=1$ ) were confounders by adding them one by one to the model. Except for BMI, these variables were all time independent. They were considered to be a confounder when the regression coefficient of at least one of the remaining independent variables changed $10 \%$ or more when the variable was added to the model. Confounders were entered into the final model. 
The interpretation of the regression coefficients is twofold: within-subjects and between-subjects effects. The 'real' interpretation is however a combination of both (31).

For each of the three scores two different models were built: the first model included the values of $\mathrm{VO}_{2}$ peak and POpeak expressed in absolute values (i.e.: $1 / \mathrm{min}$ and Watt), and in the second model $\mathrm{VO}_{2}$ peak and POpeak were expressed relative to body mass (1.e.: $\mathrm{ml} / \mathrm{kg} / \mathrm{min}$ and Watt $/ \mathrm{kg}$ ).

\section{Results}

This study was based on 97 persons who performed the Wheelchair Circuit and physical capacity tests at least twice. The number of participants at each time of measurement is shown in table 6.1. Fiftyone persons performed all three measurements. The number of participants that missed a T1, T2 or T3 measurement were 22, 22 and 2, respectively. As stated earlier, not all participants were able to obtain the physical strain scores of the Wheelchair Circuit (Table 6.1). The mean number of days ( \pm standard deviation) between T1 and T3 was $165 \pm 81$ for all participants, for persons with paraplegia $153 \pm 69$ days, and for persons with tetraplegia this was $197 \pm 104$ days.

Table 6.1. Scores of the Wheelchair Circuit and parameters of physical capacity at $\mathrm{T} 1, \mathrm{~T} 2$ and $\mathrm{T} 3$

\begin{tabular}{|c|c|c|c|c|c|c|c|c|c|}
\hline & \multicolumn{3}{|l|}{ T1 } & \multicolumn{3}{|l|}{$\mathrm{T} 2$} & \multicolumn{3}{|l|}{ T3 } \\
\hline & $\mathbf{N}$ & Mean \pm SD & range & $\mathbf{N}$ & Mean \pm SD & range & $\mathbf{N}$ & Mean \pm SD & range \\
\hline $\begin{array}{l}\text { Ability } \\
\text { score }\end{array}$ & 75 & $6.2 \pm 11.3$ & $3-8$ & 75 & $6.9 \pm 1.2$ & $3-8$ & 95 & $7.3 \pm 1.1$ & $2-8$ \\
\hline $\begin{array}{l}\text { Performance } \\
\text { time score (s) }\end{array}$ & 75 & $27.6 \pm 13.5$ & $12-83$ & 75 & $23.2 \pm 9.9$ & $10-56$ & 95 & $19.7 \pm 6.9$ & $11-41$ \\
\hline $\begin{array}{l}\text { Physical strain } \\
\text { score (\%HRR) }\end{array}$ & 62 & $44.8 \pm 18.2$ & $14-90$ & 65 & $41.9 \pm 18.9$ & $8-95$ & 83 & $37.0 \pm 18.8$ & $8-80$ \\
\hline $\begin{array}{l}\text { MMT sum } \\
\text { score }\end{array}$ & 75 & $57.0 \pm 4.5$ & $40-60$ & 75 & $57.0 \pm 5.0$ & $36-60$ & 95 & $58.0 \pm 3.8$ & $40-60$ \\
\hline $\begin{array}{l}\mathrm{VO}_{2} \text { peak } \\
(1 / \mathrm{min})\end{array}$ & 72 & $1.07 \pm 0.38$ & $0.52-3.15$ & 75 & $1.17 \pm 0.39$ & $0.49-2.07$ & 94 & $1.27 \pm 0.44$ & $0.57-2.90$ \\
\hline $\begin{array}{l}\mathrm{VO}_{2} \text { peak } \\
(\mathrm{ml} / \mathrm{kg} / \mathrm{min})\end{array}$ & 72 & $14.9 \pm 5.2$ & $6.7-38.4$ & 75 & $16.3 \pm 5.6$ & $6.8-31.8$ & 94 & $17.2 \pm 6.0$ & $6.3-38.6$ \\
\hline $\begin{array}{l}\text { POpeak } \\
\text { (Watt) }\end{array}$ & 75 & $35.3 \pm 20.6$ & $10.6-124.1$ & 75 & $41.1 \pm 19.2$ & $10.9-81.0$ & 95 & $47.8 \pm 23.0$ & $4.6-117.5$ \\
\hline $\begin{array}{l}\text { POpeak } \\
\text { (Watt/kg) }\end{array}$ & 75 & $0.48 \pm 0.27$ & $0.16-1.51$ & 75 & $0.57 \pm 0.27$ & $0.13-1.25$ & 95 & $0.64 \pm 0.31$ & $0.05-1.47$ \\
\hline
\end{tabular}

The mean age of the participants at T1 was $38 \pm 14$ years, $75 \%$ was male, $74 \%$ had a paraplegia, and $64 \%$ had a motor complete SCI. Table 6.1 shows the scores of the Wheelchair Circuit and the values of the parameters of physical capacity at the different measurement times.

In table 6.2, the correlations are displayed between the scores of the Wheelchair Circuit and parameters of physical capacity at the three measurement times. The scores of the Wheelchair Circuit 
were moderately to strong related to the parameters of physical capacity, showing the strongest correlations between the Wheelchair Circuit scores and POpeak. The scores of the Wheelchair Circuit were moderately to strong correlated to each other.

Table 6.2. Correlations between the scores of the Wheelchair Circuit and parameters of physical capacity at $\mathrm{T} 1, \mathrm{~T} 2$, and $\mathrm{T} 3$

\begin{tabular}{|c|c|c|c|c|c|c|c|c|c|}
\hline & & & 1 & 2 & 3 & 4 & 5 & 6 & 7 \\
\hline 1 & & Ability score & - & & & & & & \\
\hline 2 & $\begin{array}{l}\mathrm{T} 1 \\
\mathrm{~T} 2 \\
\mathrm{~T} 3\end{array}$ & Performance time score & $\begin{array}{l}-0.81^{*} \\
-0.71^{*} \\
-0.79^{*}\end{array}$ & - & & & & & \\
\hline 3 & $\begin{array}{l}\mathrm{T} 1 \\
\mathrm{~T} 2 \\
\mathrm{~T} 3\end{array}$ & Physical strain score & $\begin{array}{l}-0.56^{*} \\
-0.45^{*} \\
-0.68^{*}\end{array}$ & $\begin{array}{l}0.62^{*} \\
0.65^{*} \\
0.72^{*}\end{array}$ & $=$ & & & & \\
\hline 4 & $\begin{array}{l}\mathrm{T} 1 \\
\mathrm{~T} 2 \\
\mathrm{~T} 3\end{array}$ & MMT sum score & $\begin{array}{l}0.46^{*} \\
0.50^{*} \\
0.56^{*}\end{array}$ & $\begin{array}{l}-0.45^{*} \\
-0.56 * \\
-0.60 *\end{array}$ & $\begin{array}{l}-0.38^{*} \\
-0.40^{*} \\
-0.55^{*}\end{array}$ & - & & & \\
\hline 5 & $\begin{array}{l}\text { T1 } \\
\text { T2 } \\
\text { T3 }\end{array}$ & $\mathrm{VO}_{2}$ peak $(1 / \mathrm{min})$ & $\begin{array}{l}0.44^{*} \\
0.47^{*} \\
0.66^{*}\end{array}$ & $\begin{array}{l}-0.33^{*} \\
-0.42^{*} \\
-0.57^{*}\end{array}$ & $\begin{array}{l}-0.51^{*} \\
-0.63^{*} \\
-0.61^{*}\end{array}$ & $\begin{array}{l}0.26 \\
0.28 \\
0.32 *\end{array}$ & - & & \\
\hline 6 & $\begin{array}{l}\text { T1 } \\
\text { T2 } \\
\text { T3 }\end{array}$ & $\mathrm{VO}_{2}$ peak (ml $\left./ \mathrm{kg} / \mathrm{min}\right)$ & $\begin{array}{l}0.54^{*} \\
0.56^{*} \\
0.68^{*}\end{array}$ & $\begin{array}{l}-0.35^{*} \\
-0.54^{*} \\
-0.63^{*}\end{array}$ & $\begin{array}{l}-0.50^{*} \\
-0.71 * \\
-0.64 *\end{array}$ & $\begin{array}{l}0.18 \\
0.32^{*} \\
0.37 *\end{array}$ & $\begin{array}{l}0.84^{*} \\
0.83^{*} \\
0.85 *\end{array}$ & - & \\
\hline 7 & $\begin{array}{l}\mathrm{T} 1 \\
\mathrm{~T} 2 \\
\mathrm{~T} 3\end{array}$ & POpeak (Watt) & $\begin{array}{l}0.68 * \\
0.66^{*} \\
0.75^{*}\end{array}$ & $\begin{array}{l}-0.60 * \\
-0.71^{*} \\
-0.74 *\end{array}$ & $\begin{array}{l}-0.72^{*} \\
-0.75^{*} \\
-0.76^{*}\end{array}$ & $\begin{array}{l}0.51^{*} \\
0.54^{*} \\
0.52^{*}\end{array}$ & $\begin{array}{l}0.75 * \\
0.80^{*} \\
0.82^{*}\end{array}$ & $\begin{array}{l}0.56 * \\
0.69 * \\
0.69 *\end{array}$ & 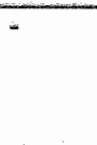 \\
\hline 8 & $\begin{array}{l}\text { T1 } \\
\text { T2 } \\
\text { T3 }\end{array}$ & POpeak (Watt/kg) & $\begin{array}{l}0.77^{*} \\
0.71^{*} \\
0.79^{*}\end{array}$ & $\begin{array}{l}-0.64^{*} \\
-0.77^{*} \\
-0.78^{*}\end{array}$ & $\begin{array}{l}-0.70^{*} \\
-0.81 * \\
-0.81 *\end{array}$ & $\begin{array}{l}0.51^{*} \\
0.55^{*} \\
0.55^{*}\end{array}$ & $\begin{array}{l}0.68^{*} \\
0.70^{*} \\
0.72^{*}\end{array}$ & $\begin{array}{l}0.68 * \\
0.83^{*} \\
0.81 *\end{array}$ & $\begin{array}{l}0.93^{*} \\
0.91^{*} \\
0.91^{*}\end{array}$ \\
\hline
\end{tabular}

${ }^{*} p \leq 0.01$

The univariate multilevel analysis of the Wheelchair Circuit showed that all scores significantly improved between $\mathrm{T} 1$ and $\mathrm{T} 2$ and between $\mathrm{T} 2$ and $\mathrm{T} 3$. The estimated ability score improvement ( \pm standard error) between $T 1$ and $T 2$ was $0.92 \pm 0.13(p<0.001)$, and $0.29 \pm 0.12(p=0.013)$ between T2 and T3. Estimated performance time improvements were $-5.69 \pm 0.96 \mathrm{~s}(\mathrm{p}<0.001)$ between T1 and $T 2$, and $-2.70 \pm 0.88 \mathrm{~s}(\mathrm{p}=0.002)$ between $\mathrm{T} 2$ and T3. Estimated physical strain improvement was $-6.8 \pm 2.0 \%(p=0.001)$ between $T 1$ and $T 2$ and $-5.7 \pm 1.8 \%(p=0.001)$ between T2 and T3. The parameters of physical capacity also improved significantly between $T 1$ and $T 2$ and between $T 2$ and $\mathrm{T} 3$, except for the $\mathrm{VO}_{2}$ peak relative to body mass, which did not improve between $\mathrm{T} 2$ and $\mathrm{T} 3$. Estimated improvements for POpeak were $9.7 \pm 1.3 \mathrm{~W}$ and $4.7 \pm 1.2 \mathrm{~W}$, for $\mathrm{T} 1-\mathrm{T} 2$ and $\mathrm{T} 2-\mathrm{T} 3$ respectively $(p<0.001)$. For the maximal oxygen uptake improvements were $0.16 \pm 0.041 / \mathrm{min}$ for $\mathrm{T} 1$ $-T 2(p<0.001)$, and $0.07 \pm 0.03 \mathrm{l} / \mathrm{min}$ for $\mathrm{T} 2-\mathrm{T} 3(\mathrm{p}=0.046)$. The MMT sum score improved $0.83 \pm$ 0.35 for $T 1-T 2(p=0.018)$, and $0.78 \pm 0.32$ for $T 2-T 3(p=0.014)$. In all scores the hierarchical level 
'rehabilitation center' did not contribute to the explanation of variance, indicating that there was no significant effect of rehabilitation center.

Table 6.3 shows the results of the multivariate multilevel analyses to estimate the longitudinal relationship between manual wheelchair skill performance and parameters for physical capacity (expressed as absolute values). The analysis using physical capacity parameters expressed relative to body mass, revealed the same results.

Table 6.3. Results of the multilevel analyses to asses the longitudinal relationship between the scores of the Wheelchair Circuit and parameters of physical capacity (regression coefficient and $95 \%$ confidence interval)

\begin{tabular}{|l|l|l|l|}
\hline & $\begin{array}{l}\text { Ability Score } \\
(\mathbf{n = 9 7 )}\end{array}$ & $\begin{array}{l}\text { Performance Time Score } \\
(\mathbf{n = 9 5 )}\end{array}$ & $\begin{array}{l}\text { Physical Strain Score } \\
(\mathbf{n = 8 1})^{*}\end{array}$ \\
\hline MMT sum score & $0.08(0.05-0.11)$ & $-0.58(-0.84--0.32)$ & Excluded \\
\hline VO 2 peak (l/min) & Excluded & Excluded & Excluded \\
\hline POpeak (Watt) & $0.03(0.02-0.03)$ & $-0.21(-0.27--0.15)$ & $-0.55(-0.66--0.44)$ \\
\hline
\end{tabular}

*model corrected for lesion levell (paraplegia vs tetraplegia)

Excluded: varlable was removed from the model after the backward elimination procedure.

Ability Score. The MMT sum score was significantly related to the ability score. The betweensubjects interpretation indicates that persons with higher MMT sum scores had higher ability scores than persons with lower MMT sum scores, and the within-subject interpretation shows that when the MMT sum score of a person improves, his/her ability score will improve also. POpeak was also significantly related to the ability score. Participants with higher POpeak values had higher ability scores than participants with lower POpeak values, and when the POpeak of a person increased, the ability score increased. The variable $\mathrm{VO}_{2}$ peak was removed from the statistical model. In conjunction with POpeak and MMT sum score it was not significantly related to the ability score. Analysis with POpeak and $\mathrm{VO}_{2}$ peak relative to body mass revealed the same results, except that lesion level was included as a confounder in this model. None of the other confounders were included in the model (Table 6.3; confounders are not shown).

Performance Time Score. Participants with high MMT sum scores performed the Wheelchair Circuit significantly faster than participants with low MMT sum scores and when the MMT sum score of a person increased, his/her performance time score decreased. The inverse relationship between POpeak and the performance time score shows that participants with higher POpeak values performed the Wheelchair Circuit significantly faster than participants with lower values of POpeak, and that an increase in POpeak, resulted in a decrease of the performance time score. Again $\mathrm{VO}_{2}$ peak was removed from the model. None of the postulated confounders were entered in the model.

Physical Strain Score. Again $\mathrm{VO}_{2}$ peak was not a significant independent variable. The physical strain score was inversely related to POpeak. Persons with a higher POpeak value experienced significantly less strain during the performance of the slope tasks than persons with lower POpeak values. When the POpeak of a participant increased, his/her physical strain score decreased. The MMT sum score was not significantly related to the physical strain score and was removed from the model. 
Lesion level was a confounder for POpeak (i.e. the POpeak regression coefficient increased when lesion level was added) and was included in the final model.

\section{Discussion}

In the present study multilevel analyses were used to examine the longitudinal relationship over time between wheelchair skill performance and physical capacity during inpatient rehabilitation in persons with SCI. It was shown that upper extremity muscle force and peak power output are important parameters for the course of wheelchair skill performance during inpatient rehabilitation. Learning wheelchair skills and improving physical capacity are important goals during the rehabilitation of persons with $\mathrm{SCI}$. Most studies that did investigate wheelchair skills only included participants that were already discharged from inpatient rehabilitation $(5,7,8,32,33)$. Only a few studies have examined changes in wheelchair skill performance during rehabilitation $(6,10)$. Most studies included small numbers of participants whereas in the present study 97 persons were included.

A significant relation between upper extremity strength and ability score, and performance time score was found. We could not demonstrate an association between upper extremity strength and the physical strain score. Our results are in agreement with the results of Noreau et al.(11) who found an association between upper extremity muscle strength and functional independence in persons with longstanding SCI. Dallmeijer et al. (6) showed that during inpatient rehabilitation both upper extremity strength and wheelchair skill performance improved, but did not study the relation between these variables.

The participants that were induded in the analyses concerning the physical strain score represent a positive selection of the population, because they had to be able to perform both slope tasks. The fact that we could not demonstrate a longitudinal relationship between upper extremity strength and the physical strain score was probably because most of the persons in this subgroup already had good upper extremity strength at $\mathrm{T} 1$, which is required for the performance of the tasks of the Wheelchair Circuit. Noreau et al. (11) also came across this phenomenon when they showed a strong relationship between muscle strength and functional independence in persons with tetraplegia, but found only a weak relationship in persons with paraplegia.

POpeak was significantly related to all the scores of the Wheelchair Circuit. This result is in accordance with other studies that also found strong associations between wheelchair skill performance and power output (5, 7-9). Dallmeijer et al. (6) and Morrison et al. (10) showed that during inpatient rehabilitation both POpeak and wheelchair skill performance improved, they did however not study the relation between these variables.

In our multilevel analyses, $\mathrm{VO}_{2}$ peak was excluded from all the final models (both relative to body mass and absolute) for any of the three scores of the Wheelchair Circuit, despite substantial bivariate correlations between these measures. However $\mathrm{VO}_{2}$ peak and POpeak are strongly intercorrelated in this study as well as in the literature (34). In terms of the International Classification of Functioning, Disability and Health (ICF) (35) ${ }_{n} \mathrm{VO}_{2}$ peak is a general fitness measure at the level of body function while POpeak in hand rim wheelchair exercise is much more a functional measure of wheelchair propulsion capacity at the activity level and is determined not only by mere oxygen uptake but also by 
gross mechanical efficiency and anaerobic power production (36). Like POpealk, the Wheelchair Circuit is also a functional measure at the activity level. From this it can be expected that POpeak is stronger related to the scores of the Wheelchair Circuit than $\mathrm{VO}_{2}$ peak, which is indeed confirmed by the figures in table 6.2. This might explain why the association between the scores of the Wheelchair Circuit and $\mathrm{VO}_{2}$ peak is overruled when both $\mathrm{VO}_{2}$ peak and POpeak are entered into the same multiple regression model.

From this study we can conclude that POpeak and upper extremity muscle strength are the parameters of physical capacity that influence wheelchair skill performance during inpatient rehabilitation of persons with SCI.

From the literature we know that both strength training of the upper extremity muscles and wheelchair exercise training have a positive effect on POpeak and upper extremity muscle strength (34, 37-40). To optimize manual wheelchair skill performance during inpatient rehabilitation, attention should be directed towards manual wheelchair exercise training and strength training of the upper body muscle groups. Guidelines for form, intensity, frequency and duration of training must be developed in future research.

\section{Study limitations}

To be included into the present study, participants had to meet several inclusion criteria: age between 18 and 65 years; wheelchair dependent; no progressive disease or psychiatric problem; no cardiovascular problems; and no serious musculoskeletal complaints of the upper extremities, neck or back. Participants that for whatever reason performed the Wheelchair Circuit or physical capacity tests only once were not included in the present study. Because of these criteria, our participants are a positive selection of the complete population of persons with an acute SCI who are admitted to a rehabilitation center, which might limit the generalization of the results.

At all measurement times, all participants that performed the Wheelchair Circuit did have an ability score, but, as described earlier, not all participants were able to attain a physical strain score. Further, a few persons who were able to perform the slope tasks were not able to perform the maximum exercise test. For this reason the physical strain results concern a further positive selection of the research population, consisting of persons with a relatively good wheelchair skill performance. We did not use imputation to replace missing values because that is not necessary when multilevel analyses are used (41).

The length of the inpatient rehabilitation period varied considerably among participants. The T3 measurement is performed at the time of discharge from the rehabilitation center. However, in some cases the time of discharge is delayed for reasons that do not concern the functional status of the patient, for instance when the necessary adaptations to their house are not completed yet, or when persons have to wait for placement in a nursing home. During the period between the moment that persons are functionally ready to be discharged and the moment that they actually leave the rehabilitation center, therapies are continued at a lower frequency. In these persons the T3 measurement may not reflect the maximum achieved capability. We do however not know how often this situation occurs and whether the wheelchair skill performance at the T3 measurement is affected by this situation. 


\section{Conclusions}

The present study shows that upper extremity muscle force and peak power output are important parameters for wheelchair skill performance during inpatient rehabilitation. To optimize wheelchair skill performance during the inpatient rehabilitation of persons with $\mathrm{SCI}$, attention should be directed towards manual wheelchair exercise training and strength training of the upper body muscle groups 


\section{References}

1. Post MWM, Asbeck van FWA, Dijk van AJ, Schrijvers AJ. Services for spinal cord injured: Availability and satisfaction. Spinal Cord 1997;35(2):109-15.

2. Pierce $L$. Barriers to access: Frustrations of people who use a wheelchair for full-time mobility. Rehabil Nurs 1998;23(3):120-5.

3. Britell CW. Wheelchair prescription. In: Lehmann JF, Kottke FJ, editors. Krusen's Handbook of Physical Medicine and Rehabilitation. 4 ed. Philadelphia: W.B. Company Saunders; 1990. p. 548-63.

4. Somers M. Spinal cord injury, functional rehabilitation. Connecticut: Appleton \& Lange; 1992.

5. Dallmeijer AJ, Woude van der LHV, Hollander AP, Angenot EL. Physical performance in persons with spinal cord injuries after discharge from rehabilitation. Med Sci Sports Exerc 1999;31(8);:1111-7.

6. Dallmeijer AJ, Woude van der LHV, Hollander AP, As van HH. Physical performance during rehabilitation in persons with spinal cord injuries. Med Sci Sports Exerc 1999;31(9):1330-5.

7. Duran FS, Lugo L, Ramirez L, Lic EE. Effects of an exercise program on the rehabilitation of patients with spinal cord injury. Arch Phys Med Rehabil 2001;82(10):1349-54.

8. Janssen TWJ, Oers van CAM, Veeger HE, Hollander AP, Woude van der LHV, Rozendal RH. Relationship between physical strain during standardised ADL tasks and physical capacity in men with spinal cord injuries. Paraplegia 1994;32(12):844-59.

9. Sawka MN, Glaser RM, Laubach LL, Al-Samkari O, Suryaprasad AG. Wheelchair exercise performance of the young, middle-aged, and elderly. J Appl Physiol 1981;50(4):824-8.

10. Morrison SA, Melton-Rogers SL, Hooker SP. Changes in physical capacity and physical strain in persons with acute spinal cord injury. Topics Spinal Cord Inj Rehabil 1997;3(1):1-15.

11. Noreau L. Relationship of impairment and functional ability to habitual activity and fitness following spinal cord injury. Int J Rehabil Res 1993;16(4):265-75.

12. Huang $C T$, McEachran AB, Kuhlemeier KV, DeVivo MJ, Fine PR. Prescriptive arm ergometry to optimize muscular endurance in acutely injured paraplegic patients. Arch Phys Med Rehabil 1983;64(12):578-82.

13. Hjeltnes N. Cardiorespiratory capacity in tetra- and paraplegia shortly after injury. Scand J Rehabil Med 1986;18(2):65-70.

14. Ellenberg M, MacRitchie M, Franklin B, Johnson S, Wrisley D. Aerobic capacity in early paraplegia: Implications for rehabilitation. Paraplegia 1989;27(4):261-8.

15. Noreau L, Shephard RJ. Spinal cord injury, exercise and quality of life. Sports Med 1995;20(4):226-50.

16. Capodaglio $P$, Grilli $C$, Bazzini $G$. Tolerable exercise intensity in the early rehabilitation of paraplegic patients. A preliminary study. Spinal Cord 1996;34(11):684-90.

17. MacPhee AH, Kirby RL, Coolen AL, Smith C, MacLeod DA, Dupuis DJ. Wheelchair skills training program: A randomized clinical trial of wheelchair users undergoing initial rehabilitation. Arch Phys Med Rehabil 2004;85(1):41-50.

18. Kirby RL, Swuste J, Dupuis DJ, MacLeod DA, Monroe R. The Wheelchair Skills Test: A pilot study of a new outcome measure. Arch Phys Med Rehabil 2002;83(1):10-8. 
19. Kilkens OJE, Dallmeijer $A J$, Wilte de $L P$, Woude van der $L H V_{r}$, Post MWM. The Wheelchair Circuit: Construct validity and responsiveness of a test to assess manual wheelchair mobility in persons with spinal cord injury. Arch Phys Med Rehabil 2004;85(3):424-31.

20. Kilkens OJE, Dallmeijer AJ, Angenot ELD, Twisk JWR, Post MWM, Woude van der LHV. Personal characteristics and injury related factors influencing the course of manual wheelchair skill performance during initial inpatient rehabilitation of persons with a spinal cord injury. Arch Phys Med Rehabil accepted for publication.

21. American Spinal Injury Association (ASIA): Reference manual for the international standards for neurological classification of spinal cord injury. Marino RJ, Ed. Chicago: American Spinal Injury Association, 2000.

22. American College of Sports Medicine. ACSM's guidelines for exercise testing and prescription. 6th ed. Philadelphia: Lippincott Willams \& Wilkins; 2000.

23. Maynard FM, Jr., Bracken MB, Creasey G, Ditunno JF, Jr, Donovan WH, Ducker TB, et al. International standards for neurological and functional classification of spinal cord injury. American Spinal Injury Association. Spinal Cord 1997;35(5):266-74.

24. Mulroy SJ, Gronley JK, Newsam CJ, Perry J. Electromyographic activity of shoulder muscles during wheelchair propulsion by paraplegic persons. Arch Phys Med Rehabil 1996;77(2):18793.

25. Schantz $P$, Bjorkman $P$, Sandberg $M$, Andersson E. Movement and muscie activity pattern in wheelchair ambulation by persons with para-and tetraplegia. Scand J Rehabil Med 1999;31(2):67-76.

26. Kendall HO, Kendall FP, Wadsworth GE. Muscles, Testing and Function. 4th ed: Lippincott Williams and Wilkins; 1971.

27. Woude van der LHV, Groot de G, Hollander AP, Ingen Schenau van GJ, Rozendal RH. Wheelchair ergonomics and physiological testing of prototypes. Ergonomics 1986;29(12):1561-73.

28. Kilkens OJE, Post MWM, Woude van der LHV, Dallmeijer AJ, Heuvel van den WJA. The Wheelchair Circuit: Reliability of a test to assess mobility in persons with spinal cord injuries. Arch Phys Med Rehabil 2002;83(12):1783-8.

29. Karvonen M, Kentala E, Mustala $O$. The effects of training on heart rate. A longitudinal study. Annals of Medicine and Experimental Blology Fenn 1957(35):307-15.

30. Goldstein H. Multilevel statistical models. New York: John Wiley \& Sons; 1995.

31. Twisk JWR. Applied longitudinal data analysis for epidemiology, A practical guide. Amsterdam: Cambridge University Press; 2003.

32. Taricco M, Colombo C, Adone R, Chiesa G, Di Carlo S, Borsani M, et al. The social and vocational outcome of spinal cord injury patients. Paraplegia 1992;30(3):214-9.

33. Janssen TWJ, Oers van CAJM, Rozendaal EP, Willemsen EM, Woude van der LHV, Hollander AP. Changes in physical capacity and physical strain during ADL in men with spinal cord injuries. Med Sci Sports Exerc 1994;28(5):551-9.

34. Janssen TWJ, Oers van CAJM, Hollander AP, Veeger HE, Woude van der LHV. Isometric strength, sprint power, and aerobic power in individuals with a spinal cord injury. Med Sci Sports Exerc 1993;25(7):863-70.

35. World Health Organisation. International Classification of Functioning, Disability and Health. ICIDH-2 final draft, Geneva: WHO 2001. 
36. Woude van der LHV, Bakker WH, Elkhuizen JW, Veeger HE, Gwinn T. Propulsion technique and anaerobic work capacity in elite wheelchair athletes: Cross-sectional analysis. Am J Phys Med Rehabil 1998;77(3):222-34.

37. Cooney MM, Walker JB. Hydraulic resistance exercise benefits cardiovascular fitness of spinal cord injured: Med Sci Sports Exerc 1986;18(5):522-5.

38. Falkel JE, Sawka MN, Levine L, Pimental NA, Pandolf KB. Upper-body exercise performance: Comparison between women and men. Ergonomics 1986;29(1):145-54.

39. Sawka MN, Foley ME, Pimental NA, Pandolf KB. Physiological factors affecting upper body aerobic exercise. Ergonomics 1983;26(7):639-46.

40. Kofsky PR, Shephard R, Davis GM, Jackson RW. Muscle strength and aerobic power - a study of lower-limb disabled males. Int Rehabil Med 1985;7(4):151-5.

41. Twisk J, Vente de W. Attrition in longitudinal studies. How to deal with missing data. $\mathrm{J}$ Clin Epidemiol 2002;55(4):329-37. 
The relation between manual wheelchair skill performance and participation of persons with spinal cord injuries one year after discharge from inpatient rehabilitation 


\section{Summary}

Objective: To describe the level of manual wheelchair skill performance and participation in persons with spinal cord injuries (SCI), one year after discharge from inpatient rehabilitation, and to test the hypothesis that wheelchair skill performance is positively related to participation.

Design: Cross sectional.

Setting: Eight rehabilitation centers in the Netherlands.

Patients: eighty-one persons with SCI.

Main outcome measures: The Wheelchair Circuit consists of eight wheelchair skills, and results in three test scores: ability, performance time and physical strain. Participation was assessed with the social dimension of the Sickness Impact Profile 68 (SIPSOC).

Results: SIPSOC was moderately related to the ability score $\left(r_{\text {spearman }}:-0.49\right)$, the performance time score $\left(r_{\text {spearman }}: 0.54\right)$, and the physical strain score $\left(r_{\text {spearman }}: 0.38\right)$. The regression analyses showed that, controlling for lesion- and personal characteristics, manual wheelchair skill performance was positively related to participation, with the strongest association for the performance time score.

Conclusions: In persons with SCI who are manual wheelchair users, wheelchair skill performance is moderately associated to participation. Training of wheelchair skills has to be an important goal of rehabilitation, and persons should be stimulated to maintain their wheelchair skills after discharge from rehabilitation. 


\section{Introduction}

Many persons with a spinal cord injury (SCI) use a wheelchair for mobility in daily life. In the Netherlands approximately $82 \%$ of individuals with $\mathrm{SCI}$ who are admitted for inpatient rehabilitation are wheelchair users, and $60 \%$ are completely dependent on a wheelchair for their mobility (1). To function independently, manual wheelchair users must posses certain wheelchair skills, l.e. the ability to use a wheelchair in different ways and circumstances, such as moving forward, backward, turning around and negotiating a curb to deal with the physical barriers they will inevitably encounter in various environments (2). Mastering wheelchair skills can make the difference between dependence and independence in daily life $(3,4)$ and wheelchair skill training is therefore a vital part of the rehabilitation process. Kilkens et al. (5), and MacPhee et al. (6) showed that during the primary inpatient rehabilitation of persons with SCI, wheelchair skill performance improved significantly. When persons with acute $\mathrm{SCI}$ are discharged from inpatient rehabilitation, indeed most of them are capable of propelling their wheelchair, and performing various wheelchair skills, such as making transfers and negotiating curbs (5).

Participation is also an Important rehabilitation outcome for persons with SCI. In the International Classification of Functioning, Disability and Health (ICF)(7), participation is defined as 'involvement in life situations" including, for example, work and school, housekeeping, social relationships and community organizations. Participation restrictions are the problems that an individual may have in involvement in life situations (7). Activity limitations are defined in the ICF as difficulties that an individual may have in execution of a task, like washing the upper body, walking or using a wheelchair (7). From the literature we know that persons with activity limitations experience participation restrictions in daily life (8-12). The relationships between the severity of the $\mathrm{SCI}$, activity limitations and participation are however unclear. In some studies an inverse relation between the severity of the injury and participation was found $(13,14)$, while other studies could not demonstrate an association between these variables $(9,15,16)$.

As stated earlier, wheelchair skill performance plays an important role in the independent performance of activities of daily life. It can be expected that there is a positive relationship between manual wheelchair skill performance and participation in persons with SCI, this has however never been studied.

The aims of the present study are 1) to describe the level of manual wheelchair skill performance and

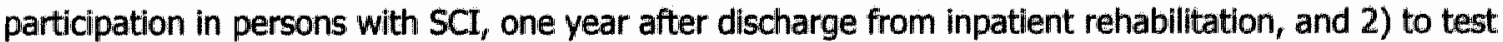
the hypothesis of a positive relationship between manual wheelchair skill performance and participation.

\section{Methods}

\section{Participants and procedure}

The present cross-sectional study was part of the Dutch research program 'Physical Strain, Work Capacity, and Mechanisms of Restoration of Mobility in the Rehabilitation of Persons with Spinal Cord Injuries'(17). For this study, persons with SCI were measured one year after discharge from inpatient rehabilitation. Eight Dutch rehabilitation centers specialized in the rehabilitation of persons with SCI 
participated in this research program. Eight trained research assistants conducted the measurements, according to a standardized protocol.

Persons were eligible to enter the program if they had an acute SCI, were between 18 and 65 years of age, were classified as A, B, C or D on the American Spinal Injury Association (ASIA) impairment scale (18), were manual wheelchair-user, did not have a progressive disease or psychiatric problem, and had enough knowledge of the Dutch language to understand the goal of the study and the testing methods. Participants were not allowed to perform the Wheelchair Circuit if they had 1) cardiovascular disorders (the absolute contra-indications as they are stated by the ACSM 2000 guidelines (19), or a resting diastolic blood pressure $>90 \mathrm{~mm} \mathrm{Hg}$ or a resting systolic blood pressure $>180 \mathrm{~mm} \mathrm{Hg}$ ), and/or 2) severe musculoskeletal complaints of the upper extremities, neck or back. After inclusion in the cohort, participants were examined by their rehabilitation physician to check for any of these contraindications.

Participants were tested in the rehabilitation centers in which they had been inpatients.

All participants completed a consent form after they had been given information about the testing procedures. All tests and protocols were approved by the Medical Ethics Committee of the Institute for Rehabilitation Research, Hoensbroek, the Netherlands.

\section{Demographic characteristics}

From the literature it is known that participation in persons with $S C I$ is related to age $(13,14,20)$, gender $(20,21)$, and educational level $(13,14,20,22)$. Therefore age at the time of the measurement, gender, and educational levell were assessed and included as covariates in the statistical analyses. Educational level was coded into three categories: low (i.e. primary school, lower vocational education or lower secondary education), medium (i.e. upper secondary education or intermediate vocational education), and high (i.e. upper vocational education or university).

\section{Lesion characteristics}

The lesion characteristics were assessed by a physician according to the International Standards for Neurological Classification of Spinal Cord Injury (23). The ASIA classifications A and B were defined as motor complete and classes $C$ and $D$ as motor incomplete. Neurological lesion levels below $T 1$ were defined as paraplegia, while lesion levels at or above T1 were defined as tetraplegia.

\section{Participation}

Participation was measured with the 68-item version of the Sickness Impact Profile (SIP68). The SIP68 measures health-related functional status by assessing the impact of disease or disability on behavioral limitations (24). The SIP68 was chosen because it is a reliable and valid measure for use in $\mathrm{SCI}(24,25)$ and its measurement concept compares closely to the ICF (7). The questionnaire consists of six subscales. According to the ICF model, four subscales measure activity limitations (i.e. Somatic Autonomy; Mobility Control; Emotional Stability; and Psychological Autonomy \& Communication) and 
two subscales measure participation (Mobility Range and Social Behavior). Following Post et al, we will use the sum score of the Mobility Range and Social Behavior subscales, SIPSOC, as a measure of participation $(14,23)$. The items of SIPSOC are displayed in table 7.2. Most items concern the domains of domestic life and interpersonal interactions and relationships, and parts of the major life areas domain and the community, social and civic life domain.

\section{The Wheelchair Circuit}

The Wheelchair Circuit $(26,27)$ is a test to assess wheelchair skill performance. It was developed and validated for this study because at the start of the study (1999) no well-described and validated wheelchair skills tests were available (26). The Wheelchair Circuit consists of eight different standardized tasks that are performed in a fixed sequence, on a hard and smooth floor surface and on a motor driven treadmill (Treadmill Giant, Bonte BV, Zwolle, The Netherlands). All participants used a standard test wheelchair, which was available in two seat widths: $0.42 \mathrm{~m}$ and $0.46 \mathrm{~m}$ (Sopur Starlight 622, Sunrise Medical GmbH, Malsch/Heidelberg, Germany).

The eight tasks are: figure-of-8 shape; crossing a doorstep (height, $0.04 \mathrm{~m}$ ); mounting a platform (height, $0.10 \mathrm{~m}$ ); $15 \mathrm{~m}$ sprint; $3 \%$ slope; $6 \%$ slope; 3 minute wheelchair propulsion; and transfer. For the slope tests, participants are asked to drive at the given slope for 10 seconds. The total time needed for the $3 \%$ and $6 \%$ slopes is about 45 seconds and 65 seconds respectively. During the performance of the circuit, the ability to perform the test items, the performance time of the figure-of8 shape and the $15 \mathrm{~m}$ sprint, and the peak heart rates during the $3 \%$ and $6 \%$ slope items on the treadmill were recordled. The heart rate (beats/min) was registered with a Polar sport tester at a 5 second storage interval (Polar Vantage NV, Polar Electro Oy, Kempele, Finland). The performance of the Wheelchair Circult leads to three different test scores: ability score, performance time score, and physical strain score.

Ability score: all test items that are performed adequately and independently are assigned one point. Three items (crossing a doorstep, mounting a platform, and transfer) can also be scored partially able and can be given half a point. All points are summed to give an overall ability score. The ability score ranges from $0-8$.

Performance time score: the sum of the performance times of the figure-of-eight shape and the $15 \mathrm{~m}$ sprint. Participants who were not able to perform both the figure-of-eight shape and the $15 \mathrm{~m}$ sprint could not be assigned a performance time score.

Physical strain score: the mean of the peak heart rates reached during each of the two slope items expressed as percentage heart rate reserve (\%HRR), with the HRR being the difference between the maximum heart rate and the heart rate at rest (28). The maximum heart rate was assessed during a maximum wheelchair exercise test, while the resting heart rate was measured after 5 minutes of rest. The protocol of the maximum wheelchair exercise test has been previously described in detail (27). The physical strain score indicates how easily a certain activity of daily life is accomplished, and is thereby a measure of skill (28). Participants who were not able to perform both the 3- and $6 \%$ slope items and/or the maximum wheelchair exercise test could not be assigned a physical strain score. The content and the development of the Wheelchair Circuit have been described in detail in previous studies $(26,27)$. Mean intrarater and interrater reliability Intra Class Correlations ranged from 0.81 up 
to $0.92(26)$. Construct validity was demonstrated by strong relationships with measures of functional status, physical capacity and lesion characteristics (27).

\section{Statistical analysis}

Analyses were performed using SPSS (version 11.0). Descriptive statistics were used to describe wheelchair skill performance and participation one year after discharge from inpatient rehabilitation. Since most measures were of ordinal level or showed a non-normal distribution, non-parametric techniques were used to examine bivariate relationships between the variables used in this study: Kendall's tau for associations between dichotomous variables and between dichotomous and ordinal variables, and Spearman correlations for the associations between ordinal variables.

To examine the proposed positive association between wheelchair skills and participation, hierarchical regression analyses were applied. For each score of the Wheelchair Circuit, a three-step analysis was performed using the following variables: age, gender, and educational level (step 1), lesion level and motor completeness (step 2) and the Wheelchair Circuit score (step 3). A fourth and final regression model used all three scores of the Wheelchair Circuit together in step 3. These regression analyses reveal for each predictor a standardized regression coefficient Beta, indicating the strength of the relationship of the predictor variable with the dependent variable corrected for the influence of other predictor variables, and for each step the amount of variance that is explained by all variables together. The expected increase of total explained variance at each following step was tested for statistical significance.

\section{Results}

Elghty-one participants filled in the SIP68 and performed the Wheelchair Circuit one year after discharge from inpatient rehabilitation. Their mean age was $39.3 \pm 13.9$ years (range $20-67$ years) and $56(69 \%)$ were men. There were $56(69 \%)$ persons with paraplegla including 17 persons with a motor incomplete lesion, and $25(31 \%)$ persons with tetraplegia including 13 persons with a motor incomplete lesion. Educational level was low for 26 persons (32\%), medium for 36 persons (44\%), high for 16 persons (20\%), and unknown for 3 persons ( $4 \%$ ).

Not all participants were able to obtain all three the scores of the Wheelchair Circuit. All 81 participants had an ability score, 76 had a performance time score but only 49 had a physical strain score. Participants who were able to obtain the physical strain score were younger ( 36.6 against 43.3 years; $p=0.034)$, had more often paraplegia $(85.7 \%$ against $43.8 \% ; p<0.001)$, had better median ability scores ( 8 versus $5 ; p<0.001$ ), better median performance time scores ( 16 versus $29 ; p<$ 0.001 ) and better median SIPSOC scores ( 5 versus $7 ; p=0.005$ ) than persons without a strain score. Table 7.1 shows the scores on SIPSOC and the Wheelchair Circuit. The distribution of the ability score was strongly skewed, with a median score of 7.5 on a scale range of $0-8$. This means that most people had a high level of wheelchair skills. SIPSOC showed that most participants suffered from participation restrictions. Only 10 participants $(12.3 \%)$ reported no restrictions at all (SIPSOC $=0$ ). 
In table 7.2 the proportion of participants reporting certain participation restrictions is displayed. More than two-thirds of the participants were doing less work in and around their house, and were less sexually active due to the $\mathrm{SCI}$. Visiting other people, going out of the house and taking care of personal and financial business were least often affected by the SCI.

Table 7.1 Distribution of scores on the Wheelchair Circuit and of participation (SIPSOC)

\begin{tabular}{|l|l|l|l|l|l|l|}
\hline & N & Range & Mean & SD & Median & IQR \\
\hline SIPSOC score & 81 & $0-18$ & 6.0 & 4.2 & 5.0 & $3.0-9.0$ \\
\hline Ability score & 81 & $0-8$ & 6.3 & 2.4 & 7.5 & $5.0-8.0$ \\
\hline Performance time score (s) & 76 & $11-57$ & 21.4 & 10.4 & 17 & $14.0-25.0$ \\
\hline Physical strain score (\%HRR) & 49 & $5.5-72.0$ & 33.5 & 16.2 & 28.9 & $21.5-44.0$ \\
\hline
\end{tabular}

IQR = Inter Quartile Range ; SIPSOC = Social dimension of the SIP68

Table 7.2 Item scores of SIPSOC: proportion of persons with SCI suffering from certain participation problems $(\mathrm{N}=80)$

\begin{tabular}{|l|l|}
\hline SIPSOC item * & $\%$ 'Applies to me' \\
\hline I am not going out to visit people at all & 2.5 \\
\hline I am getting around only within one building & 6.3 \\
\hline $\begin{array}{l}\text { I have given up taking care of personal or household business affairs, for example, } \\
\text { paying bills, banking, working on budget }\end{array}$ & 7.5 \\
\hline I am not going into town & 11.3 \\
\hline I stay away from home only for brief periods of time & 11.3 \\
\hline $\begin{array}{l}\text { I am cutting down on some of my usual inactive recreation and pastime, for example, } \\
\text { watching TV, playing cards, reading }\end{array}$ & 11.3 \\
\hline I do not get around in the dark or in unlit places without someone's help & 13.8 \\
\hline I am cutting down the length of visits with friends & 18.8 \\
\hline I am doing fewer social activities with groups of people & 18.8 \\
\hline I do my hobbies and recreation for shorter periods of time & 22.5 \\
\hline I am drinking less fluids & 22.5 \\
\hline I stay at home most of the time & 23.8 \\
\hline I am doing fewer community activities & 26.3 \\
\hline I am not doing any of the regular work around the house that I would usually do & 28.8 \\
\hline I am not doing any of the shopping that I would usually do & 30.0 \\
\hline I am not doing any of the clothes washing that I would usually do & 32.5 \\
\hline I am not doing any of the housecleaning that I would usually do & 33.8 \\
\hline I am going out for entertainments less often & 33.8 \\
\hline I am eating much less than usual & 33.8 \\
\hline I am doing less of the regular daily work around the house than I would usually do & 60.0 \\
\hline My sexual activity is decreased & 61.3 \\
\hline I am not doing heavy work around the house & 71.3 \\
\hline
\end{tabular}

* Items in order of ascending values 
In table 7.3, the bivariate correlations between demographic characteristics, lesion characteristics, scores of the Wheelchair Circuit, and participation are displayed.

The SIPSOC score was moderately related to all three Wheelchair Circuit scores. Persons who had fewer participation restrictions showed higher ability scores $(R=-0.49)$, lower performance time scores $(R=0.54)$ and lower physical strain scores $(R=0.38)$ on the Wheelchair Circuit. Participation was also moderately correlated to age $(R=0.34)$ and weakly related to lesion level $(R=-0.26)$.

Table 7.3 Bivariate relations between demographic variables, lesion characteristics, Wheelchair Circuit scores, and SIPSOC score $(\mathrm{N}=45-75)$

\begin{tabular}{|l|l|l|l|l|l|l|l|l|}
\hline & age & gender & $\begin{array}{l}\text { Educa- } \\
\text { tion }\end{array}$ & $\begin{array}{l}\text { Lesion } \\
\text { level }\end{array}$ & $\begin{array}{l}\text { Motor } \\
\text { complete- } \\
\text { ness }\end{array}$ & $\begin{array}{l}\text { Ability } \\
\text { score }\end{array}$ & $\begin{array}{l}\text { Time } \\
\text { score }\end{array}$ & $\begin{array}{l}\text { Strain } \\
\text { score }\end{array}$ \\
\hline Age $^{*}$ & - & & & & & & & \\
\hline Gender $^{\dagger}$ & -0.12 & - & & & & & & \\
\hline Educational level $^{t}$ & -0.18 & $0.22^{*}$ & - & & & & & \\
\hline Lesion level $^{\dagger}$ & -0.03 & -0.04 & 0.07 & - & & & & \\
\hline Motor completeness $^{\dagger}$ & $-0.39^{* *}$ & 0.09 & 0.07 & 0.19 & - & & & \\
\hline Ablity score $^{*}$ & $-0.38^{* *}$ & 0.15 & 0.08 & $0.57^{* *}$ & 0.18 & - & & \\
\hline Performance time score & $0.53^{* *}$ & -0.21 & $-0.34^{* *}$ & $-0.48^{* *}$ & -0.18 & $-0.79^{* *}$ & - & \\
\hline Physical straln score & -0.03 & 0.07 & -0.05 & $-0.28^{* *}$ & 0.10 & $-0.36^{* *}$ & $0.41^{* *}$ & - \\
\hline SIPSOC score $^{*}$ & $0.34^{* *}$ & -0.13 & -0.06 & $-0.26^{*}$ & -0.05 & $-0.49^{* *}$ & $0.54^{* *}$ & $0.38^{* *}$ \\
\hline
\end{tabular}

Continuous varlables: Spearman correlations

'Dichotomous varlables: Kendall's Tau

* $p \leq 0.05$, *** $p \leq 0.01$

Gender: $0=$ female, $1=$ male; Educational level: $0=$ low, $1=$ medlum, $2=$ high; Lesion level: $0=$ tetraplegla, $1=$ paraplegla; Motor completeness: $0=$ Incomplete, $1=$ complete

Table 7.4 shows the results of the multiple regression analyses. In the first model, the addition of the ability score at step 3 increased the amount of explained variance with $5 \%(p<0.05)$. In the final model, only age and the ability score were significant predictors of participation. In the second model using the performance time score, the results were comparable, the time score adding $6 \%$ explained variance $(p<0.05)$. In the third model using the physical strain score $(\mathrm{N}=47)$, hardly any variance was explained by demographic and injury characteristics, and the addition of the strain score to the model increased the amount of explained variance from $0 \%$ to $20 \%(p<0.01)$. Finally, adding all three scores of the Wheelchair Circuit together at step 3 showed that the performance time score was a stronger predictor of participation than the ability or physical strain score. 


\begin{tabular}{|c|c|c|c|c|c|c|c|c|c|}
\hline \multirow[b]{2}{*}{ Step } & \multirow[b]{2}{*}{$\begin{array}{l}\text { Independent } \\
\text { variables }\end{array}$} & \multicolumn{2}{|c|}{$\begin{array}{l}\text { Ability Score } \\
(N=78)\end{array}$} & \multicolumn{2}{|c|}{$\begin{array}{l}\text { Time score } \\
(\mathrm{N}=73)\end{array}$} & \multicolumn{2}{|c|}{$\begin{array}{l}\text { Strain score } \\
(\mathrm{N}=47)\end{array}$} & \multicolumn{2}{|c|}{$\begin{array}{l}\text { All three scores } \\
(N=47)\end{array}$} \\
\hline & & Beta & Adj. $R^{2}$ & Beta & Adj. $R^{2}$ & Beta & $\overline{A d j} R^{2}$ & Beta & Adj. $\mathrm{R}^{2}$ \\
\hline 1 & $\begin{array}{l}\text { Age } \\
\text { Gender } \\
\text { Educational level low } \\
\text { (reference) } \\
\text { Educational level } \\
\text { medium } \\
\text { Educational level high }\end{array}$ & $\begin{array}{l}-0.04 \\
0.06\end{array}$ & $0.12^{* *}$ & $\begin{array}{l}0.001 \\
0.13\end{array}$ & $0.13^{*}$ & $\begin{array}{l}0.21 \\
0.27\end{array}$ & 0.01 & $\begin{array}{l}0.26 \\
0.27\end{array}$ & 10,01 \\
\hline 2 & $\begin{array}{l}\text { Lesion level } \\
\text { Motor completeness }\end{array}$ & $\begin{array}{l}-0.11 \\
0.18\end{array}$ & $0.21^{* *}$ & $\begin{array}{l}-0.07 \\
0.18\end{array}$ & $0.19 *$ & $\begin{array}{l}-0.05 \\
-0.04\end{array}$ & 0.00 & $\begin{array}{l}0.09 \\
-0.02\end{array}$ & 0.00 \\
\hline 3 & $\begin{array}{l}\text { Ability score } \\
\text { Time score } \\
\text { Strain score }\end{array}$ & $\begin{array}{l}-0.33^{*} \\
- \\
-\end{array}$ & $0.26^{*}$ & $0.34 *$ & $0.25^{*}$ & $\begin{array}{l}- \\
0.46^{* * *}\end{array}$ & $0.20 * *$ & $\begin{array}{l}-0.16 \\
0.45^{* *} \\
0.27\end{array}$ & 0.34 \\
\hline
\end{tabular}

${ }^{*}$ Only the final regression model is displayed

$* \mathrm{p} \leq 0.05, * * \mathrm{p} \leq 0.01$

Gender was coded 0 =female, $1=$ male; Lesion level coded as 0 =tetraplegia, $1=$ =paraplegia; Motor completeness coded as $0=$ incomplete, $1=$ complete.

\section{Discussion}

In this study the association between wheelchair skill performance and participation was examined. A number of studies have examined participation of persons with $\mathrm{SCI}(9,13-16,20,29-31)$. In these studies three different measures of participation were used: SIPSOC $(14,15)$, time spent in productivity and leisure activities $(9,13,20,29,31)$, and the Craig Handicap Assessment and Reporting Technique (CHART) $(16,30)$.

The SIPSOC scores found in the present study (mean value $=6.0$ ) correspond well with the mean value of 6.1 found by Dallmeijer et al. (15) and of 7.5 found by Post et al. (14).

The relation between wheelchair skill performance and participation has, to our knowledge, never been studied. Post et al. (24) found a correlation of 0.42 between the Mobility Control scale and the Social Behavior scale of the SIP68. In a large study by Whiteneck et al. (32), the FIM motor score explained $20 \%$ of the variance of scores on the Craig Handicap Assessment and Reporting Technique, which corresponds to a correlation of 0.45 . Dallmeijer et al. (15) found correlations between -0.39 and -0.51 between physical performance measures and SIPSOC. The correlations with SIPSOC in our study were in the same range: -0.49 for ability, 0.54 for time, and 0.38 for strain. These results support the validity of results from the Wheelchair Circuit. Also, these figures underscore the relevance of distinguishing the ICF levels of activities and of participation in rehabilitation research (33). The influence of personal and environmental factors results in not more than moderate correlations between functioning at the levels of activities and of participation, as is shown by these studies $(15,24,32,33)$. 
The results of the present study showed that, when demographic variables and lesion characteristics have been taken into account, still a significant proportion of the variance of participation can be explained by the scores of the Wheelchair Circuit. When the three scores were entered together into one multiple regression model, the performance time score was the only score that was still significantly related to participation. However, the subgroup in which this analysis could be performed $(\mathrm{N}=47)$ is a positive selection of our total study group. In this subgroup, the ability score clearly showed a ceiling effect with a median score of 7.5 on a $0-8$ point scale. This may explain that the performance time score was more strongly related to participation than the ability score. The performance time score also overruled the physical strain score. Physical strain was assessed from the maximum heart rates reached during the performance of the $3 \%$ and $6 \%$ slope tasks, which were both performed on a treadmill at a belt velocity of $0.56 \mathrm{~m} / \mathrm{s}$. This speed is rather slow (34-36), which is also illustrated by the relatively low 'percentage of heart rate reserve (\%HRR; IQR $=21.5-44.0)$. In 'real life' persons can freely adjust their speed to the difficulty of the task and thus, to a certain extend, determine their level of physical strain. This might explain why the association between the physical strain score and participation is somewhat weaker than the association between the performance time score and participation.

The strong relationship between participation and the performance time score can be explained from the fact that the performance time score is very realistically related to the activities of daily life. In daily life it frequently occurs that a person has to make a short sprint at high speed, for instance to catch the bus, or to prevent something on the stove to burn.

\section{Limitations of the study}

Because of the cross-sectional design of the present study, it is not possible to prove a causal relationship between wheelchair skill performance and participation in persons with SCI. It is likely to presume that good wheelchair skill performance has a positive effect on participation, however the opposite is also possible. Longitudinal research is required to establish the causality of the relations found in this study.

To be included into the cohort, persons had to meet several inclusion criteria: age between 18 and 65 years; wheelchair dependent; no progressive disease or psychiatric problem; no cardiovascular problems; and no serious musculoskeletal complaints of the upper extremities, neck or back. Because of these criteria, our participants are a selection out of the complete population of persons with SCI. The Wheelchair Circuit consists of a selection of all possible wheelchair tasks, and it might be that tasks that are relevant for participation are not included in this test. However, during its development it became clear that most relevant skills are included in the test, even though they are not separately tested. For example: making a wheelie is not tested, but being able to make a wheelie is conditional to being able to mount the platform.

In this study, the Wheelchair Circuit was performed in a standard wheelchair. This was necessary to ensure comparability of the measurements in our main longitudinal study in which persons with SCI are followed from the start of functional rehabilitation to one year after discharge. It is possible that our participants would have obtained even better scores when they were allowed to use their own wheelchair, and the relation between wheelchair skill and participation may have been even stronger than we found now. 
All participants who performed the Wheelchair Circuit did have an ability score, and the far majority obtained a performance time score, but only those participants who were able to perform both the $3 \%$ and $6 \%$ slope tasks and the maximum exercise test could obtain a physical strain score. Because of this the analyses that included the physical strain score concerned a positive selection of the research population, consisting of persons with a relatively good wheelchair skill performance. This is further supported by the fact that the physical strain scores displayed in the present study (mean: $33.5 \%$ HRR) are low compared to those found in other studies. Janssen et al. (37) observed 43 male persons with longstanding SCI (1-29 years after injury) during a workday and assessed the physical strain induced by several different activities. The mean physical strain recorded during the negotiation of slopes (inclination and length not defined, self-selected speed) was just above $40 \% H R R$. In a study of Dallmeijer et al. (38), eighteen persons with $\mathrm{SCI}$, ascended a slope with an inclination of $6 \%$ and a length of $6 \mathrm{~m}$, at a self-selected speed, one year after their discharge from inpatient rehabilitation. The mean physical strain induced by this task was somewhat higher than $40 \% \mathrm{HRR}$. Because of these limitations the generalization of our results may be limited.

\section{Conclusion}

Manual wheelchair skill performance of persons with SCI is positively associated to participation. During initial rehabilitation, it is important to implement training and theraples aimed at achieving an optimal level of wheelchair skill performance. Persons should further be stimulated to maintain their wheelchair skills after discharge from inpatient rehabilitation. 


\section{References}

1. Post MWA, Asbeck van FWA, Dijk van AJ, Schrijvers AJ. Services for spinal cord injured: Availability and satisfaction. Spinal Cord 1997;35(2):109-15.

2. Pierce $L L$. Barriers to access: Frustrations of people who use a wheelchair for full-time mobility. Rehabil Nurs 1998;23(3):120-5.

3. Somers M. Spinal cord injury, functional rehabilitation. Connecticut: Appleton \& Lange; 1992.

4. Britell CW. Wheelchair prescription. In: Lehmann JF, Kottke FJ, editors. Krusen's Handbook of Physical Medicine and Rehabilitation. 4 ed. Philadelphia: W.B. Company Saunders; 1990. p. 548-63.

5. Kilkens OJE, Dallmeijer AJ, Angenot ELD, Twisk JWR, Post MWM, Woude van der LHV. Personal characteristics and injury related factors influencing the course of manual wheelchair skill performance during initial inpatient rehabilitation of persons with a spinal cord injury. Arch Phys Med Rehabil Accepted for publication.

6. MacPhee AH, Kirby RL, Coolen AL, Smith C, MacLeod DA, Dupuis DJ. Wheelchair skills training program: A randomized clinical trial of wheelchair users undergoing initial rehabilitation. Arch Phys Med Rehabil 2004;85(1):41-50.

7. WHO. International Classification of Functioning, Disability and Health. ICIDH-2 final draft. Geneva: WHO, 2001.

8. Blake K. The social isolation of young men with quadriplegia. Rehabil Nurs 1995;20(1):17-22.

9. Pentland W, Harvey AS, Smith T, Walker J. The impact of spinal cord injury on men's time use. Spinal Cord 1999;37(11):786-92.

10. Law M. Participation in the occupations of everyday life. Am J Occup Ther 2002;56(6):640-9.

11. Hart. long-term outcomes following spinal cord injury. NeuroRehabilitation 1995;5:57-73.

12. Noreau L, Shephard RJ. Spinal cord injury, exercise and quality of life. Sports Med 1995;20(4):226-50.

13. Noreau L. Productlvity outcomes of individuals with spinal cord injury. spinal cord 1999;37(10):730-6.

14. Post MWM, Witte de LP, Asbeck van FWA, Dijk van AJ, Schrijvers AJ. Predictors of health status and life satisfaction in spinal cord injury. Arch Phys Med Rehabil 1998;79(4):395-401.

15. Dallmeijer AJ, Woude van der LHV. Health related functional status in men with spinal cord injury: Relationship with lesion level and endurance capacity. Spinal Cord 2001;39(11):577-83.

16. Whiteneck GG, Charlifue SW, Gerhart KA, Overholser JD, Richardson GN. Quantifying handicap: A new measure of long-term rehabilitation outcomes. Arch Phys Med Rehabil 1992;73:519-26.

17. Woude van der LHV, Dallmeijer AJ, Veeger DJ, Drongelen van S, Kilkens OJE, Post MWM, et al. Physical strain, work capacity and restoration of mobility of individuals with a spinall cord injury: A multicenter study. In: Woude van der LHV, editor. 3rd International Congress on Restoration of (Wheeled) Mobility in SCI Rehabilitation: State of the Art; 2004; Amsterdam: Rehabilitation Research and Development Service; 2004. p. 62-3.

18. American Spinal Injury Association (ASIA): Reference manual for the international standards for neurological classification of spinal cord injury. Marino RJ, Ed. Chicago: American Spinal Injury Association,2000. 
19. American College of Sports Medicine. ACSM's guidelines for exercise testing and prescription. 6th ed. Philadelphia: Lippincott Willams \& Wilkins; 2000.

20. Tomassen PC, Post MWM, Asbeck van FWA. Return to work after spinal cord injury. Spinal Cord $2000 ; 38(1) ; 51-5$.

21. Whiteneck $G$, Tate $D$, Charlifue $S$. Predicting community reintegration after spinal cord injury from demographic and injury characteristics. Arch Phys Med Rehabil 1999;80(11):1485-91.

22. Dijkers MP. Correlates of life satisfaction among persons with spinal cord injury. Arch Phys Med Rehabil 1999;80(8):867-76.

23. Maynard FM, Jr., Bracken MB, Creasey G, Ditunno JF, Jr., Donovan WH, Ducker TB, et al. International standards for neurological and functional classification of spinal cord injury. American Spinal Injury Association. Spinal Cord 1997;35(5):266-74.

24. Post MWM, Bruin de A, Witte de LP, Schrijvers A. The SIP68: A measure of health-related functional status in rehabilitation medicine. Arch Phys Med Rehabil 1996;77(5):440-5.

25. Nanda U, Mclendon PM, Andresen EM, Armbrecht E. The SIP68: An abbreviated sickness impact profile for disability outcomes research. Qual Life Res 2003;12(5):583-95.

26. Kilkens DJE, Post MWM, Woude van der LHV, Dallmeijer AJ, Heuvel van den WJA. The Wheelchair Circuit: Reliability of a test to assess mobility in persons with spinal cord injuries. Arch Phys Med Rehabil 2002;83(12):1783-8.

27. Kilkens OJE, Dallmeijer AJ, Witte de LP, Woude van der LHV, Post MWM. The Wheelchair Circuit: Construct validity and responsiveness of a test to assess manual wheelchair mobility in persons with spinal cord injury. Arch Phys Med Rehabil 2004;85(3):424-31.

28. Karvonen $M$, Kentala $E$, Mustala $O$. The effects of training on heart rate. A longitudinal study. Annals of Medicine and Experimental Biology Fenn 1957(35):307-15.

29. Yerxa EJ, Locker SB. Quality of time use by adults with spinal cord injuries. Am J Occup Ther 1990;44(4):318-26.

30. Krause JS, Broderick L. Outcomes after spinal cord injury: Comparisons as a function of gender and race and ethnicity. Arch Phys Med Rehabill 2004;85(3):355-62.

31. Taricco M, Colombo C, Adone R, Chiesa G, Di Carlo S, Borsani M, et al. The social and vocational outcome of spinal cord injury patients. Paraplegia 1992;30(3):214-9.

32. Whiteneck G, Meade MA, Dijkers MP, Tate DG, Bushnik T, Forchheimer MB. Environmental factors and their role in participation and life satisfaction after spinal cord injury. Arch Phys Med Rehabil 2004;85(11):1793-803.

33. Jette AM, Haley SM, Kooyoomjian JT. Are the ICF Activity and Participation dimensions distinct? J Rehabil Med 2003;35(5):145-9.

34. Fay BT, Boninger ML, Fitzgerald SG, Souza AL, Cooper RA, Koontz AM. Manual wheelchair pushrim dynamics in people with multiple sclerosis. Arch Phys Med Rehabil 2004;85(6):93542.

35. Kulig K, Newsam CJ, Mulroy SJ, Rao S, Gronley JK, Bontrager EL, et al. The effect of level of spinal cord injury on shoulder joint kinetics during manual wheelchair propulsion. Clin Biomech (Bristol, Avon) 2001;16(9):744-51.

36. Mukherjee G, Samanta A. Physiological response to the ambulatory performance of hand-rim and arm-crank propulsion systems. J Rehabil Res Dev 2001;38(4):391-9. 
37. Janssen TWJ, Ders van CAJM, Woude van der LHV, Hollander AP. Physical strain in daily life of wheelchair users with spinal cord injuries. Medicine and Science in Sports and Exercise 1994:661-70.

38. Dallmeljer AJ, Woude van der LHV, Hollander AP, Angenot EL. Physical performance in persons with spinal cord injuries after discharge from rehabilitation. Med Sci Sports Exerc $1999 ; 31(8) ; 1111-7$. 


\section{8}

Discussion 


\section{Introduction}

The majority of persons with spinal cord injuries ( $\mathrm{SCl}$ ) will be dependent on a wheelchair for their mobility for the rest of their lives. To function independently, wheelchair users must possess a variety of wheelchair skills to be able to deal with the physical barriers they will certainly come across in various environments (1). Training of wheelchair skills is therefore an important part of the inpatient rehabilitation after SCI (2).

Although wheelchair skill performance is seen as an important aspect for independent mobility and daily functioning, up till now only little research has been done to examine the development of wheelchair skill performance during rehabilitation (2-6).

From the literature it is known that wheelchail skill performance is related to personal-and lesion characteristics, the prevalence of secondary complications, and physical capacity $(4,5,7-23)$. Up till now however no research has been done to study the longitudinal relationship between manual wheelchair skill performance and personal- and lesion characteristics, secondary complications, and physical capacity in persons with SCI during inpatient rehabilitation.

As stated earlier, wheelchair skill performance plays an important role in the independence in daily life, and it can be expected that there is a positive relationship between manual wheelchair skill performance and participation in persons with SCI. This relationship has however never been studied. Increasing the knowledge of the issues mentioned above is important since it may influence the rehabilitation treatment process, and the treatment goals, which are set during rehabilitation. Thereby it may help to optimize the process of learning wheelchair skill performance, and it can also be useful to enhance participation after discharge from inpatient rehabilitation.

The main research questions of the present thesis were:

1. Is the Wheelchair Circuit a reliable, valid and responsive test to assess wheelchair skill performance?

2. How does manual wheelchair skill performance develop during inpatient rehabilltation of persons with SCI?

3. Is the development of manual wheelchair skill performance related to personal- and lesion characteristics, secondary complications, and physical capacity?

4. Is there a relationship between manual wheelchair skill performance and participation in persons with $\mathrm{SCI}$, one year after discharge from inpatient rehabilitation?

This chapter starts with an overview of the main results of the study. Then some methodological considerations, practical implications, and recommendations for future research will be discussed, and finally the overall conclusion will be presented. 


\section{Main results}

\section{The Wheelchair Circuit}

The systematic review of wheelchair skills tests available in the literature showed that there are different tests applied to measure wheelchair skill performance in persons with $\mathrm{SCI}(4-6,10,12,15$, 24-34). The main result of the review was that, at the time of the review, there was no standard test available to measure wheelchair skill performance in persons with SCI. As a result of this conclusion, a functional test to measure wheelchair skill performance - the Wheelchair Circuit - was developed within the scope of this study. The Wheelchair Circuit consists of eight tasks: figure-of-eight shape, crossing a doorstep, mounting a platform, $15 \mathrm{~m}$ sprint, $3 \%$ and $6 \%$ slope, 3 minute wheelchair propulsion, and transfer. The performance of the Wheelchair Circuit leads to three different test scores: ability score, performance time score, and physical strain score. The clinimetric qualities of the Wheelchair Circuit were evaluated, and the overall inter- and intrarater reliability, construct valldity, and responsiveness of the Wheelchair Circuit were good.

\section{Development of manual wheelchair skill performance during rehabilitation}

The development of wheelchair skill performance during inpatient rehabilitation was studied. During inpatient rehabilitation wheelchair skill performance improved significantly, the largest improvement occurred during the first three months of the rehabilitation period.

In order to estimate 1) the level of wheelchair skill performance at the time of discharge from inpatient rehabilitation, and 2) the expected improvement in wheelchair skill performance during inpatient rehabilitation, predictive models were constructed. It was concluded that age and lesion level were the most important determinants for the level of wheelchair skill performance at the time of discharge. Age and BMI were the most important variables to predict the change in wheelchair skill performance during inpatient rehabilitation.

\section{Relationship between wheelchair skill performance and personal- and lesion characteristics, and secondary complications}

The variables age and lesion level showed the strongest relation to the scores of the Wheelchair Circuit, indicating that the wheelchair skill performance of younger persons was significantly better than that of older persons, and that persons with paraplegia had significant better wheelchair skill performance than persons with tetraplegia.

The prevalence of secondary complications was a univariately significantly related to all three the scores of the Wheelchair Circuit. In the multivariate analyses these relationships were overruled by age and lesion level. 


\section{Relationship between wheelchair skill performance and physical capacity}

The relationship between wheelchair skill performance and physical capacity is very interesting because physical capacity can, in contrast with personal- and lesion characteristics, be trained and improved during rehabilitation.

Peak power output and upper extremity muscle strength were significantly related to the scores of the Wheelchair Circuit designed in this study. Increase in peak power output and upper extremity muscle strength was related to increase in wheelchair skill performance.

\section{Relationship between manual wheelchair skill performance and participation}

In this thesis the relationship between manual wheelchair skill performance and participation one year after discharge from inpatient rehabilitation were studied. The results showed that, controlling for personal- and lesion characteristics, manual wheelchair skill performance was positively related to participation.

\section{Methodological considerations}

This study is part of a prospective cohort study conducted in eight rehabilitation centers with an SCI unit in the Netherlands. We studied the wheelchair skill performance of a large number of persons with $\mathrm{SCI}$ during their inpatient rehabilitation. The inpatient rehabilitation period is an essential period for persons with SCI to learn to be independent in dally life.

In this section a number of methodological issues regarding the studies presented in this thesis will be discussed.

\section{Selection of study population}

In this study only a subgroup of the entire population of persons with SCI was included. To enter the cohort, persons had to meet the following inclusion criteria: acute $\mathrm{SCI}$, between 18 and 65 years of age, classification A, B, C or D on the ASIA Impairment Scale (35), wheelchair dependent, no progressive disease or psychlatric problem, and enough knowledge of the Dutch language to understand the goal and testing methods of the study.

From seven rehabilitation centers information on the numbers of excluded persons are known. A total of 163 persons were excluded for different reasons. Twenty-six persons refused to participate, 81 persons were not wheelchair-dependent, 22 persons had a progressive disease, 10 persons did not have enough knowledge of the Dutch language, 16 persons did have psychiatric problems, and eight persons were excluded for unknown reasons.

In the Netherlands, approximately $82 \%$ of individuals with SCI, who had been inpatients in a specialized rehabilitation center, use a wheelchair for their mobility (36). Within the chosen inclusion and exclusion criteria, we have a clearly defined and representative study population, for whom the questions under study are very relevant. However, the results of this study may not be valid for 
people with SCI who are confined to an electric wheelchair, to people with SCI who are not wheelchair user and to people with SCI outside the age-range of our study (children and elderly).

\section{Drop out during the study}

Participants were measured four times: three times during their inpatient rehabilitation period and once one year after discharge.

For 169 persons, of the 205 persons who were initially included, the drop out data were known at the time this chapter was written. Of these 169,43 (25\%) dropped out at some point during the study due to different reasons. Twelve persons did no longer want to participate, 12 persons were excluded because they were no longer wheelchair dependent, three persons dropped out because of the occurrence of a psychiatric problem, five persons were transferred to another rehabilitation center, seven persons died during the study period, two persons were mistakenly included in the study, and two persons could no longer be reached. The participants who dropped out did not differ from persons that did complete all the measurements with respect to gender, age, cause of injury, and level and completeness of the lesion. It is therefore not likely that drop out has influenced the study results.

\section{Measurement times}

The four measurement times used in this study were: at the start of functional rehabilitation (T1), three months later (T2), at the time of discharge (T3), and one year after discharge from inpatient rehabilitation (T4). To examine patterns of change, measurements need to be performed at least three times during the course of treatment (37), and the choice of measurement times should be in accordance with the goal of the study.

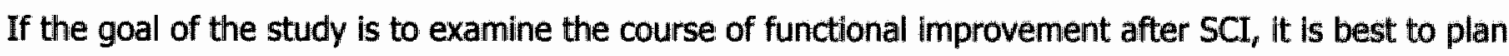
the measurement times at fixed time intervals after the time of injury. When the study aim is to assess changes in functional status during rehabilitation, the measurement times can however best be planned at fixed points in time after admission to the rehabilitation center (e.g. admission and discharge from the rehabilitation center).

Although the goal of the study described in this thesis was to assess changes in mobility in persons with SCI during their rehabilitation, a measurement at admission was not possible because most people are bedridden when they are transferred to the rehabilitation center. For this reason, the first measurement was planned at the moment that persons were able to sit in their wheelchair for at least three consecutive hours, which is the moment that functional rehabilitation starts. Because of this, the time between admission to the rehabilitation center and the performance of $\mathrm{T} 1$ differed greatly between participants.

The second measurement (T2) was performed at a fixed period of three months after $T 1$. T3 was performed at discharge from clinical rehabilitation. This means that the period between T1 and T3 covers the period of functional rehabilitation, in which the largest progress in wheelchair skills is expected. However, possible changes in functional capacity between admission and $\mathrm{T} 1$ are not 
covered, possibly leading to an underestimation of the actual progress of wheelchair skills during inpatient rehabilitation.

In the present study, not all participants were able to perform the Wheelchair Circuit at all three measurement times.

A number of participants (i.e. almost $12 \%$ of the study population) could not perform the T1 measurement because they were still wearing a halo or a brace at the time of the measurement. It is possible that the drop out of these persons has led to a slight overestimation of the wheelchair skill performance at T1. It was however examined whether persons that did not perform the T1 measurement had lower scores on the Wheelchair Circuit at T2 and T3 than persons who had performed the T1 measurement, and it was shown that at T2 and T3 there was no difference in the scores of the Wheelchair Circuit between these participant groups.

Roughly a quarter of the participants did not perform the T2 measurement because their entire inpatient rehabilitation period lasted three months or less. These participants skipped the $T 2$ measurement and thus performed only the T1 and the T3 measurement. The drop out of these persons may have led to a slight underestimation of the wheelchair skill performance at T2.

\section{The Wheelchair Circuit}

The review presented in this thesis showed that there are a number of tests available to evaluate manual wheelchair mobility. The majority has, however, not been evaluated on reliability, validity or responsiveness. There were two tests that exceed the others: the test of Harvey et al. (27) and the wheelchair skills test (WST) of Kirby et al. $(5,16)$.

Harvey's test consists of six different tasks, and the scoring system takes into account the level of assistance and time required to complete the tasks. The test has good interrater reliability but its validity has not been assessed. The WST includes the performance of 50 skills that concern the handling of the wheelchair, transfers to and from the wheelchair, and the maneuvering of the wheelchair. The skills are scored an an ordinal scale: fail / pas / not applicable / not a goal. The reliability and the validity of the WST have been tested and are good.

In contrast to the Wheelchair Circuit, the WST does not register the time needed to perform the skills, and both the WST and Harvey's test do not provide any information on the physical strain induced by the performance of the tasks. These variables can, however, provide valuable information. When a person requires a disproportionately long amount of time to perform a certain wheelchair task, the performance of this task will probably not be practicable in the person's daily live. The same applies to the physical strain attained during the performance of a wheelchair skill.

Another advantage of the Wheelchair Circuit is that the performance time score and the physical strain score make it possible to detect changes in wheelchair skill performance in persons who have achieved the maximum ability score of 8 , or did have the same ability score at two successive measurement times.

When the Wheelchair Circuit is compared to other tests that are used to assess wheelchair skill performance in persons with $\mathrm{SCI}$ (Chapter 2), it can be concluded that:

- The Wheelchair Circuit has been adequately tested on both validity and reliability.

- It is one of few tests that have been developed especially for the assessment of manual wheelchair skill performance in persons with $\mathrm{SCI}$. 
- Because of the limited number of tasks included, the test is convenient to perform, does not require a long time, and the test results are easy to interpret.

- The scoring system is uncomplicated, and provides information on several aspects of wheelchair skill performance.

The main score of the Wheelchair Circuit is the ability score; it is easy to calculate and provides plain information about the ability of persons to perform the various wheelchair skills. Although the Wheelchair Circuit consists of tasks with different difficulty levels, the mean ability score found at T1 was just below 5 , at $\mathrm{T} 4$ the mean ability score was 6 , and in persons with good wheelchair skill performance, the ability score showed a ceiling effect. For these persons the two remaining scores of the Wheelchair Circuit (performance time score and physical strain score) can and should be used to get a better insight in a persons' wheelchair skill performance.

At the different measurement times, not all persons were able to obtain all the three scores of the Wheelchair Circuit. All persons that performed the Wheelchair Circuit were given an ability score, but to be assigned a performance time score persons had to be able to perform both the figure-of-eight shape and the $15 \mathrm{~m}$ sprint, and to be given a physical strain score persons had to perform both the 3and $6 \%$ slope items and the maximum wheelchair exercise test. On average only $60 \%$ of the participants were able to obtain a physical strain score. It was found that persons who had been able to obtain a physical strain score (at the T4 measurement) were younger, did more often have a paraplegia, had higher ability scores and lower performance time scores than persons without a physical strain score. This confirms the remark that the physical strain score is very suitable to evaluate the wheelchair skill performance of persons with high ability scores.

\section{Practical Implications}

In this thesis it is emphasized that wheelchair skills are very important for persons with SCI who depend on a wheelchair for their mobility. Therefore wheelchair skill training is an important part of the inpatient rehabilitation of persons with SCI. The Wheelchair Circuit is in a number of ways a useful instrument in optimizing this training. It can be used to provide useful information concerning a person's wheelchair skill performance at a certain moment in time, it can help to define rehabilitation goals concerning mobility, and it can also be used to evaluate the progression made regarding wheelchair mobility during rehabilitation, thus evaluating the rehabilitation process.

Both age and lesion level have shown to be important determinants of the development of wheelchair skill performance during inpatient rehabilitation after SCI. Increasing the duration and/or frequency of wheelchair skill training in older persons and in persons with a tetraplegia may be useful to reduce the adverse position these persons have concerning wheelchair skill performance. Paying extra attention to the performance of manual wheelchair exercise training and strength training of the upper body during inpatient rehabilitation may also help to optimize the development of wheelchair skill performance in these vuinerable groups.

Although we could not demonstrate a strong relationship between secondary complications and wheelchair skill performance, the prevalence of secondary complications was univariately associated with the scores of the Wheelchair Circuit. These results once again underline the importance of the prevention of secondary complications during inpatient rehabilitation. 
The predictive models that were constructed in this thesis to estimate the level of wheelchair skill performance at the time of discharge from inpatient rehabilitation, and the expected change in wheelchair skill performance during inpatient rehabilitation can be useful in rehabilitation practice. They can for instance be used for the selection of appropriate rehabilitation goals and the evaluation of the treatment plan concerning wheelchair mobility. It should however be kept in mind that the predictive models were based on rather small numbers of participants and only explainedl a small percentage of the variance.

\section{Future research}

- In this section we want to start with emphasizing the need for international standardization of wheelchair skills test. The review in this thesis showed that up till now, there is no standard test to measure wheelchair skill performance. The use of many different tests makes it very difficult to compare study results. Therefore, there is a need for international standardization of wheelchair skills test, and the Wheelchair Circuit developed here could be used as a starting point in this process.

Future research could best concentrate on further validation of existing tests instead of developing even more tests. The selection of the most relevant items of these tests and combining elements of various tests might lead to a superior test, that may eventually become the gold standard in the measurement of wheelchair skill performance.

- We suggest a further validation of the Wheelchair Circuit:

- Assessment of the content validity of the test by examining the feedback from participants who have performed the test and from clinicians who have conducted the test.

- Examine whether the test is also useful in the assessment of wheelchair skill performance in persons with long-standing SCI

- Study if the test can also be used to measure wheelchair skill performance in persons with dlagnoses different than SCI

- Furthermore it would be interesting to study whether the Wheelchair Circuit can be a useful tool in the process of wheelchair prescription/selection for persons with an SCI.

- To enlarge the insight into the development of wheelchair skills in persons with SCI during their inpatient rehabilitation, we propose studying the relationship between wheelchair skill performance and treatment properties during inpatient rehabilitation. In this respect we also recommend shorter and fixed time-intervals between the measurements during inpatient rehabilitation (e.g. weekly measurements).

- We further suggest a more detailed study of the relationship between the development of wheelchailr skill performance and physical capacity. In chapter 6 it was recommended that during rehabilitation attention should be directed towards manual wheelchair exercise training and strength training of the upper body muscle groups to improve wheelchair skill performance. More research can give guidelines concerning the form, intensity, frequency and duration of these trainings. 
- It would be very interesting to study the relationship between wheelchair skill performance and participation a few years after discharge from inpatient rehabilitation. Than the following questions could be answered:

- Is there a number of years after discharge, still a positive association between wheelchair skill performance and participation?

- Do persons have a high level of participation because their wheelchair skill performance is good, or did their wheelchair skill performance improve as a result of their high participation level?

\section{Overall conclusion}

Mastering of wheelchair skills is very important for persons with an $\mathrm{SCI}$ who are dependent on a wheelchair for their mobility. Wheelchair skill training therefore is a vital part of the inpatient rehabilitation period.

In this thesis the Wheelchair Circuit was developed. The Wheelchair Circuit is a standardized test to measure wheelchair skill performance in persons with $\mathrm{SCI}$. The Wheelchair Circuit has shown to be a useful test with good reliability, validity, and sensitivity to change.

Up till now only little was known about the development of wheelchair skill performance in persons with SCI during rehabilitation (2-6). Some studies provided some insight in factors that influence wheelchair skill performance $(4,5,7-23)$ but this has, until now never been a study goal.

This thesis showed that during inpatient rehabilitation, the wheelchair skill performance of persons with SCI improves significantly, and that age, lesion level, peak power output, and upper extremity muscle strength are important parameters for the development of wheelchair skill performance during inpatient rehabilitation.

Although it is plausible to expect a positive relationship between manual wheelchair skill performance and participation in persons with SCI, this had never been studied before. This thesis showed that wheelchair skill performance is positively associated to participation, which subscribes the importance of wheelchair skill training during the rehabilitation of persons with SCI. Concerning wheelchair skill training, extra attention should be paid to older persons, and persons with a tetraplegia. During rehabilitation, manual wheelchair exercise training and strength training of the upper body muscle groups may contribute to the development of the wheelchair skill performance of persons with an SCI. 


\section{References}

1. Pierce LL. Barriers to access: Frustrations of people who use a wheelchair for full-time mobility. Rehabil Nurs 1998;23(3):120-5.

2. MacPhee AH, Kirby RL, Coolen AL, Smith C, MacLeod DA, Dupuis DJ. Wheelchair skills training program: A randomized clinical trial of wheelchair users undergoing initial rehabilitation. Arch Phys Med Rehabil 2004;85(1):41-50.

3. Capodaglio P, Grilli C, Bazzini G. Tolerable exercise intensity in the early rehabilitation of paraplegic patients. A preliminary study. Spinal Cord 1996;34(11):684-90.

4. Dallmeijer AJ, Woude van der LHV, Hollander AP, As van HH. Physical performance during rehabilitation in persons with spinal cord injuries. Med Scl Sports Exerc 1999;31(9):1330-5.

5. Kirby RL, Swuste J, Dupuis DJ, Macleod DA, Monroe R. The Wheelchair Skills Test: A pilot study of a new outcome measure. Arch Phys Med Rehabil 2002;83(1):10-8.

6. Taricco M, Apolone G, Colombo $C_{r}$ Filardo G, Telaro E, Liberati A. Functional status in patients with spinal cord injury: A new standardized measurement scale. Gruppo Interdisciplinare Valutazione Interventi Riabilitativi. Arch Phys Med Rehabil 2000;81(9):1173-80.

7. Ballinger DA, Rintala DH, Hart KA. The relation of shoulder pain and range-of-motion problems to functional limitations, disability, and perceived health of men with spinal cord injury: A multifaceted longitudinal study. Arch Phys Med Rehabll 2000;81(12):1575-81.

8. Beekman CE, Miller-Porter $L$, Schoneberger M. Energy cost of propulsion in standard and ultralight wheelchairs in people with spinal cord injuries. Phys Ther 1999;79(2):146-58.

9. Dahlberg $A$, Kotila $M$, Kautiainen $H$, Alaranta $H$. Functional independence in persons with spinal cord injury in Helsinki. J Rehabil Med 2003;35(5):217-20.

10. Dallmeijer AJ, Woude van der LHV, Hollander AP, Angenot EL. Physical performance in persons with spinal cord injuries after discharge from rehabilitation. Med Sci Sports Exerc 1999;31(8):1111-7.

11. Dalyan M, Cardenas DD, Gerard B. Upper extremity pain after spinal cord injury. Spinal Cord 1999;37(3):191-5.

12. Duran FS, Lugo L, Ramirez L, Lic EE. Effects of an exercise program on the rehabilitation of patients with spinal cord injury. Arch Phys Med Rehabil 2001;82(10):1349-54.

13. Gerhart KA, Bergstrom E, Charlifue SW, Menter RR, Whiteneck GG. Long-term spinal cord injury: Functional changes over time. Arch Phys Med Rehabil 1993;74(10):1030-4.

14. Greenwald BD, Seel RT, Cifu DX, Shah AN. Gender-related differences in acute rehabilitation lengths of stay, charges, and functional outcomes for a matched sample with spinal cord injury: A multicenter investigation. Arch Phys Med Rehabil 2001;82(9):1181-7.

15. Janssen TWJ, Oers van CAJM, Veeger HE, Hollander AP, Woude van der LHV, Rozendal RH, Relationship between physical strain during standardised ADL tasks and physical capacity in men with spinal cord injuries. Paraplegia 1994;32(12):844-59.

16. Kirby RL, Dupulis DJ, MacPhee AH, Coolen AL, Smith $\mathrm{C}$, Best KL, et al. The Wheelchair Skills Test (version 2.4): Measurement properties. Arch Phys Med Rehabil 2004;85(5):794-804.

17. McKinley WO, Gittler MS, Kirshblum SC, Stiens SA, Groah SL. Spinal cord injury medicine. 2. Medical complications after spinal cord injury: Identification and management. Arch Phys Med Rehabil 2002;83(3 Suppl 1):S58-64, S90-8. 
18. Morrison SA, Melton-Rogers $\mathrm{SL}_{s}$ Hooker SP. Changes in physical capacity and physical strain in persons with acute spinal cord injury. Topics Spinal Cord Inj Rehabil 1997;3(1):1-15.

19. Noreau L. Relationship of impairment and functional ability to habitual activity and fitness following spinal cord injury. Int J Rehabil Res 1993;16(4):265-75.

20. Sawka MN, Glaser RM, Laubach LL, Al-Samkari O, Suryaprasad AG. Wheelchair exercise performance of the young, middle-aged, and elderly. J Appl Physiol 1981;50(4):824-8.

21. Schönherr MC, Groothoff JW, Mulder GA, Eisma WH. Functional outcome of patients with spinal cord injury: Rehabilitation outcome study. Clin Rehabil 1999;13(6):457-63.

22. Warschausky S, Kay JB, Kewman DG. Hierarchical linear modeling of FIM instrument growth curve characteristics after spinal cord injury. Arch Phys Med Rehabil 2001;82(3):329-34.

23. Yarkony GM, Roth E, Heinemann AW, Lovell LL. Spinal cord injury rehabilitation outcome: The impact of age. J Clin Epidemiol 1988;41(2):173-7.

24. Bolin I, Bodin P, Kreuter M. Sitting position - posture and performance in C5 - C6 tetraplegia. Spinall Cord 2000;38(7):425-34.

25. Duffill J, Buckley J, Lang D, Neil-Dwyer G, McGinn F, Wade D. Prospective study of omental transposition in patients with chronic spinal injury. J Neurol Neurosurg Psychiatry 2001;71(1):73-80.

26. Dunkerley AL, Ashburn A, Stack EL. Deltoid triceps transfer and functionali independence of people with tetraplegia. Spinal Cord 2000;38(7):435-41.

27. Harvey LA, Batty J, Fahey A. Reliability of a tool for assessing mobility in wheelchairdependent paraplegics. Spinal Cord 1998;36(6);427-31.

28. Hutzler Y. Physical performance of elite wheelchair basketball players in armcranking ergometry and in selected wheeling tasks. Paraplegla 1993;31(4):255-61.

29. Janssen TWJ, Oers van CAJM, Woude van der LHV, Hollander AP. Reliability of heart rate responses to non-steady-state activities of daily living in men with spinal cord injuries. Scand J Rehabil Med 1994; 26(2):71-8.

30. Janssen TWJ, Oers van CAJM, Rozendaal EP, Willemsen EM, Hollander AP, Woude van der LHV. Changes in physical strain and physical capacity in men with spinal cord injuries. Med Sci Sports Exerc 1996;28(5):551-9.

31. Jebsen RH, Trieschmann RB, Mikulic MA, Hartley RB, McMillan JA, Snook ME. Measurement of time in a standardized test of patient mobility. Arch Phys Med Rehabil 1970;51(3):170-5.

32. Lehmann JF, Warren CG, Halar E, Stonebridge JB, DeLateur BJ. Wheelchair propulsion in the quadriplegic patient. Arch Phys Med Rehabil 1974;55(4):183-6.

33. Mizukami M, Kawai N, Iwasaki Y, Yamamoto Y, Yoshida Y, Koyama N, et al. Relationship between functional levels and movement in tetraplegic patients. A retrospective study. Paraplegia 1995;33(4):189-94.

34. Vanlandewijck YC, Daly DJ, Theisen DM. Field test evaluation of aerobic, anaerobic, and wheelchair basketball skill performances. Int J Sports Med 1999;20(8):548-54.

35. American Spinal Injury Association (ASIA): Reference manual for the international standards or neurological classification of spinal cord injury. Marino RJ, Ed. Chicago: American Spinal Injury Association, 2000.

36. Post MWM, Asbeck van FWA, Dijk van AJ, Schrijvers AJ. Services for spinal cord injured: Availability and satisfaction. Spinal Cord 1997;35(2):109-15. 
37. Bode RK, Heinemann AW. Course of functional improvement after stroke, spinal cord injury, and traumatic brain injury. Arch Phys Med Rehabil 2002;83(1):100-6. 


\section{English summary}

\section{Introduction}

The majority of persons with spinal cord injuries (SCI) will be dependent on a manual wheelchair for their mobility for the rest of their lives. The mastering of wheelchair skills will enhance their independence and participation in daily life, and the actual training of these skills therefore is a vital part of the inpatient rehabilitation process.

Although wheelchair skill performance is seen as an important aspect for independent mobility, daily functioning, and participation, there is only little known about the development of wheelchair skill performance in persons with $\mathrm{SCI}$ during and after inpatient rehabilitation. Thereby, only little insight exists in the longitudinal relationship between manual wheelchair skill performance and personal- and lesion characteristics, secondary complications, and physical capacity during inpatient rehabilitation. The association between manual wheelchair skill performance and participation in persons with SCI has also never been studied.

Enlarging our knowledge of the development of wheelchair skills is important since it may influence the rehabilitation treatment process, and the treatment goals, which are set during rehabilitation. Moreover it may be used to optimize the process of learning wheelchair skill performance, and to enhance participation after discharge from inpatient rehabilitation.

In the present study, a functional test was developed to assess wheelchair skill performance in persons with SCI: the Wheelchair Circuit. The Wheelchair Circuit consists of 8 standardized tasks: figure-of-eight shape, crossing a doorstep, mounting a platform, $15 \mathrm{~m}$ sprint, negotiating a 3- and a $6 \%$ slope, 3 minute wheelchair propulsion, and finally performing a transfer. The performance of the Wheelchair Circuit leads to three different test scores: ability score, performance time score, and physical strain score.

\section{Aims and research questions}

The primary aims of the present study are 1) to assess the clinimetric qualities of the Wheelchair Circuit, 2) to evaluate the development of manual wheelchair skill performance during the inpatient rehabilitation of persons with $\mathrm{SCI}$, and to identify factors that affect this process, and 3) to study the relationship between manual wheelchair skill performance and participation in persons with $\mathrm{SCI}$ after discharge from inpatient rehabilitation.

The main research questions of this thesis are:

1. Is the Wheelchair Circuit a reliable, valid and responsive test to assess wheelchair skill performance?

2. How does manual wheelchair skill performance develop during inpatient rehabilitation of persons with acute SCI?

3. Is the development of manual wheelchair skill performance related to personal- and lesion characteristics, secondary complications, and physical capacity?

4. Is there a relationship between manual wheelchair skill performance and participation in persons with $\mathrm{SCI}$, one year after discharge from inpatient rehabilitation? 


\section{Results}

Chapter 2 reports on a systematic review of wheelchair skills tests that are available in the literature. The search resulted in 24 different wheelchair skills tests that showed large variation in the skills that were included, and the outcome measures that were used. The clinimetric properties of only two tests were adequately investigated. The main conclusion of the review was that, at the start of this study, there was no standard test to measure wheelchair skill performance.

In Chapter 3 the Wheelchair Circuit, the test to assess manual wheelchair skill performance that was developed in this study is described, and the reliability of the Wheelchair Circuit is investigated.

A convenience sample of persons with $\mathrm{SCI}$, who were all in the final stage of their inpatient rehabilitation, performed the Wheelchair Circuit on three different occasions, and the measurements were conducted by two different raters. The results showed that the overall inter- and intrarater reliability of the Wheelchair Circuit is good.

Chapter 4 demonstrates that the Wheelchair Circuit is a vallid and responsive instrument for measuring manual wheelchair mobility in persons with $\mathrm{SCI}$.

Chapter 5 illustrates that during inpatient SCI rehabilitation the scores of the Wheelchair Circuilt significantly improve, with the largest improvement occurring during the first three months. The development of wheelchair skill performance is significantly influenced by age and lesion level. Older persons and persons with tetraplegia have lower scores on the Wheelchair Circuit than younger persons and persons with paraplegia.

Age and Body Mass Index (BMI) are the most important variables to predict the scores of the Wheelchair Circuit at the time of discharge. At the end of their inpatient rehabilitation, older persons, and persons with a higher BMI will have lower scores on the Wheelchair Circuit than younger persons and persons with a lower BMI.

Chapter 6 shows that upper extremity muscle force and peak power output are important parameters for the development of wheelchair skill performance during inpatient rehabilitation. Persons with higher upper extremity muscle force and higher peak power output will have higher scores on the Wheelchair Circuit than persons with lower upper extremity muscle force and lower peak power output.

Chapter 7 shows that in persons with SCI, one year after discharge from inpatient rehabilitation, manual wheelchair skill performance is positively related to participation. This association remains significant when demographic variables and lesion characteristics are taken into account. In this study participation was assessed with the social dimension of the 68-item Sickness Impact Profile (SIP68).

\section{Conclusions and recommendations}

- The Wheelchair Circuit is a reliable, valid and responsive instrument to assess manual wheelchair mobility in persons with SCI. The Wheelchair Circuit is a compact measurement, which is convenient to perform. The scoring system is uncomplicated, easy to interpret, and provides information on several aspects of wheelchair skill performance.

- During the inpatient rehabilitation, older persons and persons with tetraplegia reach a lower level of wheelchair skill performance than younger persons and persons with paraplegia. In future research it can be investigated whether increasing the duration and/or frequency of wheelchair 
skill training in older persons and in persons with a tetraplegia is useful to reduce the adverse position these persons have concerning wheelchair skill performance.

- There is a positive relation between the development of wheelchair skill performance, peak power output, and upper body muscle strength during the rehabilitation of persons with $\mathrm{SCl}$. From this it is concluded that, in order to optimize the development of wheelchair skill performance, attention should be directed towards manual wheelchair exercise training and strength training of the upper body muscle groups.

- In persons with SCI, manual wheelchair skill performance is positively associated to participation one year after discharge from inpatient rehabilitation. To stimulate the level of participation after discharge it is important to pay extra attention to training and therapy aimed at achieving an optimal level of wheelchair skill performance during the inpatient rehabilitation period. Furthermore persons should be stimulated to maintain their wheelchair skills after discharge from inpatient rehabilitation. 


\section{Nederlandse samenvatting}

\section{Introductie}

De meeste personen met een dwarslaesie zijn voor de rest van hun leven afhankelijk van een rolstoel om zich te kunnen voortbewegen. Omdat het beheersen van rolstoelvaardigheden de onafhankelijkheid in het dagelijks leven aanzienlijk zal verbeteren, is de training van rolstoelvaardigheid een belangrijk onderdeel van de klinische revalidatie van mensen met een dwarslaesie.

Alhoewel rolstoelvaardigheid wordt gezien als een belangrijk aspect van mobiliteit en dagelijks functioneren, is er slechts weinig kennis beschikbaar over de ontwikkeling van rolstoelvaardigheid tijdens en na de klinische revalidatle van mensen met een dwarslaesie. De term rolstoelvaardigheid wordt in dit onderzoek gebruikt voor de vaardigheid in het rijden en manoeuvreren met een handbewogen rolstoel.

Er bestaat ook weinig inzicht in de relatie tussen de ontwikkeling van rolstoelvaardigheid en persoonsen laesiekenmerken, secundaire stoornissen en de fysieke capaciteit tijdens de klinische revalidatie periode. De relatie tussen rolstoelvaardigheid en maatschappelijke participatie is ook nog nooit eerder onderzocht.

Het vergroten van de kennis over de ontwikkeling van rolstoelvaardigheid tijdens de revalidatie en over de relatie tussen rolstoelvaardigheid en persoons- en laesiekenmerken, secundaire stoornissen en fysieke capaciteit, is belangrijk omdat dit van invloed kan zijn op de revalidatiedoelen die gesteld worden tijdens de klinische revalidatle en de therapleën die gegeven worden om deze doelen te bereiken. Deze kennis kan ook nuttig zljn om het proces van het leren van rolstoelvaardigheid tijdens de revalidatie positief te beïnvloeden.

In dit onderzoek werd een test ontwikkeld om de rolstoelvaardigheid van mensen met een dwarslaesie te meten: het rolstoelcircuit. Het rolstoelcircuit bestaat uit 8 gestandaardiseerde taken: 8 -vorm, oversteken van een drempel, oprijden van een platform, $15 \mathrm{~m}$ sprint, $3 \%$ en $6 \%$ helling, 3 minuten rolstoel rijden en het maken van een transfer.

De uitvoering van het rolstoelcircuit leidt tot drie verschillende scores: de uitvoerbaarheidscore, de tijdscore en de fysieke inspanningscore.

\section{Doelen en onderzoeksvragen van de studie}

De belangrijkste doelen van deze studie zijn 1) het bepalen van de klinimetrische kwaliteiten van het rolstoelcircult, 2) het evalueren van de ontwikkeling van manuele rolstoelvaardigheid tijdens de klinische revalidatie van mensen met een dwarslaesie, en het identificeren van factoren die deze ontwikkeling beïnvloeden, en 3 ) het bestuderen van de relatie tussen manuele rolstoelvaardigheid en participatie in het dagelijks leven bij mensen met een dwarslaesie na ontslag uit het revalidatiecentrum. 
De belangrijkste onderzoeksvragen van dit proefschrift zijn:

1. Is het rolstoelcircuit een betrouwbare, valide en sensitieve test voor het meten van rolstoelvaardigheid?

2. Wat is de vooruitgang in rolstoelvaardigheid tijdens de klinische revalidatie van mensen met een dwarslaesie?

3. Is de ontwikkeling van rolstoelvaardigheid gerelateerd aan persoons- en laesiekenmerken, secundaire stoornissen, en fysieke capaciteit?

4. Is er een relatie tussen rolstoelvaardigheid en participatie bij mensen met een dwarslaesie, een jaar na het ontslag uit het revalidatiecentrum?

\section{Resultaten}

Hoofdstuk 2 betreft een literatuurstudie naar de verschillende tests voor het meten van rolstoelvaardigheid die beschikbaar zijn in de literatuur. Er werden 24 verschillende rolstoelvaardigheid-testen gevonden die in veel opzichten van elkaar verschilden. Zo waren er grote verschillen in het aantal taken waaruit de testen bestonden en de uitkomstmaten die werden gebruikt. Slechts van twee testen waren de klinimetrische kwaliteiten voldoende onderzocht.

De belangrijkste conclusie van deze literatuurstudie was dat er bij de start van het onderzoek geen gestandaardiseerde test beschikbaar was voor het meten van rolstoelvaardigheid.

In hoofdstuk 3 wordt het rolstoelcircuit, de test voor rolstoelvaardigheid die in dit onderzoek is ontwikkeld, beschreven en wordt de betrouwbaarheid van het rolstoelcircuit onderzocht.

Een aantal mensen met een dwarslaesie, allemaal in de eindfase van de klinische revalidatie, voerden het rolstoelcircuit uit op drie verschillende momenten. De metingen werden afgenomen door twee verschillende onderzoeksassistenten.

De resultaten lieten zien dat de inter- en intrabeoordelaarsbetrouwbaarheid van het rolstoelcircuit over het algemeen goed is.

Uit hoofdstuk 4 blijkt dat het rolstoelcircuit een valide en responsief instrument is om manuele rolstoelvaardigheid te meten in mensen met een dwarslaesie.

Hoofdstuk 5 illustreert dat, tijdens de klinische revalidatie van mensen met een dwarslaesie, de scores van het rolstoelcircuit significant verbeteren, waarbij de grootste verbetering plaatsvindt in de eerste drie maanden. De ontwikkeling van rolstoelvaardigheid wordt beinvloed door leeftijd en laesiehoogte. Oudere mensen en mensen met een tetraplegie scoren lager op het rolstoelcircuit dan jongere mensen en mensen met een paraplegie.

Leeftijd en Body Mass Index (BMI) zijn de meest belangrijke determinanten voor het voorspellen van de scores van het rolstoelcircuit op het moment van ontslag uit het revalidatiecentrum. Aan het einde van de klinische revalidatie, hebben oudere mensen en mensen met een hogere BMI lagere scores op het rolstoelcircuit dan jongere mensen en mensen met een lagere BMI.

Hoofdstuk 6 laat zien dat spierkracht van de bovenste extremiteiten en piek vermogen belangrijke parameters zijn voor de ontwikkeling van rolstoelvaardigheid tijdens de klinische revalidatieperiode. Mensen met meer spierkracht van de bovenste extremiteiten en mensen met een hoger prestatievermogen zullen op het rolstoelcircuit hoger scoren dan mensen met minder spierkracht van de bovenste extremiteiten en een lager prestatievermogen. 
Uit hoofdstuk 7 blijkt dat er, een jaar na ontslag uit het revalidatiecentrum, een positief verband is tussen rolstoelvaardigheid en participatie. Dit verband blijft significant wanneer gecontroleerd wordt voor kenmerken van de persoon en de dwarslaesie. In deze studie is participatie gemeten met behulp van de sociale dimensle van de 68-item Sickness Impact Profile (SIP68).

\section{Conclusies en aanbevelingen}

- Het rolstoelcircuit is een betrouwbare, valide en responsieve test voor het meten van manuele rolstoelvaardigheid bij mensen met een dwarslaesie. Het rolstoelcircuit is een compact en eenvoudig uit te voeren meetinstrument. Het score systeem is eenduidig te interpreteren en geeft informatie over verschillende aspecten van manuele rolstoelvaardigheid.

- Oudere mensen en mensen met tetraplegie bereiken tijdens de klinische revalidatie een minder hoog niveau van rolstoelvaardigheid dan jongere mensen en mensen met paraplegie. In verder onderzoek zou nagegaan kunnen worden of het opvoeren van de duur en/of de frequentie van rolstoeltraining bij oudere mensen en bij mensen met een tetraplegie helpt om de achterstand in rolstoelvaardigheid die deze mensen hebben te verminderen.

- Er bestaat een positieve relatie tussen de ontwikkeling van rolstoelvaardigheid, prestatievermogen en spierkracht van de bovenste extremiteiten bij mensen met een dwarslaesie. Hieruit kunnen we concluderen dat, om de ontwikkeling van rolstoelvaardigheid te optimaliseren, er tijdens de klinische revalidatie aandacht besteed moet worden aan rolstoeltraining en krachttraining van de spiergroepen van de bovenste extremiteiten.

- Een jaar na ontslag uit het revalidatiecentrum is er bij mensen met een dwarslaesie een positieve relatie tussen rolstoelvaardigheid en participatie. Dit verband onderstreept het belang van het bereiken van een hoog niveau van rolstoelvaardigheid tijdens de revalidatie. Daarnaast moeten mensen gestimuleerd worden om deze rolstoelvaardigheid op peil te houden na ontslag uit het revalidatiecentrum. 


\section{About the author}

$09-03-1972$

$1984-1990$

$1990-1995$

$1995-1998$

$1999-2004$
Born in Roermond, the Netherlands.

Secondary school, Bisschoppelijk college Schöndeln, Roermond, the Netherlands.

Physical therapy, Hogeschool Eindhoven, the Netherlands.

Human movement sciences, Vrije Universiteit Amsterdam, the Netherlands

- Health science in relation to human movement

- Psychology of human movement.

PhD student, IRv, Hoensbroek, the Netherlands. 